\title{
Capturing the Demographic Dividend in Pakistan
}

\author{
Zeba Sathar \\ Population Council \\ Rabbi Royan \\ John Bongaarts \\ Population Council
}

Follow this and additional works at: https://knowledgecommons.popcouncil.org/departments_sbsr-pgy

Part of the Demography, Population, and Ecology Commons, Family, Life Course, and Society Commons, and the International Public Health Commons How does access to this work benefit you? Let us know!

\section{Recommended Citation}

Sathar, Zeba, Rabbi Royan, and John Bongaarts (eds.). 2013. "Capturing the demographic dividend in Pakistan." Islamabad: Population Council. 


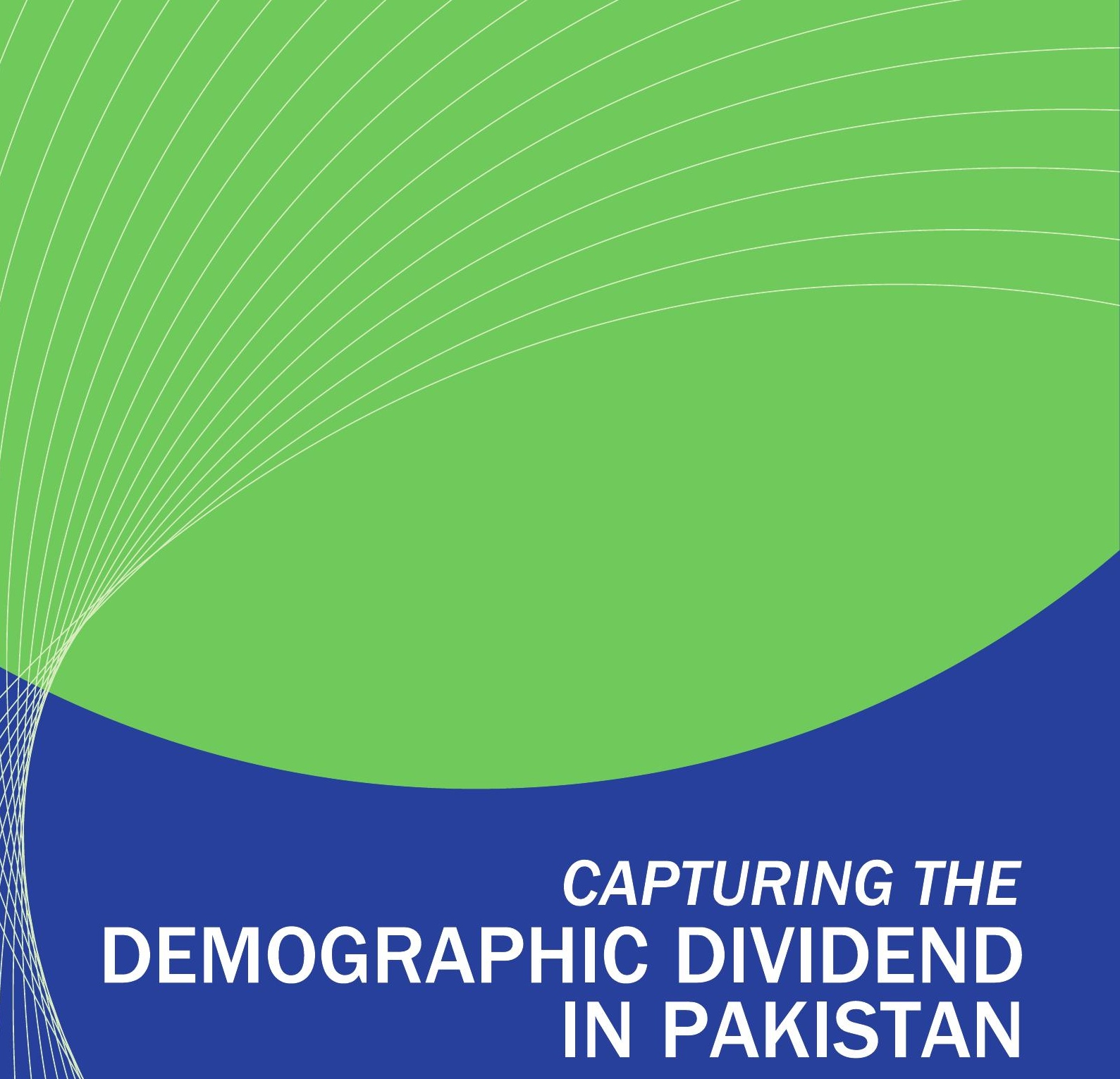

\author{
ZEBA A. SATHAR \\ RABBI ROYAN \\ JOHN BONGAARTS \\ EDITORS
} WITH A FOREWORD BY DAVID E. BLOOM 


\title{
CAPTURING THE DEMOGRAPHIC DIVIDEND IN PAKISTAN
}

\author{
ZEBA A. SATHAR \\ RABBI ROYAN \\ JOHN BONGAARTS \\ EDITORS
}

WITH A FOREWORD BY DAVID E. BLOOM 


\section{Population Council}

The Population Council confronts critical health and development issues-from stopping the spread of HIV to improving reproductive health and ensuring that young people lead full and productive lives. Through biomedical, social science, and public health research in 50 countries, we work with our partners to deliver solutions that lead to more effective policies, programs, and technologies that improve lives around the world. Established in 1952 and headquartered in New York, the Council is a nongovernmental, nonprofit organization governed by an international board of trustees.

(C) 2013 The Population Council, Inc.

Population Council

One Dag Hammarskjold Plaza

New York, NY 10017 USA

Population Council

House No. 7, Street No. 62

Section F-6/3

Islamabad, Pakistan

http://www.popcouncil.org

The United Nations Population Fund is an international development agency that promotes the right of every woman, man, and child to enjoy a life of health and equal opportunity. UNFPA supports countries in using population data for policies and programmes to reduce poverty and to ensure that every pregnancy is wanted, every birth is safe, every young person is free of HIV and AIDS, and every girl and woman is treated with dignity and respect.

\section{Library of Congress Cataloging-in-Publication Data}

Capturing the demographic dividend in Pakistan / Zeba Sathar, Rabbi Royan, John Bongaarts, editors. -- First edition.

pages ; $\mathrm{cm}$

Includes bibliographical references.

ISBN 978-0-87834-129-0 (alkaline paper) 1. Pakistan--Population--Economic aspects.

2. Demographic transition--Economic aspects--Pakistan. 3. Age distribution (Demography) --Economic aspects--Pakistan. 4. Economic development--Pakistan. I. Sathar, Zeba A., editor of compilation. II. Royan, Rabbi, editor of compilation. III. Bongaarts, John, 1945- editor of compilation.

HB3640.5.A3C37 2013

304.6095491--d c 23

2013002049 


\section{CONTENTS}

CONTRIBUTORS

FOREWORD

vii

by David E. Bloom

ACKNOWLEDGMENTS

$\mathbf{x i}$

CHAPTER ONE Overview: The Population of Pakistan Today

by Rabbi Royan and Zeba A. Sathar

CHAPTER TWO Population Trends in Pakistan

by John Bongaarts, Zeba A. Sathar, and Arshad Mahmood

CHAPTER THREE Education and Population: Closely Linked Trajectories for Pakistan

by Asif Wazir, Anne Goujon, and Wolfgang Lutz

CHAPTER FOUR Why Has Pakistan Not Reaped Its Demographic Dividend?

by Rashid Amjad

CHAPTER FIVE Population and Poverty Dynamics in Rural Pakistan:

Evidence from the Longitudinal Household Survey

by G.M. Arif

CHAPTER SIX Meeting the Challenge of Demographic Change through Equitable Development

by Akmal Hussain

CHAPTER SEVEN What Hampers Population Policy in Pakistan? The Crossroads of Women's Empowerment and Development Agendas by Saba Gul Khattak

CHAPTER EIGHT Policies for Capturing the Demographic Dividend in Pakistan by John Bongaarts, Ali Mohammad Mir, and Arshad Mahmood

CHAPTER NINE Conclusions

by Zeba A. Sathar and Rabbi Royan 



\section{CONTRIBUTORS}

RASHID AMJAD is Professor of Economics and Director, Graduate Institute of Development Studies at the Lahore School of Economics. He was Vice-Chancellor of the Pakistan Institute of Development Economics 2007-12. He has a doctorate in Economics from the University of Cambridge.

G.M. ARIF is Joint Director at the Pakistan Institute of Development Economics in Islamabad. He received his doctorate in Demography from the Australian National University. He has served as the Vice President of the Population Association of Pakistan, 2010-12.

JOHN BONGAARTS has served as a Vice President for over 20 years at the Population Council, New York, and is currently a Distinguished Scholar and Chairman of the Institutional Review Board of the Population Council. His contributions to the field of population sciences have earned him several distinctions, most recently the IUSSP Laureate in 2013.

ANNE GOUJON shares her time as research scholar in demography between the Vienna Institute of Demography (Austrian Academy of Sciences) and the World Population Program (International Institute for Applied Systems Analysis - IIASA), both located in Austria. She received her Ph.D. from the University of Vienna.

AKMAL HUSSAIN is Distinguished Professor of Economics at the Forman Christian College University and Senior Fellow, PIDE. His doctorate in Economics is from the University of Sussex and B.A. (Hons.) and M.A. from Cambridge University. He holds several advisory positions including the Panel of Economists, the Working Group on Poverty Reduction Strategy and board member South Asia Centre for Policy Studies.

SABA GUL KHATTAK is an independent researcher with a Ph.D. in Political Science. She has served as Member (Social Sectors) Planning Commission of Pakistan and previously as Executive Director, Sustainable Development Policy Institute (SDPI), Islamabad.

WOLFGANG LUTZ is Leader of the World Population Program (International Institute for Applied Systems Analysis - IIASA), Director of the Vienna Institute of Demography of the Austrian Academy of Sciences and Professor at the WU-Vienna University of Economics. He is Founding Director of the Wittgenstein Centre for Demography and Global Human Capital. He has a Ph.D. in Demography from the University of Pennsylvania and a doctorate in Statistics from University of Vienna.

ARSHAD MAHMOOD is a Program Associate and Director of Research at the Population Council, Pakistan. He received his doctorate in Sociology from the University of Southern California and his Master's in Demography from the Australian National University. 
ALI MOHAMMAD MIR obtained his Master's in public health from the University of Leeds on the prestigious Chevening scholarship and his Bachelors in Medicine from the Rawalpindi Medical College. He is Program Associate and Director of Programs with the Population Council, Pakistan. He holds the honorary position of Vice President of the Population Association of Pakistan.

RABBI ROYAN received his Master's in Economic Policy from Boston University and is the UNFPA Country Representative in Pakistan. He joined UNFPA in 2003 and has worked in senior positions as a population and development advisor in New York and at the Regional Office in Bangkok. He has also held senior-level positions in the Malaysian Government.

ZEBA A. SATHAR received her doctorate in Medical Demography from London School of Hygiene and Tropical Medicine and is Country Director, Population Council, Pakistan. She received the award of Tamgha-i-Imtiaz by the President of Pakistan in March 2006 in recognition of her meritorious services to the development sector in Pakistan.

ASIF WAZIR received his doctorate in Demography from the University of Vienna and is a Senior Researcher at the Population Council, Pakistan. He has been guest Research Scholar at the World Population Program, IIASA. 


\section{FOREWORD}

There is widespread concern that rapid population growth in Pakistan - much faster than in the rest of South Asia - is impeding Pakistan's economic development. Indeed, it is difficult to grasp the reality that Pakistan is on course to have as many as 120 million more people in 2050 than it does now, which would bring its population to 300 million.

For much of the time since Malthus, it was widely believed that rapid population growth presented a problem for a population's standard of living. But that view fell out of favor in the mid to late 1980s in light of studies that proffered the view that population growth, in and of itself, is neutral in its effect on economic growth. More recently, however, we have come to recognize that rapid population growth does indeed impede the pace of economic growth. In addition, we have learned that economic growth is also powerfully driven by the age structure of the population. Indeed, the last 15 years have witnessed a sea change in thinking about the role of population in the development process. Population dynamics matter a lot, and we are deepening our understanding of why. At this point, it is absolutely clear that the pattern and pace of demographic change in Pakistan in the coming decades have the potential to mightily affect the country's macroeconomic performance.

The intuition about the importance of evolving demographics is straightforward. Countries typically start out with high rates of mortality and fertility. Public health improvements, medical advances, and better access to health care lead to declining mortality, particularly among infants and children. This results at first in an increase in the number of young people. But as couples begin to see that their children are likely to survive to adulthood and to be able to care for them when they are old, they begin to choose to have fewer children. Societal norms and expectations change, too, reinforcing this trend and leading to completion of a "demographic transition". After a while, with birth rates having fallen, the earlier, large cohort of children becomes a population that is concentrated in the prime years for working and saving. In addition, increased rates of labor force participation will ensue among that cohort because of low numbers of children, and rising life expectancies will naturally encourage higher savings rates in expectation of longer periods of retirement. If the relatively large working/saving-age cohort is productively employed and has incentives and opportunities to save, a country can undergo more rapid economic growth - an outcome known as the "demographic dividend".

A great deal of evidence supports the idea that demographic transitions can promote higher rates of economic growth. Indeed, experience from an array of countries has shown that reducing the fertility rate can help spur economic advancement. By contrast, countries in which fertility has remained high are struggling to have their economies grow. 
The current rapid rate of population growth in Pakistan is imposing a crushing burden of youth dependency on the economy. Countries like Pakistan, where fertility is declining relatively slowly, are confronting a situation in which large numbers of young people are seeking "good jobs", but they are not finding them. As these young people enter the prime working-age years, one challenge Pakistan and other countries face is taking action to ensure that swelling cohorts of working-age people are productively employed, so that their numbers may be translated into economic benefits for the country as a whole.

The fact that economic growth can be spurred by demographic change matters because policymakers have many interventions at hand to catalyze and accelerate the requisite changes and to capture the potential economic benefits that follow. The relevant options vary according to the stage to which a country has progressed with respect to the demographic transition.

For example, demographic transitions are typically (a) triggered by improvements in infant and child health, which traditionally result from public health investments in primary health care, safe water and sanitation, and vaccines and drugs; and (b) accelerated by the provision of family planning and reproductive health supplies and services, and the expansion of education and job opportunities for girls and women. Realization of the economic benefits of these changes is naturally related to the economy's capacity to absorb workers into productive employment, which is, in turn, strengthened by good governance; efficient infrastructure and prudent fiscal and macroeconomic management; well-developed financial markets; and above all, wide and deep investments in education and training.

Even independently of demographics, these are all desirable policy strategies. But the stakes are much greater when a demographic dividend is in prospect. Coordinating population and economic policies magnifies the size of the potential dividend and enhances the likelihood of its being captured. Such coordination is especially crucial because there is both promise and peril embodied in an age structure that has a relatively large working-age share. Large cohorts of prime-age individuals can be a recipe for social and political instability when unemployment rates are high.

If, in 10 or 20 years, Pakistan still has a large number of unemployed or underemployed people, including tens of millions of young people, the country may face crises that dwarf those it has experienced to date. For sure, Pakistan's demographic profile is changing: fertility is slowly decreasing, and people are living longer. These changes are likely to continue regardless of actions taken by the government. But the effects these changes will bring are not yet determined. If Pakistan succeeds in strengthening education and bringing the full panoply of reproductive rights and reproductive health services to women, it will have taken two important steps in transforming demographic change into poverty reduction and better lives for the great majority of Pakistanis. If it also takes other policy actions that can spur productive employment and investment, positive outcomes are all the more likely. Sitting still, by contrast, is a recipe for economic stagnation and, likely, greater political and civil conflict. Indeed, a central challenge of 
development in Pakistan is ensuring that economic growth is inclusive, i.e., that the benefits of a growing economy are delivered throughout the income distribution.

This book brings together many ideas that have been discussed for some time in Pakistan and around the world. The compelling path forward it lays out, which entails extensive development of education and major efforts in the reproductive health arena, offers an inviting and highly achievable means for shaping and harnessing Pakistan's growing population in a way that promotes inclusive economic development. As such, this book can be considered part of a blueprint for development in Pakistan.

My hope is that this book will clarify the issues at stake and that the people and policymakers of Pakistan will join together in bringing about the changes needed to move all of the country's citizens toward greater prosperity. By giving voice to people who have extensive experience in the population and development arenas, it opens up the possibility that these ideas may finally gain serious traction in Pakistan.

DAVID E. BLOOM Harvard School of Public Health 



\section{ACKNOWLEDGIMENTS}

This book was conceived as part of UNFPA's Eighth Country Program of Pakistan to ensure that key policy makers, professionals, academics, and students, within Pakistan and outside, recognize the important opportunities and challenges faced by the country in terms of its demographic issues and the close linkages between population and development. It was also felt that there was a need to disseminate the analysis in the book to wider audiences so that the multi-sectoral policy actions required could be appreciated and acted upon. These policy directions are not just suggestive, but imperative for Pakistan's future development and stability. It was with this in mind that UNFPA collaborated with the Population Council to put together this volume with the hope of activating policy discourse on population and development in Pakistan.

Apart from the contributions of the authors, several persons have been extremely supportive and generous with their time, and we are extremely grateful to them. John May, Population Reference Bureau, reviewed all the chapters. David Bloom graciously agreed to write the foreword to the book. Batool Zaidi, University of North Carolina, provided useful comments on the first draft of the book. Imran Mahmood, Population Council, compiled the list of references and followed up with the authors. Lastly, under the direction of Christina Tse in the Population Council's Office of Publishing and Creative Services, Robert Heidel edited the chapters and Michael Vosika arranged the layout and final form of the book for publication. 



\section{CAPTURING THE DEMOGRAPHIC DIVIDEND IN PAKISTAN}


- 2

4. 66 There is growing concern within $\frac{-2}{3}$ and outside the country that a central development challenge for Pakistan is how it addresses the rapid growth of population, which if left unchecked could exert a drag on economic growth and delay the onset of the demographic dividend. 99

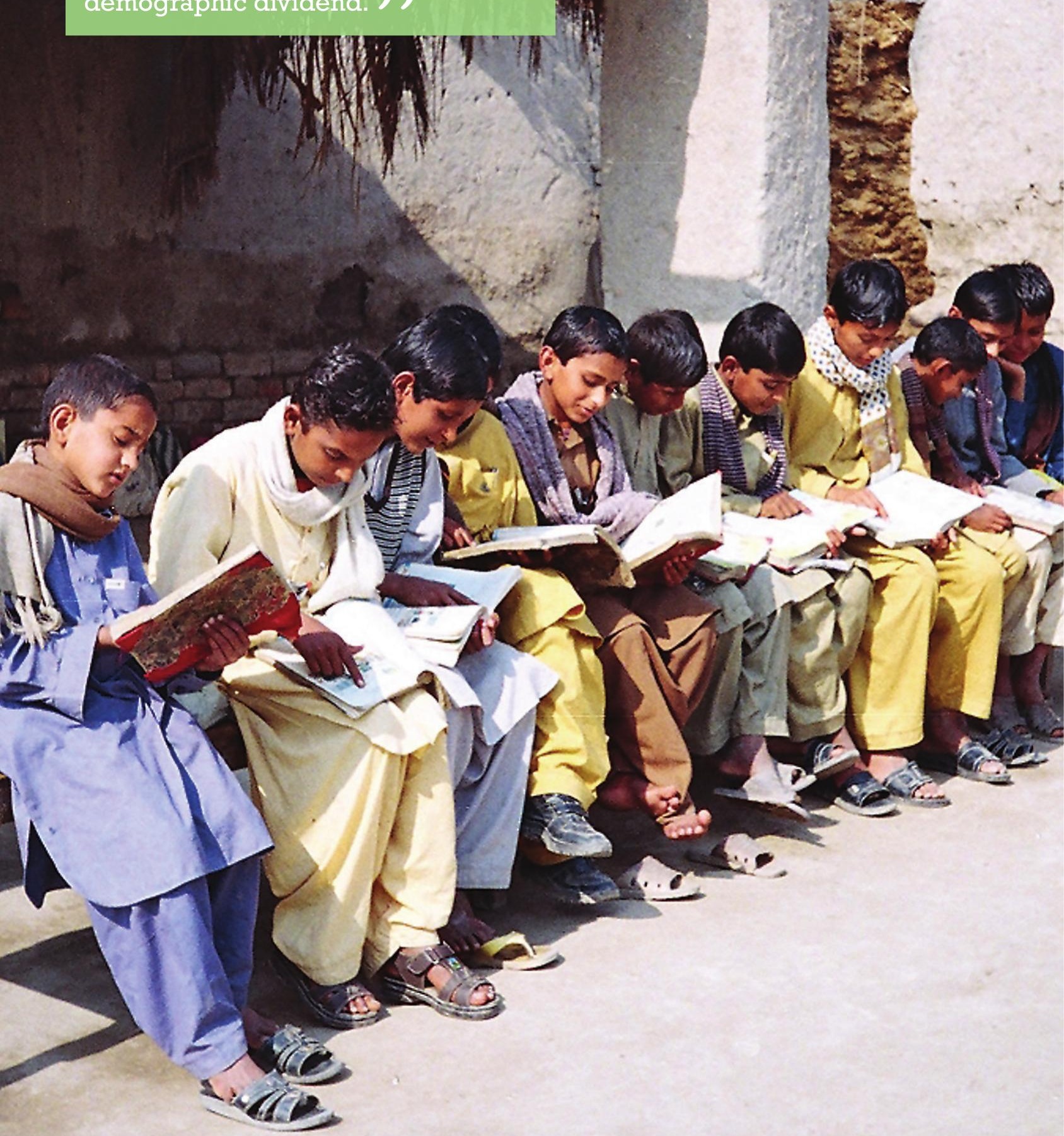




\section{CHAPTER ONE \\ Overview: \\ The Population \\ of Pakistan Today}

\section{RABBI ROYAN and ZEBA A. SATHAR}

Pakistan is facing manifold challenges. In addition to a fragile economy, the country has experienced frequent disasters both natural and human-made. Between 2005 and 2012, for instance, the country underwent the devastating 2005 earthquake, the 2008 internally displaced persons (IDP) crisis which continues up to now, the floods of 2010 which affected more than 20 million people and caused about US $\$ 10$ billion in damages, and the 2011 floods affecting some 8 million people. As a result of both weak economic growth and the impact of disasters, and compounded by challenges of governance and low levels of investment in the social sectors, Pakistan has not made much headway toward achieving the UN Millennium Development Goals. ${ }^{1}$

These challenges have been exacerbated by continued rapid growth of the population currently at around 2.1 percent per annum. ${ }^{2}$ The size of Pakistan's population, which was 33 million at the time of partition and independence in 1947, has increased fivefold since then, reaching 180 million currently, making Pakistan the sixth most populous country in the world. High population growth is compounded by continued, although declining, high levels of fertility. In terms of fertility decline in the Asia-Pacific region, Pakistan is lagging behind all countries except Afghanistan and Timor Leste. The total fertility rate 
(TFR) in Pakistan, has declined slowly in recent decades to 4.1 births per woman in the 2006-07 PDHS survey (PDHS 2006-07), ${ }^{3}$ with significant differentials among income groups. According to the same survey, the TFR of the lowest wealth quintile was 5.8 births, while that of the richest was 3.0: a difference of 2.8 births. Women in the youngest reproductive age group of 15-19 had a fertility rate of 51 births per 1,000 women, illustrating that early marriage and childbearing persist. In fact, about 50 percent of girls marry before their 20th birthday.

There is therefore growing concern within and outside the country that a central development challenge for Pakistan is how it addresses the rapid growth of population, which if left unchecked could exert a drag on economic growth and delay the onset of the demographic dividend. ${ }^{4}$ There are concerns too that although Pakistan is on the cusp of benefiting from the dividend given changes in age structure, the dividend may be lost because of failure to tackle population growth.

\section{Purpose of the volume}

It is in the above context that this volume was planned. Its purpose is to reiterate to planners and policy makers that population factors are integral to the development debate, especially as Pakistan makes the transition to the youth bulge. Currently, 28 percent of the population is between ages 15 and 29. Translating this "youth bulge" into a "demographic dividend" is a principal challenge and the main theme of this volume. A key message is that Pakistan's economic prospects will hinge on how it captures the positive aspects of the demographic dividend through policy choices that favor investments in education and skills formation, health, and employment creation and employability. The volume highlights the potential boost to economic growth that can result from the demographic dividend. According to Bloom and Williamson (1998), between 25 percent and 40 percent of East Asia's "economic miracle" can be attributed to the demographic transition that countries in the region were experiencing at the time.

\section{The demographic dividend in Pakistan}

The demographic transition is the transition from a rough equilibrium of high fertility and high mortality, through a period of rapid growth when declining mortality coexists with continuing high fertility, to an ultimate equilibrium of low fertility and low mortality. In the process of completing the transition, several potential scenarios determine the total size and age structure of the population. These features are mostly determined by the size of the population at the onset of the transition, the speed of the transition, and the period of time required to achieve the full transition. One outcome of the demographic transition, which has recently been touted as important for development outcomes, is the "demographic dividend" or "demographic bonus." This occurs in the last stages of the demographic transition, a situation happening in Pakistan, where fertility is in the process of falling toward replacement level. 
The demographic bonus or demographic dividend refers to the opportunity created over a period of about 40-50 years during which, as a result of reduced proportions of dependent children, the proportion of the population of labor force age increases significantly, resulting in direct and indirect opportunities to increase per capita output. The impact of age structure on economic development was first posited by Coale and Hoover (1958), but the magnitude of the effect was not realized until the 1990s. At that time the theory was tested retrospectively in relation to East Asia in careful work associated with Andrew Mason, David Bloom, Jeffrey Williamson, Allen Kelley, and others; their work has been summarized in two important collections of papers: Birdsall, Kelley, and Sinding (2001) and Mason (2001).

The decrease in the dependency ratio, and the fertility reduction that causes it, can affect output per capita in a number of ways. These in turn can be divided into two components: factors that influence the proportion of the working-age population, and factors that influence the output per worker. The most obvious effect of the demographic bonus is to increase the proportion of the population of working age. If a) labor force participation rates are constant, and b) output per worker is constant, then a given percent increase in the proportion of working age will result in the same percent increase in per capita output. Of course, conditions a) and b) are affected by many factors. In itself, however, the increase in the proportion of the working-age population is a positive opportunity. Fertility decline has another effect, freeing women to participate more fully in the labor force. Whether through delaying age at marriage or ending childbearing earlier, women in a low-fertility setting are able to spend more of their productive years in paid employment. Such benefits related to the changing age structure are beginning to materialize in Pakistan.

Reduced dependency ratios can also affect per capita output through several intermediate channels, such as by facilitating increased savings and investment at both micro and macro levels. At the micro level, parents with fewer dependent children can more readily afford productive investments. At the macro level, resources otherwise needed to support an increasing population can be put directly to productive investments. Another channel is through improving the quality of human capital, since fewer resources are required to meet the demands for more schools, teachers, and so on. A third channel is through improved health: having fewer children results in physically and mentally stronger children, which ultimately allows them to become more productive adults. All these effects can, under the right circumstances, be large and important.

This volume revisits the population and development debate through the demographic dividend framework, which links the issues of family planning, education, and employment in a single paradigm. It shows the close linkages between many sectors, but particularly population and health; education and the labor force; and employment. Instead of a single-sector focus, this volume emphasizes the interlinkages across sectors and analyzes the interrelationships and interdependence between them. It also highlights the important underlying issue of gender disparities and the position of women and their ability to implement fertility decisions and to reach equality in acquiring education and securing employment. The paradigm is being utilized extensively in the latest responses 
by the population field to the continuation of population growth (World Economic Forum 2012). The idea of reaping the potential of the demographic dividend has increasingly become the focal point of the renewed debate.

The population field faces international neglect attributable to three major factors. First, conservative elements (mainly the religious right) saw population policy, and family planning in particular, as code words for abortion and coercion. Second, economists thought population growth was a problem that had been solved and an endogenous variable taking care of itself. Third, the health establishment became preoccupied with addressing the HIV/AIDS epidemic. Population issues are now making a comeback, in large part because of the clear link between the demographic dividend and economic growth. In addition, the health establishment sees the link with saving maternal and child lives, and conservatives acknowledge that abortions can actually be averted through family planning.

Another factor driving the renewed emphasis on population and development is the latest UN projections, which show that world population will reach the 9 billion mark. Rapid growth is concentrated in some parts of the world, mainly Africa, but also Pakistan and Northern India. Pakistan, with its still high levels of fertility, stands more in the league of African countries rather than with countries in its own continent.

\section{Can Pakistan have a rapid fertility transition?}

It would be misleading to highlight only the positive aspects of the favorable age structures which led to the demographic dividend in East Asia and some Latin American economies. The chapters that follow instead point out that while the dividend is still possible in Pakistan, its realization requires strong policy interventions.

A main issue is whether Pakistan should be concerned that its population size has increased fivefold since 1947. Growth is expected to continue for several more decades, with the total possibly nearly doubling over the next century. This projection implies that the population will have multiplied approximately tenfold between 1900 and 2100 . In Chapter 2 John Bongaarts, Zeba Sathar, and Arshad Mahmood review alternative population projections to 2050 and discuss the demographic drivers of this phenomenal population growth. The authors employ a well-known decomposition technique and alternative projections to assess the impacts of the speed of fertility decline and the population growth momentum embodied in the generations already born who in turn will reproduce.

A key policy question is how to reduce future growth through voluntary measures and to curb the country's unsustainable rate of population growth. An obvious response is to strengthen the family planning program. Women in Pakistan have high levels of unmet need for contraception, and as a result many unplanned and unwanted pregnancies occur each year. Preventing such pregnancies and reducing fertility and population growth lead to a range of health, social, and economic benefits as documented in the following chapters. 
Any program-induced fertility decline changes the future trajectory of population growth. According to the standard projection used in this volume, the population of Pakistan will grow from 174 to 302 million between 2010 and 2050 (Population Council 2011). This projection is based on the assumption that fertility will continue to decline over the next few decades. If no further investments in family planning are made, then the fertility trajectory could easily be half a birth higher, in which case the population of Pakistan would reach 342 million in 2050. On the other hand, if strong new investments in family planning are made, the future fertility trajectory could easily be half a birth below the medium variant, leading to a population of 266 million by 2050. In other words, the difference between a very weak and a strong program scenario is 76 million people by 2050 .

The preceding summary of projections for Pakistan has focused on one aspect of population growth: population size and how it changes over time. But projections also produce a number of other statistics, in particular population by age and sex. As discussed in later chapters, levels and trends in the age composition have consequences for socio-economic development, particularly education and employment and poverty and health. Between 1950 and 2000 Pakistan's population was very young, with about 60 percent below the age of 25 , and the age structure changed little in the twentieth century. However, large changes are expected in coming decades (Sathar 2011).

This projected change in age composition is the result of declining fertility: with fewer births, younger generations will become smaller than older generations. The population under age 15 has recently leveled off owing to the decline in fertility that started in the 1990s. The population over 65 is very small but growing. In contrast, the population of working ages (15-64) is large and rapidly growing. The huge future increase in the projected working-age population represents both an opportunity and a challenge. If these people can be employed productively, the country will benefit from the so-called demographic dividend. On the other hand, if many working-age adults cannot find employment or are underemployed, adverse social, economic, and even political consequences are likely to result (Sathar 2011).

\section{How rapidly can Pakistan achieve universal primary education?}

In Pakistan, indicators measuring progress in education are lagging behind those found in most other countries with similar levels of per capita income. Pakistan particularly needs to increase the proportion of males and females who complete primary education. In Chapter 3 Asif Wazir, Anne Goujon, and Wolfgang Lutz examine the close association between education and population trends and present some scenarios for the intertwined trajectories in the next four decades. The authors contend that while education has been emphasized by the government and international development agencies throughout Pakistan's history, schooling has failed to play a central role in the country's development. One of the critical requirements for capturing the demographic dividend is to improve the basic levels of education and skills of the working-age population. The strong relationship between education and population well-being has been recognized in countries at all stages of development, and is particularly critical 
in countries, like Pakistan, that are in the middle stages of the demographic transition (Bongaarts 2011; Sathar 2007). Progress in Pakistan has been gradual. Younger age groups are better educated than older age groups, and the gender gap is narrower than 20 years ago. But progress is not commensurate with policy statements and intent and with the needs of the country.

Another clear message in Chapter 3 is that Pakistan needs to intensify investments in basic education to ensure that more children, particularly girls and children living in rural and remote areas, can enroll in school. This step will help ensure the attainment of universal primary education, the minimum level of education required to secure jobs in most sectors of the economy today. More investment is required to ensure that higher numbers reach secondary and tertiary levels of schooling as well. As the authors demonstrate, current progress in education is so slow that universal primary education is not likely to be achieved over the next five decades.

Of the several pathways through which population and education are linked, the authors single out four particular associations. The first is that as fertility falls, the cohorts entering schoolgoing ages shrink. The share of the school-age population (5-19 years old) in Pakistan was around 34 percent in 2010. Although this proportion will decline to 26 percent in 2035, the school-age population will continue to grow, rising from 59 million in late 2010 to 68 million in 2035. This implies that until 2035, more children will need to be enrolled, more schools will have to be built and more teachers will have to be trained and hired.

The second is the strong inverse association between female education and fertility levels. Female education levels are positively correlated with demand for and use of contraception and negatively associated with desired family size and fertility. As educational levels increase and the better-educated cohorts of young women enter reproductive ages, they have lower fertility. Educated women are also more likely to educate their own children.

The third association is the one most closely related to this volume. Substantial and immediate investments in education will lead to a better-educated working-age population by 2030, as children currently aged 5-19 enter the labor force. While investments have increased over the last decade, it will be many more years before Pakistan can benefit from a well-educated work force. This is especially the case if population growth remains high at around 2 percent. The authors' projections show that significant increases in the working-age population will occur during the next four decades, rising from 85 million in 2010 to 178 million in 2050. This large labor force, if it is well educated, highly skilled, and sufficiently employed, could be a key asset for Pakistan.

Finally, a genuine escalation of education rates can only occur with gains in gender equity in terms of both education and employability, as more and more women become eligible for jobs requiring secondary and tertiary education. In 2010, according to the Labour Force Survey, women accounted only for 22 percent of the active labor force. This population has to double at the very least to ensure that more than half of the workingage population is employed. 


\section{How much economic growth is required?}

In Chapter 4 Rashid Amjad considers several reasons why Pakistan may have failed to take advantage of the first few decades of the demographic dividend. First, Pakistan's rates of investment and domestic savings are substantially lower than those of its neighbors, averaging only about 17 percent and 12 percent of gross domestic product (GDP) respectively in the last four decades, and showing signs of decline. According to Amjad, almost 80 percent of Pakistan's GDP growth during 1960-2005 was the result of increases in capital and labor inputs. Only 20 percent was attributable to total factor productivity (TFP). TFP has also fluctuated, explaining 38 percent of GDP growth in the 1980s, 18 percent in the 1990s, and 22 percent during 2001-2005. Given the recent rapid deceleration of economic growth, TFP fell further and sharply in the past five years.

Pakistan's poor economic performance in recent years has had an adverse effect on realizing the expected gains. Sluggish economic performance has led to falling employment absorption capacity, as reflected in the decline in the ratio of employment to the working-age population from 56 percent in 1973 to 48 percent in $2002 .^{5}$

Another reason is the low re-allocation of labor to higher-value-added sectors. The share of industry in employment has remained flat (at around 20 percent) post-1980, meaning that the higher-productivity sector of the economy has not generated sufficient new jobs to raise overall productivity. The share of manufacturing has also stagnated at around 12 percent. Moreover, growth of total factor productivity has been much lower in Pakistan than in India, particularly in the services sector.

Amjad recommends several steps that would allow Pakistan to reap the demographic dividend. These include creating more and better jobs for women and men, especially the young labor market entrants; empowering women, reducing gender disparities, and increasing female labor force participation rates; and investing far more substantially in education and skills. But the country's highest priority is to reduce the high growth rate of population. An important underlying conclusion of Chapter 4 is that without reducing its population growth rate, not only will Pakistan's demographic dividend be further delayed, but the continued high growth rate of the working-age population will make it impossible to achieve necessary levels of economic growth and job creation. Such an outcome could convert the expected dividend into a disaster.

In Chapter 5 G. M. Arif argues that demographic factors in Pakistan contribute to poverty at both macro and micro levels. Focusing on the micro level, he describes the links between demographic factors and poverty dynamics in rural areas of the country. One can draw five conclusions from his analysis. First, household size increases the risk of remaining in chronic poverty or being "transitory poor" (moving into or out of poverty). The implication is that larger families, because of demographic pressure, are more likely to live either in chronic poverty or in transitory poverty. Second, high dependency ratios are associated with both long-term (chronic) poverty and transitory poverty. This could be explained by the probable association between higher proportions of dependents in relation to persons of working age and lower saving rates. With household 
resources used to meet consumption needs, little is left for investment. Third, an increase in the working-age population has a negative association with chronic poverty, but has no significant role in helping households to move out of poverty. Fourth, without efforts to improve both the health status of the poor and vulnerable and their educational levels, it remains difficult for households to escape poverty. Fifth, household assets, particularly landholdings, keep households out of chronic poverty. Despite the importance of assets for household well-being, however, demographic pressures may push many families into poverty and make the movement out of poverty difficult.

In Chapter 6 Akmal Hussain suggests that addressing the challenge of demography and development will require a change in the institutional structure of economic growth and public policy. The creative energies of the young need to be engaged in the process of economic growth, especially given their growing share of the working-age population. Over 60 percent of Pakistan's population is below age 30. The labor force in the age group 15-49, estimated at 96 million in 2010, is projected to increase to 181 million by 2050 , while the total labor force is expected to increase from 110 million to 235 million over the same period. Thus, unless these young people are given access to education, health, and livelihoods, the very economic potential of this demographic change can have explosive social and political consequences.

Hussain argues that because of the low employment elasticity associated with the existing economic structure, GDP growth of 5 percent has been generating employment for less than 1 million persons per year. The policy challenge is how to reduce poverty and generate employment for the more than 3 million people who will be entering the labor force annually over the next four decades. This will require a sustained rate of GDP growth of 7 to 8 percent, and a restructured growth process that increases the elasticity of employment growth and is also pro-poor. According to Hussain, achieving these strategic priorities warrants institutional changes that will enable the middle class and the poor to acquire productive assets and equitable access to the markets for credit, goods, and services. In Hussain's assessment, the current institutional structure generates rents only for a small elite by restricting competition and excluding the poor and middle class from investment and high-wage employment opportunities.

In Chapter 7 Saba Gul Khattak argues also for institutional changes to broaden the scope and domain of population policies particularly to incorporate gender issues. These include political instruments such as the National Finance Commission award to the provinces, which is largely based on population size. The approach to population policy has to change by linking a large range of concerns which connect several sectors and abandoning the exclusive focus on influencing women's reproductive behavior.

In Chapter 8 John Bongaarts, Ali Mir, and Arshad Mahmood contend that achieving the demographic dividend will require reversal of the stalled fertility decline. Learning from the experiences of East Asia as well as of Muslim countries such as Bangladesh, Iran, Indonesia, and Malaysia, it was clear that fertility decline was critical in realizing the demographic dividend and was also a major factor in reducing poverty. After de- 
cades of very rapid population growth, the prospect of slower growth lies ahead because fertility is declining. The future trajectory of population growth is highly sensitive to the timing and extent of further fertility declines.

In Chapter 9 Zeba Sathar and Rabbi Royan conclude by reexamining many of the suggestions in previous chapters for capturing the demographic dividend. Population policy alone will not suffice, but it is closely linked with health, education, labor and employment, youth, gender, and economic growth.

\section{Notes}

1 A set of goals, targets, and indicators agreed to by UN member countries in 2000 to measure social and development progress.

2 Government of Pakistan. 2012. Pakistan Economic Survey 2011-12. Islamabad: Finance Division, Economic Advisor's Wing.

3 Pakistan Demographic and Health Survey, 2006-07.

4 The growth in income or consumption per capita attributable to a demographic transition or declining dependency ratios.

5 Labour Force Survey (various issues). 
66 The population of Pakistan has increased fivefold since 1947 , reaching 180 million today. Growth is expected to continue for several more decades, with the total possibly nearly doubling over the next century. 98

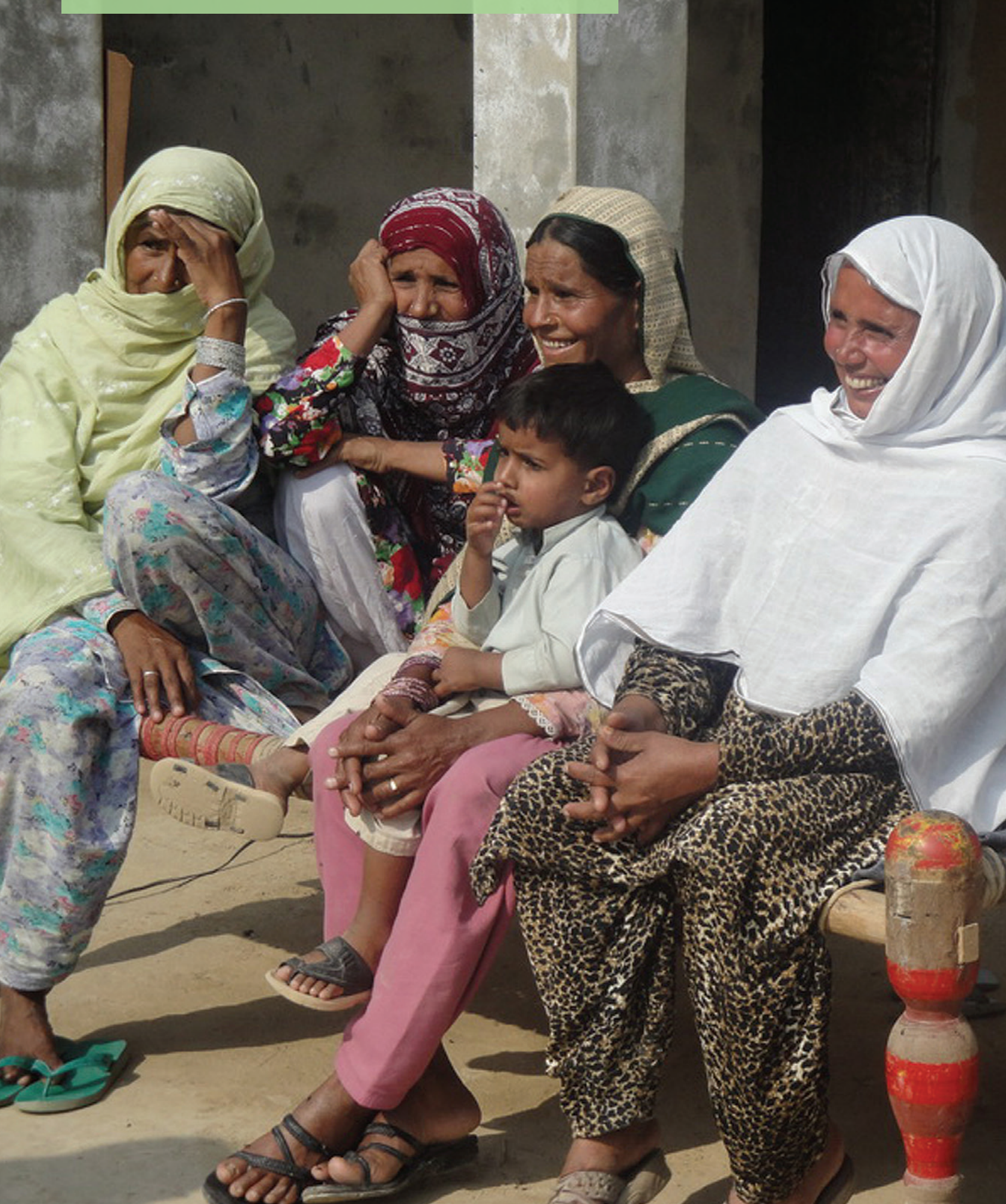




\section{CHAPTER TWO \\ Population Trends in Pakistan}

JOHN BONGAARTS, ZEBA A. SATHAR, and ARSHAD MAHMOOD

The modern expansion of the population of Pakistan (a part of India before 1947 and West Pakistan until 1971) started in the early decades of the twentieth century with the onset of a long-term decline in the death rate. By 1950 population size had risen slowly to 38 million, from 23 million in 1900. Since then growth has accelerated sharply as a lower incidence of epidemics and famines as well as improvements in public health and standards of living resulted in further rapid declines in mortality. The population of Pakistan has increased fivefold since 1947, reaching 180 million today. Growth is expected to continue for several more decades, with the total possibly nearly doubling over the next century. This projection implies that the population will have multiplied more than tenfold between 1900 and 2100. The sheer size of the population, and the changes in age structure resulting from declining fertility in particular, have clear implications for social and economic development.

This chapter reviews alternative population projections to 2050 and discusses the demographic drivers of the country's phenomenal population growth. We use a wellknown decomposition technique and alternative projections to assess the impacts of the speed of fertility decline and of population momentum - the growth embodied in the generations already born. 


\section{Alternative projections: How many Pakistanis?}

Past demographic trends, although somewhat irregular depending on sources used (e.g., surveys, censuses, and fertility histories), are fairly well established, but there is considerable uncertainty about the future. This is evident from the differences between projections made by leading population organizations. Below, we compare four projections, as illustrated in Figure 2.1.

- UN 2008 and 2010. The United Nations publishes projections for all countries in the world and updates them biannually. Projection methods are standardized across countries, and limited resources are available to investigate conditions in individual countries.

- National Institute of Population Studies (NIPS) 2010. The most recent NIPS projection for Pakistan is based on a detailed assessment of demographic trends up to 2008. This is the official set of projections used by the Government of Pakistan.

- Population Council (PC) 2011. A new projection was made for this volume to take into account the latest information on demographic developments in Pakistan.

As we pointed out above, the period 1950-2010 saw a nearly fivefold increase in the population to around 174 million. The projections through 2050 present alternative scenarios for fertility, with the UN 2010 estimates showing the beginning of an eventual leveling off at 270 million while the UN 2008 estimate shows a 2050 population of 323 million that continues to increase. The NIPS projections very closely track the UN 2010 projections but do not provide estimates beyond 2030. The 2011 Population Council projections generate a population of 302 million in 2050, about 30 million more than the UN 2010 projections but considerably less than the earlier UN projections.

\section{FIGURE 2.1 Population growth 1950-2010 and alternative population projections 2010-2050}

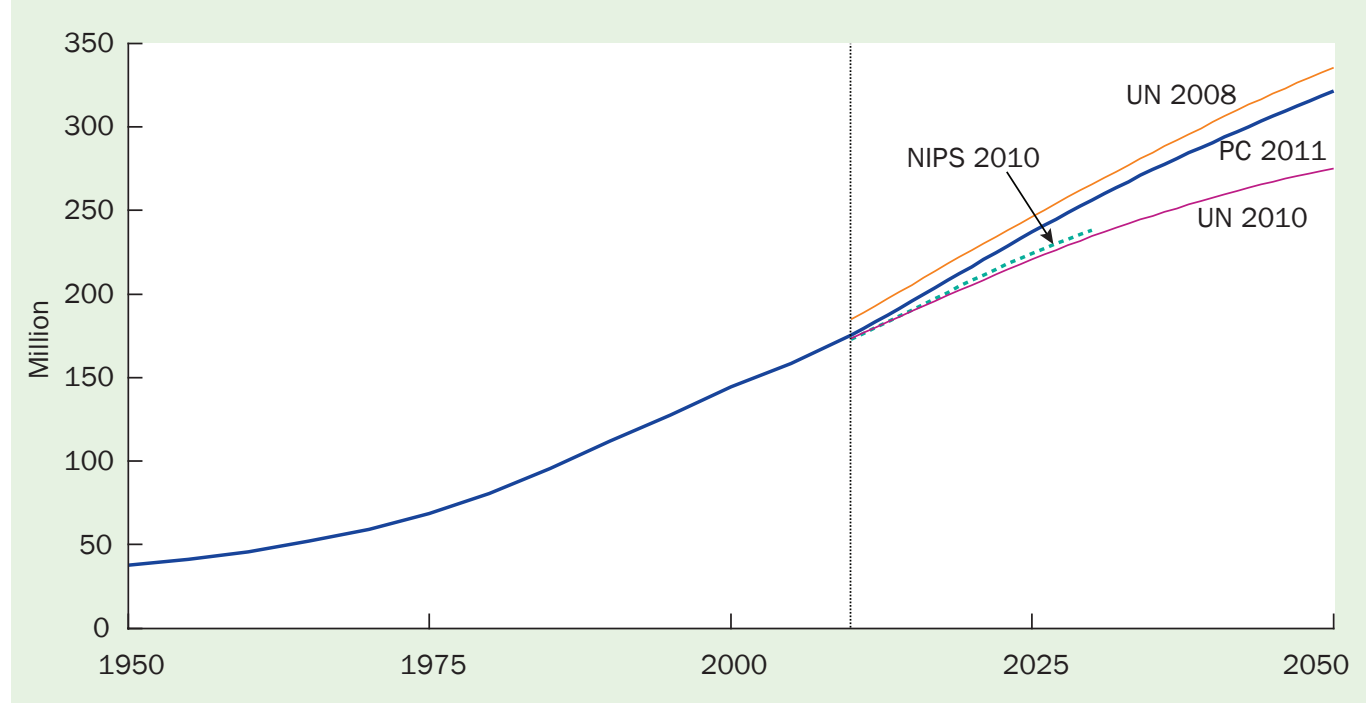

SOURCE: Population Council 2011; NIPS 2010; UN 2009 and 2011. 


\section{How important is the speed of fertility decline?}

The main cause of differences between the four projections lies in their assumptions about future levels in fertility. Figure 2.2 plots the fertility trends incorporated in the four projections. Each assumes that fertility declines at a steady pace over time before levelling off at around 2 births per woman in 2050. The differences between trajectories are largely due to significant differences in the level of fertility assumed at baseline in 2010 . Recent estimates of fertility are available from two main sources: 1) the 2006-07 Pakistan Demographic and Health Survey (PDHS) estimates a TFR of 4.1, which implies a total fertility rate of 3.9 for 2007 (National Institute of Population Studies, 2008), and 2) the Pakistan Demographic Survey (PDS) estimates a TFR of 3.7 in 2007 (Federal Bureau of Statistics, 2009). The UN 2008 and PC projections are consistent with the PDHS, while NIPS and UN 2010 are more consistent with the lower total fertility rates of the PDS series. The NIPS projection, which ends at 2030, assumes a very rapid decline in the total fertility rate to 2.3 in 2027. In the analysis presented below, we rely on the PC projections because they are the most up-to-date in terms of the baseline data for 2010 and anticipated trends in fertility. The major difference in expectation between the UN 2010 and the PC projections is that fertility is expected to decline much more gradually in the latter, reaching replacement about five years later and plateauing at 2, while the UN actually assumes that fertility will decline further. The earlier UN 2008 estimates expected fertility to reach replacement sometime after 2050.

The results presented in Figures 2.1 and 2.2 demonstrate that future population trends are sensitive to trends in fertility. This finding needs to be assessed further to

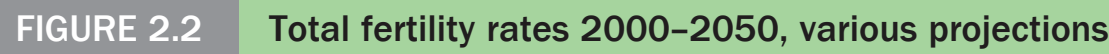

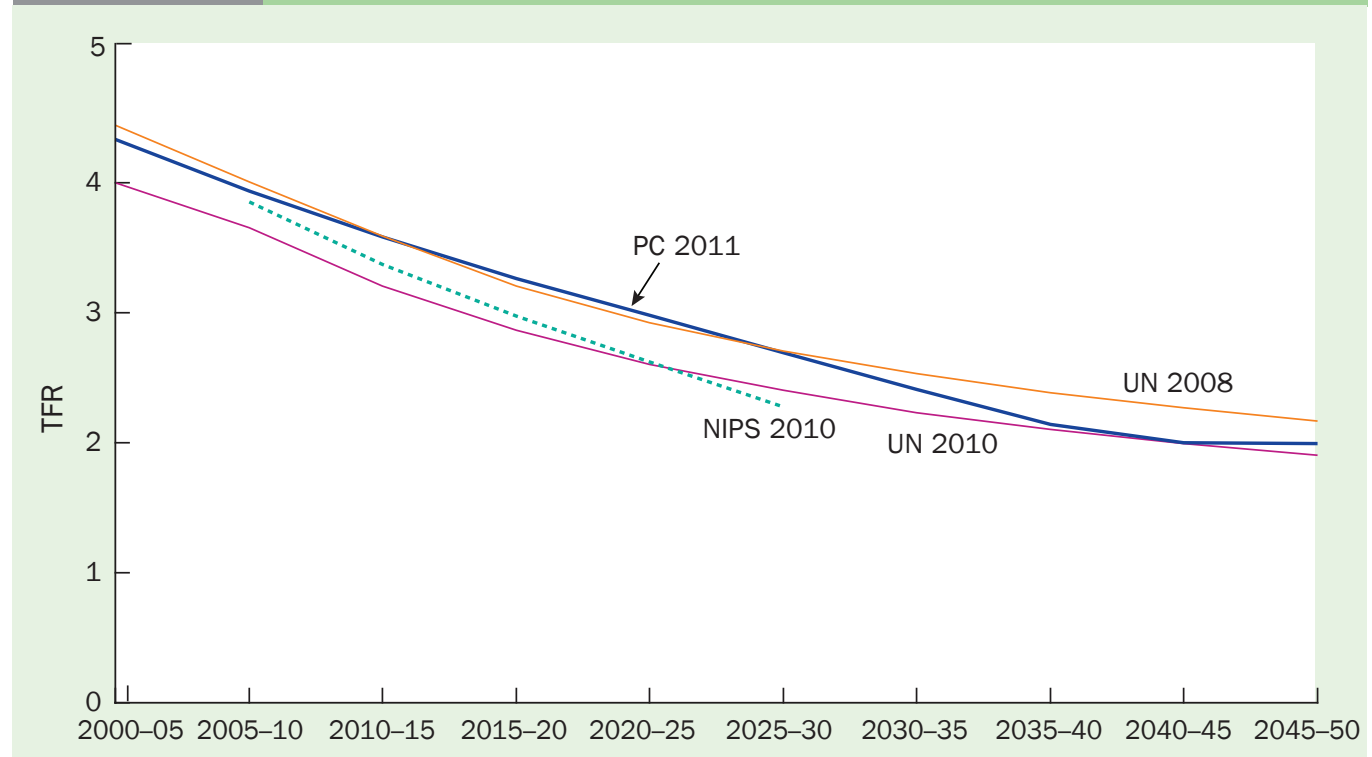


specify the actual impact of the speed of fertility decline on population growth and its subsequent effect on various aspects of social and economic development. To do this, we present three hypothetical population projections to 2050 and compare them to the standard PC projection:

Assumption 1: Constant fertility projection, which holds fertility constant from 2010 onward.

Assumption 2: High variant, which assumes that fertility is half a birth higher than in the standard PC projection throughout.

Assumption 3: Low variant, which assumes that fertility is half a birth lower than in the standard PC projection throughout.

The population projections associated with these variants are plotted in Figure 2.3. As expected, the constant fertility variant yields the highest population trajectory. It reaches 395 million in 2050, 94 million above the standard PC projection of 302 million. In the low variant the size of the population and the growth trajectory show a levelling off in the population of Pakistan by 2035. The high and low variants are respectively 40 million above and 38 million below the standard PC projection. The high and low variants indicate that even relatively small variations in future fertility trends have a large impact on population trends. This finding has important policy implications that we discuss later.

The preceding summary of projections for Pakistan has focused on population size and how it changes over time. But projections also produce a range of other statistics,

\section{FIGURE 2.3 Population projections to 2050 comparing constant, high, standard PC, and low fertility scenarios}

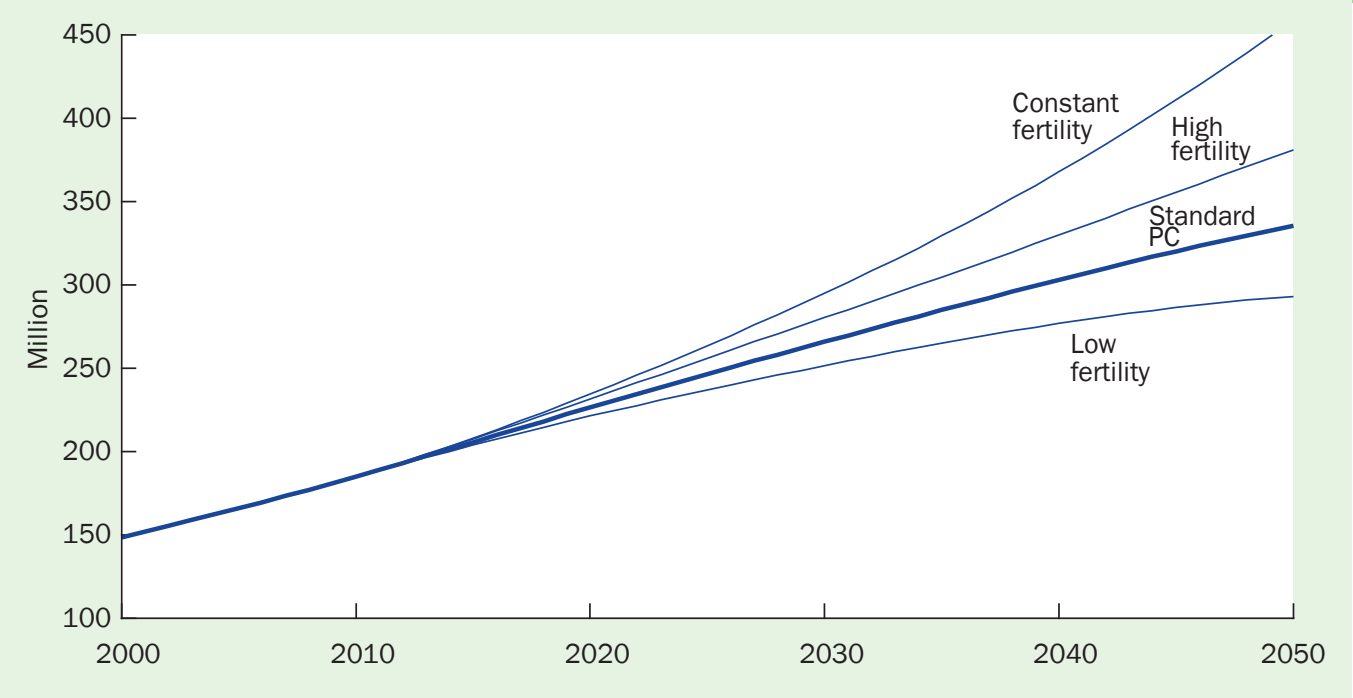

SOURCE: Population Council 2011. 
in particular population by age and sex. As discussed in later chapters, levels and trends in the age composition have important consequences for socioeconomic development, particularly education, employment, poverty, and health. Between 1950 and 2000 Pakistan's population was very young, with about 60 percent below the age of 25 and the age structure changed little in the twentieth century. However, large changes are expected in coming decades (Sathar 2011).

This projected change in age composition is the result of declining fertility: with fewer births, younger generations will become smaller than older generations. Figure 2.4 plots trends in the number of people in three age groups from 2000 to 2050 . The population under age 15 has recently levelled off as a result of the decline in fertility that started in the 1990s. The population 65 and over is very small but growing. In contrast, the population aged 15-64 is large and rapidly growing. The substantial future increase in the projected working-age population represents both an opportunity and a challenge. If these men and women can be employed productively, the country will benefit from the so-called demographic dividend. On the other hand, if many working-age adults cannot find employment or are underemployed, adverse social, economic, and political consequences are likely to occur (Sathar 2011).

\section{Components of future population growth: Why growth will continue}

The preceding projections indicated that, even with rapid fertility declines, population growth in Pakistan will continue for some decades. The expected future growth is attributable to four main demographic factors (Bongaarts 1994; Bongaarts and Bulatao 1999). We discuss these below.

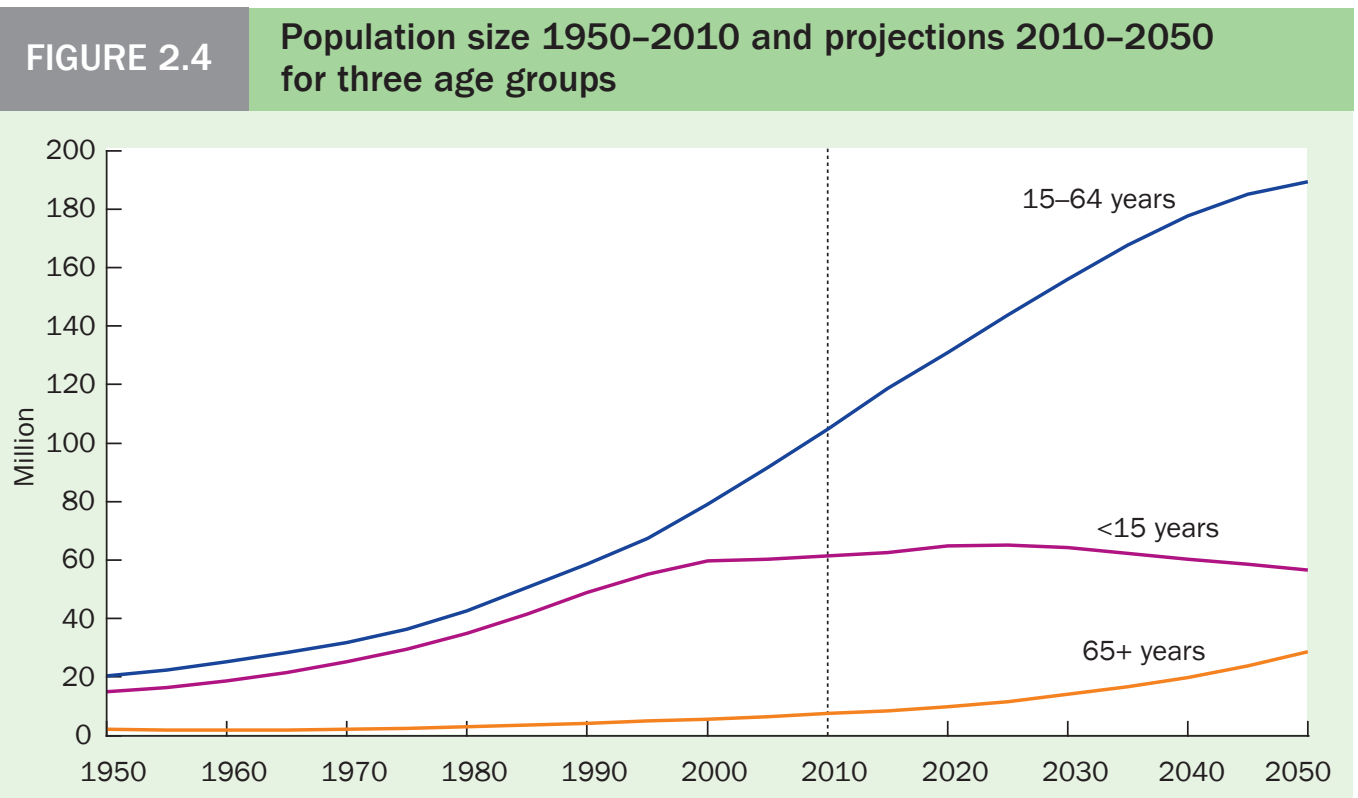

SOURCE: Population Council 2011. 


\section{High fertility}

Fertility will be considered "high" if it exceeds the replacement level of 2.1 children per woman. Replacement is a critical factor in population dynamics because it equals the fertility level that, if maintained over time, produces zero population growth. Positive deviations from replacement lead in the long run to persistent population growth, while negative deviations lead to decline. Currently, replacement fertility equals 2.3 births per woman in Pakistan (this level exceeds 2 because children who die before reaching the reproductive ages have to be replaced with additional births).

Fertility in Pakistan has been above replacement for most of its history, with levels approaching 7 births per woman in the 1960s, declining to around 6 in the 1980s and to its current level of 3.7. As shown in Figure 2.2, the PC projection assumes that fertility will decline further in the future, eventually stabilizing at 2 births per woman in the long run. Because current and projected levels are above replacement, high fertility will remain one of the key forces contributing to further population growth until replacement fertility is reached.

\section{Declining mortality}

Rapid declines in mortality have been the main cause of population growth in the past. Since the middle of the twentieth century, Pakistan has experienced exceptionally rapid improvements in life expectancy, rising from 41 years in 1950-55 to 65 years today. These improvements are in large part due to the global spread of medical and public health technology (e.g., immunization, antibiotics), rising standards of living and nutrition, and improved medical care after World War II. Over the next 40 years, projections assume that life expectancy will continue to rise, reaching 72 years in 2050 . Thus the impact of mortality decline will continue.

\section{Population momentum from a young age structure}

Even if fertility were immediately lowered to the replacement level, population growth would continue in most countries in the developing world. The reason for this is a young age structure, which is the result of high fertility and rapid population growth in recent decades. With a large proportion of the population under age 25 , further growth in the coming decades is assured. The relative abundance of these young people results in a birth rate that is higher than the death rate even if fertility is at replacement. This effect on future growth is called population momentum.

The effect of population momentum can be reduced significantly if young people marry later and delay their first birth. In addition, the likelihood is that young people in Pakistan will have smaller families than earlier generations, but not uniformly. Better-educated young people, especially women, are likely to have much lower fertility than their parents, but uneducated youth will deviate less from their parents' behavior. 


\section{Migration}

International migration can significantly affect population growth in some countries (e.g., into the US, and out of other countries, e.g., Mexico), but it often has a very small demographic impact in others. For Pakistan the net flow of out-migration is estimated at 1 per 1,000 population. This makes migration a very small component, only slightly slowing population growth. The forthcoming census is expected to give a better idea of both in-migration from neighboring countries and out-migration, particularly to the Middle East.

A full analysis of the contribution of each of these four demographic factors to future population growth will not be attempted here. Instead, we focus on the contribution of high fertility. To assess the role of high fertility we compare two projections:

1) The standard projection (Population Council 2011), which is determined by all four factors. It includes the effect of high fertility.

2) A hypothetical replacement projection, which is identical to the standard projection except that fertility is set to the replacement level from 2010 onward. This projection excludes the effect of high fertility.

Figure 2.5 presents these two projections for Pakistan. From a baseline level of 174 million in 2010, the standard projections yield a population of 302 million in 2050. In contrast, the replacement projection yields a population of just 264 million. The difference between these projections measures the impact of high fertility, measured in absolute terms as 38 million or in relative terms as the percent increase in population due to high fertility (12.5 percent).

\section{FIGURE $2.5 \quad$ Alternative population projections for 2005-2050 and population growth components}

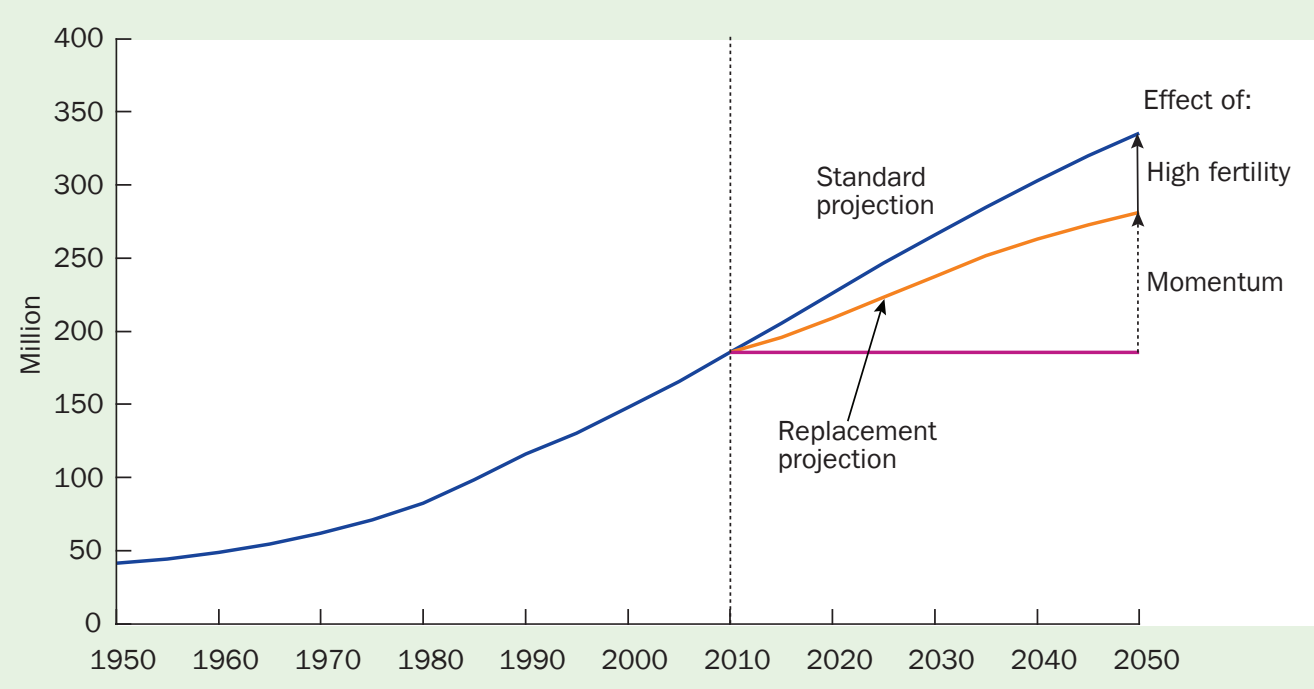

SOURCE: Population Council 2011. 
Even with instant attainment of replacement fertility, the population of Pakistan is still expected to grow by 53 percent (an addition of 91.7 million) over the next four decades. More than half of all population growth between now and 2050 is attributable to the momentum inherent in the country's young age structure (the effects of mortality and migration are small and offsetting). This growth represents the children who will be born to parents currently aged under 30 and will be influenced by marriage timing and wanted and unwanted fertility of that group.

\section{Unwanted and wanted fertility and unmet need for contraception}

The preceding decomposition indicates that high fertility is one of the main drivers of continued rapid population growth in Pakistan. From a policy perspective it is important to note that high fertility can in turn be attributed to two underlying causes: wanted and unwanted fertility.

1) Unwanted childbearing occurs when women have more children than they desire. About one in four births in Pakistan is unwanted, and a similar proportion is mistimed (National Institute of Population Studies 2008). Furthermore, an estimated one million abortions are performed each year, many of them under unsafe conditions (Sathar et al. 2007). These unplanned pregnancies contribute to population growth and are a major factor in maternal mortality. About 5 percent of maternal deaths result from postabortion complications (National Institute of Population Studies 2008), and additional indirect deaths related to abortion raise this proportion to almost 10 percent (Jafarey et al. 2010). Unplanned childbearing occurs because women encounter multiple obstacles to the use of contraception (Bongaarts and Bruce 1995; Cleland et al. 2006; Casterline and Sinding 2000; Casterline et al. 2001; Westoff and Bankole 1995), including:

- Lack of knowledge of contraception and sources of supply

- Low quality and limited availability of family planning services

- Cost of method, services, travel, and time

- Health concerns and side effects

- Objections from husbands or other family members

- Concerns about moral and social acceptability

These obstacles lead some women to forgo contraceptive use despite their intention to avoid pregnancy. Such women have an "unmet need" for contraception. In Pakistan 37 percent of married women are estimated to have an unmet need (National Institute of Population Studies, 2008). As shown in Figure 2.6 contraceptive use has increased substantially over the past two decades, reaching 30 percent in 2007 . However, unmet need has risen more substantially, because the demand for contraception has risen at a faster pace than contraceptive use.

Figure 2.7 summarizes the relationship between pregnancy planning status and outcomes. In 2007 nearly 7 million pregnancies occurred in Pakistan, 39 percent of which (2.7 million) were unintended (data courtesy of Susheela Singh). Of the 7 million 


\section{FIGURE 2.6}

Contraceptive prevalence rate and unmet need for family planning, 1991, 2001, and 2007

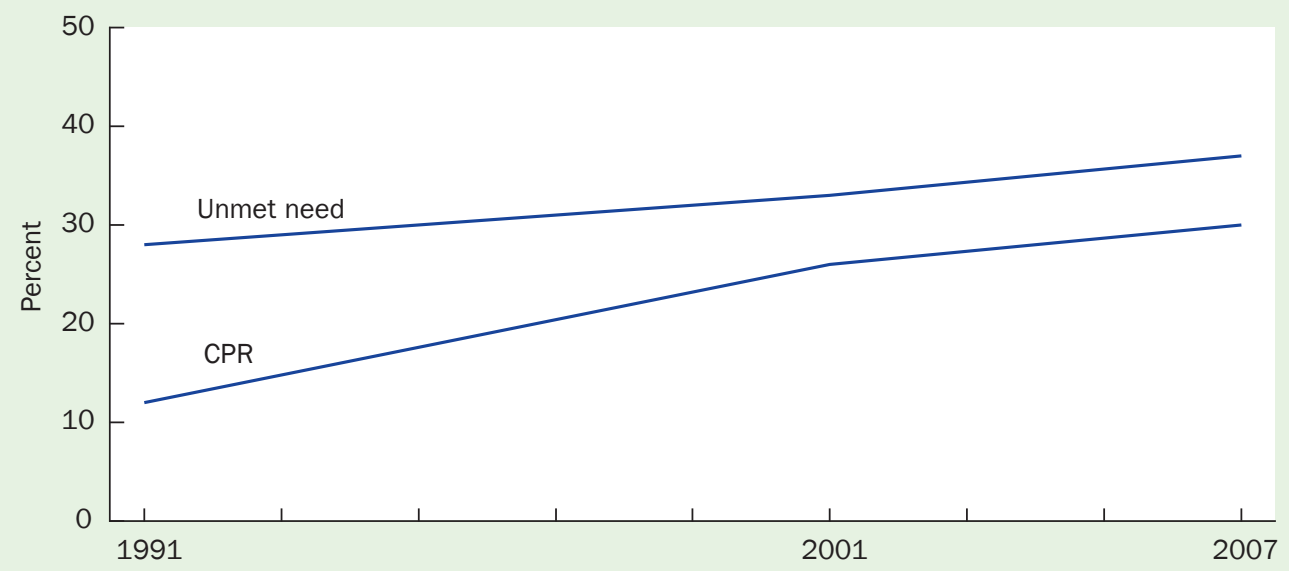

SOURCES: Pakistan Demographic and Health Surveys 1991 and 2006-07; Pakistan Reproductive Health and Family Planning Survey 2001.

\section{FIGURE 2.7}

Planning status and outcome of pregnancies in Pakistan, 2006-07

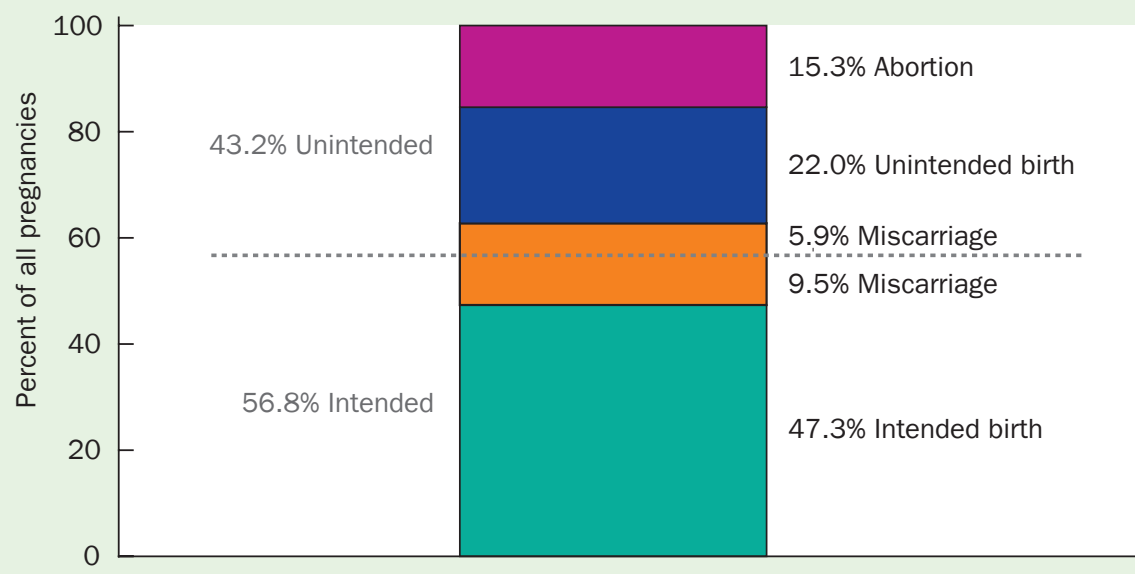

SOURCE: Courtesy of Susheela Singh, Guttmacher Institute.

pregnancies, 15 percent ended in induced abortion, and 28 percent ended as unintended births or miscarriages, with detrimental health and economic effects for women and their families. The remaining 57 percent were intended pregnancies that resulted mostly in intended births as well as a small number of miscarriages. If Pakistan were to invest in a strong family planning program with a wide array of high-quality services, it could avoid between 22 percent and 37 percent of unintended births and a large portion of induced abortions. 
2) Wanted fertility comprises all births that women have until they achieve their desired family size. In other words, wanted fertility equals the fertility that would be observed if all unwanted births could be eliminated. (This is not the same as the level of fertility that would be observed if all women could achieve their ideal family size, because some women fail to reach their desired family size.) According to the 2006-07 Pakistan DHS, the wanted total fertility rate was 3.2 births per woman. This implies that the observed fertility of 4.1 births per woman is 33 percent higher than it would be without unwanted childbearing. Wanted fertility is strongly linked to societal norms, but more importantly to women's residence, education, and income level. Wanted fertility among highly educated women in urban areas is close to replacement, while the rural poor still want close to four children. Wanted fertility ranges from a high of 4.2 births per woman among the poorest women to 2.4 births per woman among the wealthiest. Figure 2.8 shows similar differences by level of education.

\section{FIGURE 2.8 Wanted and unwanted fertility by wealth quintile and level of education, 2006-07}

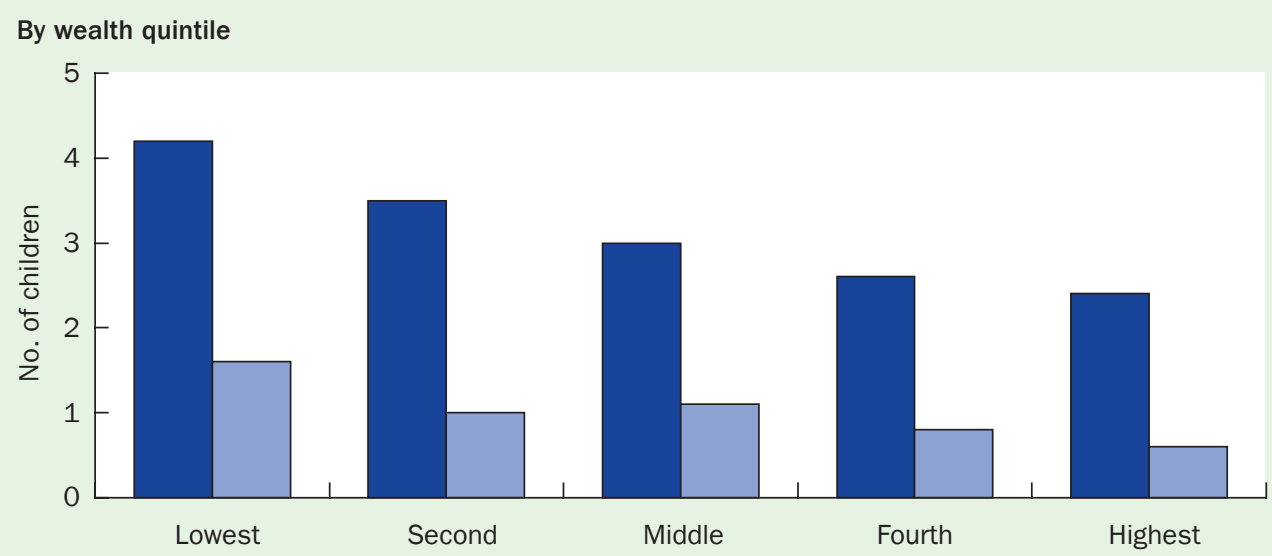

By level of education

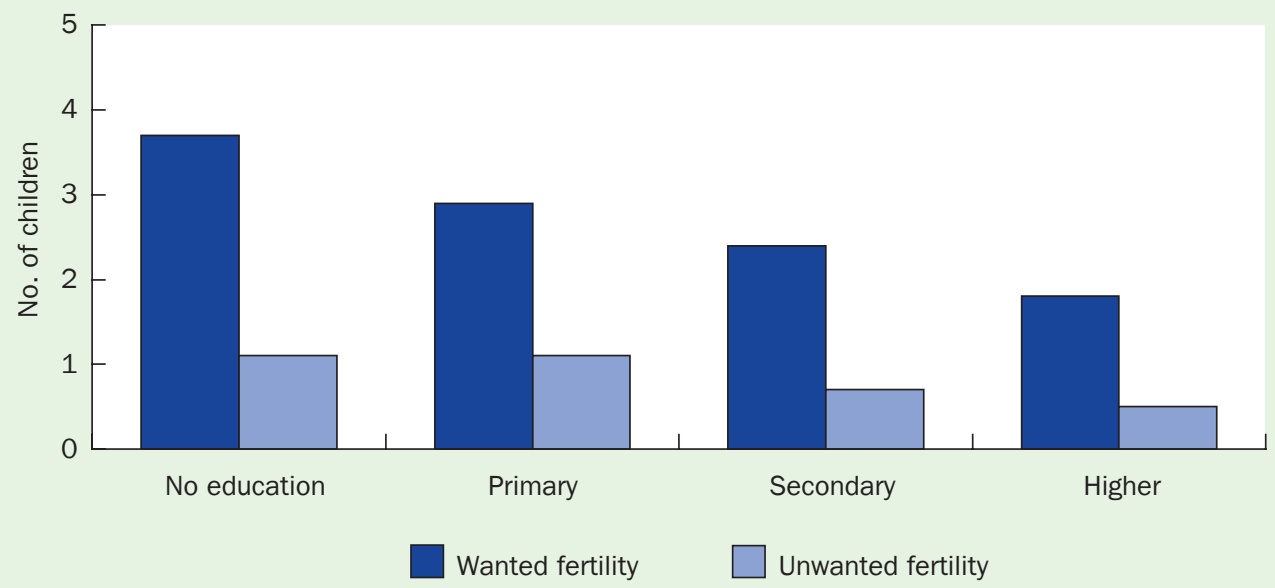

SOURCE: Pakistan Demographic and Health Survey 2006-07. 
Among the main reasons for these differences are that women with higher socioeconomic status marry later, use contraception more effectively, have more knowledge about and access to contraception, have greater autonomy in reproductive decisionmaking, and are more motivated to implement their preferences because of the higher opportunity costs of unintended childbearing. Policy options to reduce inequalities in wanted fertility must include increasing access to female education and reducing income inequalities.

Both unwanted and wanted childbearing are more common among poor, rural, and uneducated women than among their well-off, urban, and educated counterparts. Figure 2.8 shows these fertility components by wealth quintile in Pakistan. Unwanted fertility declines from 1.6 to 0.6 between the poorest and wealthiest quintiles. The policy option here is clearly to eliminate unwanted fertility through provision of higher-quality, more evenly distributed family planning services.

\section{Conclusion}

Pakistan is at a critical point in its demographic transition. After decades of rapid population growth, the prospect of slower growth lies ahead because fertility is declining. The future trajectory of population growth is very sensitive to the timing and extent of further fertility declines. The key policy question is how to reduce growth further through voluntary measures. An obvious response is to strengthen the family planning program. Women in Pakistan have high levels of unmet need for contraception, and as a result many unplanned and unwanted pregnancies occur each year. Preventing such pregnancies and reducing fertility and population growth lead to a variety of health, social, and economic benefits as will be documented in the following chapters.

Any program-induced fertility decline changes the future trajectory of population growth. As we noted above, a small change in fertility can have a large impact on future population size. According to the standard (medium variant) projection, the population of Pakistan will grow from 174 million to 302 million between 2010 and 2050. This projection is based on the assumption that fertility will continue to decline rapidly over the next few decades. This projection assumes some strengthening of Pakistan's family planning program. On the other hand, if no further investment in family planning is made, then fertility could be half a birth higher and the population of Pakistan could reach 342 million in 2050. Alternatively, if a strong investment in family planning is made, the future fertility trajectory could be half a birth below the medium variant, leading to a population of just 266 million by 2050. Thus, the difference between a weak and a strong family planning program scenario is approximately 76 million people by 2050 .

Additional policy responses are also desirable because even if all unwanted childbearing could be avoided, population growth would still be substantial. The reasons are high desired family size and population momentum. One of the most effective ways to address these drivers of growth is through improvements in girls' education. 
66 Only with strong near-term investments in education will Pakistan be able

to significantly reduce its currently

unsustainable high rate of population

growth and harvest the fruits of long-term

human capital development. 99
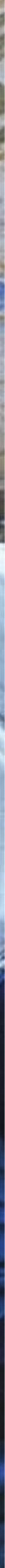


\section{CHAPTER THREE}

\section{Education and \\ Population: Closely \\ Linked Trajectories for Pakistan}

\section{ASIF WAZIR, ANNE GOUJON, and WOLFGANG LUTZ}

Pakistan faces high levels of population growth entailing a large population of schooling age, and low levels of economic development with increasing spread of poverty and unemployment over the past few decades. Consequently, some 39 percent of 15-24-yearold Pakistani women and 21 percent of men were illiterate in 2009 (UNESCO database). ${ }^{1}$ The prevalence of illiteracy in the country is therefore large, especially among women: 61 percent were illiterate in 2009, compared to 31 percent of men. On the positive side, enrollment rates point toward progress as 74 percent of children were enrolled in primary school and two-thirds of children were completing the full 5-year cycle of primary education. Out of these primary-educated children, 75 percent were moving on to secondary-level studies. However, universal enrollment of all children aged 5 to 16 years in compulsory education is far from being achieved. More than 7 million children, mostly those in rural area, are estimated to be out of school. ${ }^{2}$

The next few decades will be crucial for Pakistan as the majority of its population will be of working age: the median age in Pakistan is 22 years (Wazir 2012). It is well estab- 
lished internationally that investments in primary and secondary education to increase the access of both boys and girls and the resulting gains in human capital of younger adults are key drivers of economic growth and poverty alleviation (Lutz et al., 2008). More specifically, studies such as Abbasa and Foreman-Peck (2007) show that a larger stock of human capital ${ }^{3}$ is crucial for economic growth, particularly as it relates to the ability of the labor force to absorb new technologies.

Progress in education is closely intertwined with the demographic and development history of countries. There are two explanations for those linkages. First, education levels clearly influence demographic behavior. The most visible illustration of this is the impact of education on women's fertility, which is systematically lower at higher levels of educational attainment. This negative relationship between education and fertility has been recognized in all countries at all stages of development, and is particularly strong in countries, like Pakistan, that are in the middle of the demographic transition (Cleland 2000; Martin and Juarez 1995; Bongaarts 2011). Hence further increases in education, especially in a context where women's needs for contraception are largely met, can lower fertility levels and consequently the future rate of population growth.

The second explanation is that education at the macro-level acts as a good proxy for development. Hence measuring a population's educational attainment, whether in the work force or overall, is a valid measure of the well-being of individuals and societies more generally. This is well reflected in the three components of the Human Development Index (HDI), which is comprised of education, health, and economic status. In turn, both health and economic growth crucially depend on education. Even beyond these classic dimensions of development education is critical for the quality of governance, autonomy of women, and civic freedom (Lutz et al. 2010; Lutz and K.C. 2011). Education enables a country to propel itself on a successful development path as exemplified, for example, by the Asian Tigers.

\section{High levels of illiteracy in Pakistan}

Pakistan's record on education has been unimpressive, exemplified by low levels of public expenditure. In a recent study, Goujon and Wazir (2011) have shown that the Pakistani educational system has failed to provide the basic infrastructure and quality of education and to eliminate gender imbalances in schooling. Aly's (2007) white paper summarizes educational policy developments since independence:

Periodically, the State of Pakistan addressed the educational needs of the people and the aspirations of the State in this regard.... Apart from the common denominator of Islam and national cohesion, the statements of vision and purpose for the national education system in Pakistan have tended to reflect the dominant political paradigm and compulsions of the day.... [M] ost of these noble assertions remained rhetoric, now confined to the dustbins of history.

Whether the failure lies in the lack of investments or in the inadequate implementation of policies, examination of Table 3.1 offers a good measure of the gap between discourse and action. The overall increase in literacy rates from 16 percent in 1951 to 55 


\begin{tabular}{|c|c|c|c|c|c|c|c|c|}
\hline \multirow[t]{2}{*}{ TABLE 3.1} & \multicolumn{8}{|c|}{$\begin{array}{l}\text { Literacy rates (in percent) of the population } 10 \text { years and over, by } \\
\text { sex and province and for Islamabad, 1951-2010 }\end{array}$} \\
\hline & 1951 & 1961 & 1972 & 1981 & 1998 & 2004 & 2007 & 2010 \\
\hline \multicolumn{9}{|l|}{ Sex } \\
\hline Male & 19 & 27 & 30 & 35 & 55 & 63 & 69 & 67 \\
\hline Female & 12 & 8 & 12 & 16 & 32 & 36 & 44 & 42 \\
\hline Both sexes & 16 & 16 & 22 & 26 & 44 & 50 & 56 & 55 \\
\hline \multicolumn{9}{|l|}{ Province } \\
\hline Punjab & & & 21 & 27 & 47 & 51 & 59 & 57 \\
\hline Sindh & & & 30 & 32 & 45 & 54 & 56 & 58 \\
\hline KPK & & & 16 & 17 & 35 & 40 & 49 & 46 \\
\hline Balochistan & & & 10 & 10 & 27 & 33 & 46 & 37 \\
\hline Islamabad & & & & 48 & 73 & 82 & & 80 \\
\hline
\end{tabular}

SOURCES: Census data for 1951, 1961, 1972, 1981, and 1998; PSLM for 2004-05, 2007-08, and 2010-11.

percent in 2010 is grossly inadequate over that length of time, and even more so when looking at the rates for women, which were stagnant from 1951 to 1981 . There is sharp disparity in education levels across regions as well, particularly visible between urban and rural areas and across provinces. National averages tend to underestimate how far populations in rural areas and the less developed provinces, particularly women, are lagging in terms of educational attainment.

Enrollment ratios shed light on the present situation in schooling and represent the engine of future human capital. Table 3.2, which shows gross enrollment ratios for the last decade, suggests significant progress at the level of primary and lower secondary education. ${ }^{4}$ By 2010, primary gross enrollments were 99 percent for boys and 82 percent for girls. Lower secondary enrollments were 59 percent for boys and 48 percent for girls. Moreover, only 62 percent of children who enter primary school complete that level, and 74 percent of those children go on to the secondary level (not shown).

\section{TABLE 3.2 Gross enrollment ratios (in percent), 2000-2010}

\begin{tabular}{|c|c|c|c|c|c|c|c|c|c|c|c|}
\hline Level/sex & 2000 & 2001 & 2002 & 2003 & 2004 & 2005 & 2006 & 2007 & 2008 & 2009 & 2010 \\
\hline \multicolumn{12}{|l|}{ Primary } \\
\hline Male & 82 & 83 & 84 & 85 & 91 & 94 & 89 & 93 & 93 & 92 & 99 \\
\hline Female & 56 & 56 & 57 & 62 & 66 & 71 & 69 & 76 & 77 & 77 & 82 \\
\hline \multicolumn{12}{|c|}{ Lower secondary } \\
\hline Male & - & - & - & 38 & 41 & 43 & 47 & 51 & 50 & 49 & 59 \\
\hline Female & - & - & - & 26 & 29 & 32 & 35 & 38 & 38 & 38 & 48 \\
\hline \multicolumn{12}{|c|}{ Upper secondary } \\
\hline Male & - & - & - & 24 & 27 & 24 & 24 & 26 & 28 & 28 & - \\
\hline Female & - & - & - & 21 & 23 & 20 & 19 & 20 & 21 & 22 & - \\
\hline \multicolumn{12}{|l|}{ Tertiary } \\
\hline Male & - & - & 3 & 3 & 3 & 5 & 5 & 6 & 6 & - & - \\
\hline Female & - & - & 2 & 2 & 3 & 4 & 4 & 5 & 5 & - & - \\
\hline
\end{tabular}

SOURCES: UNESCO database, PSLM 2010-11. 
Table 3.3 tracks the educational attainment of the working-age population of Pakistan across censuses. The majority of Pakistan's population was uneducated until the twenty-first century, and this was still the case for two-thirds of women by 2006/07. For those with access to education, the path often stopped at lower secondary education (below matriculation level), with only a small proportion of males and females attaining upper secondary or university education.

The dichotomy between political discourse and policy implementation is troubling in the case of Pakistan, particularly concerning education. Education has been credited by the government and international development agencies as playing a central role in the successful development of Pakistan, yet progress has been meager at all levels. This is the case for two main reasons: investments in education have been too low and the schoolage population continues to grow rapidly. With 35 percent of its population below age 15 in 2010, Pakistan was spending less than 3 percent of its GNP on education.

\section{Education and fertility transition}

The most recent Demographic and Health Survey in Pakistan, conducted in 2006-07, shows that highly educated women are at the forefront of the fertility decline, with a total fertility rate (TFR) of 2.3 children, in contrast to a TFR of 4.8 for women with no education. The survey data on fertility levels by women's educational attainment in Table 3.4 show a consistent difference of 2-3 children between women with no education and those with secondary or post-secondary education. Education has a profound effect on all determinants of fertility. In 2006-07, there was a 6-year difference between the median age at marriage of women without education and those with higher education. In addition, contraceptive prevalence rates are consistently higher as one moves up the education scale. Soomro and Mahmood (2004) argue that family planning programs in Pakistan would have difficulty reaching illiterate women and recommend that investment in female education should be prioritized.

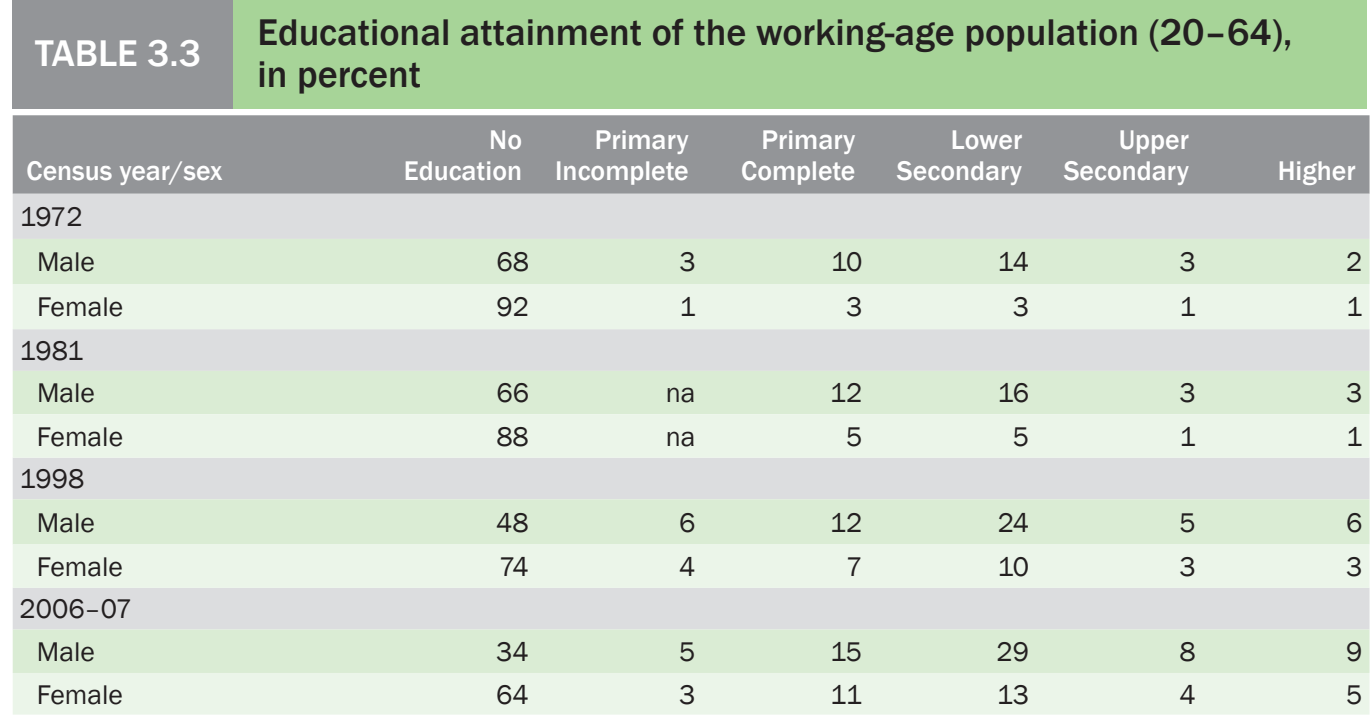

SOURCE: Goujon and Wazir 2011. 


\begin{tabular}{|c|c|c|c|c|}
\hline TABLE 3.4 & $\begin{array}{l}\text { Total fertility rates by level of } \\
\text { Pakistan, } 1975,1990-91,2\end{array}$ & $\begin{array}{l}\text { tional a } \\
1 \text {, and }\end{array}$ & $\begin{array}{l}\text { nent in } \\
-07\end{array}$ & \\
\hline Level & $1975^{a}$ & $1990-91^{\mathrm{b}}$ & $2000-01^{c}$ & $2006-07$ \\
\hline No education & 6.5 & 5.2 & 5.4 & 4.8 \\
\hline Primary & 5.9 & 4.3 & 3.9 & 4.0 \\
\hline Secondary & l 31 & 3.9 & \multirow{2}{*}{ \} 2.8} & 3.1 \\
\hline Tertiary & $\int^{3.4}$ & 2.8 & & 2.3 \\
\hline Total & 6.3 & 4.9 & 4.6 & 4.1 \\
\hline
\end{tabular}

SOURCES: (a) ISI 1975. (Pakistan World Fertility Survey); (b) NIPS and Macro International, Inc. 1992. (Pakistan Demographic and Health Survey 1990-91); (c) NIPS 2001. (Pakistan Reproductive Health and Family Planning Survey) (rates are calculated for 1997-2000); ${ }^{\text {d) }}$ NIPS and Macro International, Inc. 2008. (Pakistan Demographic and Health Survey 2006-07).

\section{Methodology and objectives}

The methodology in the analysis that follows is based on the multi-state population projection method $^{5}$ (see Rogers 1975 and 1995 for more details), using the PDE population projection software. ${ }^{6}$ The population of Pakistan is subdivided into four educational categories: no education, primary education, secondary education, and tertiary education. Each subpopulation is further stratified into five-year age groups by sex, to which we apply education-specific assumptions regarding fertility, mortality, and migration. Transition rates between education categories allow us to model changes in the education sector. The population pyramid of Pakistan in 2010 by four levels of education is shown in Figure 3.1, based on United Nations (2011) estimates by age and sex and the age- and sex-structure of educational attainment from the 2006-07 DHS. ${ }^{7}$

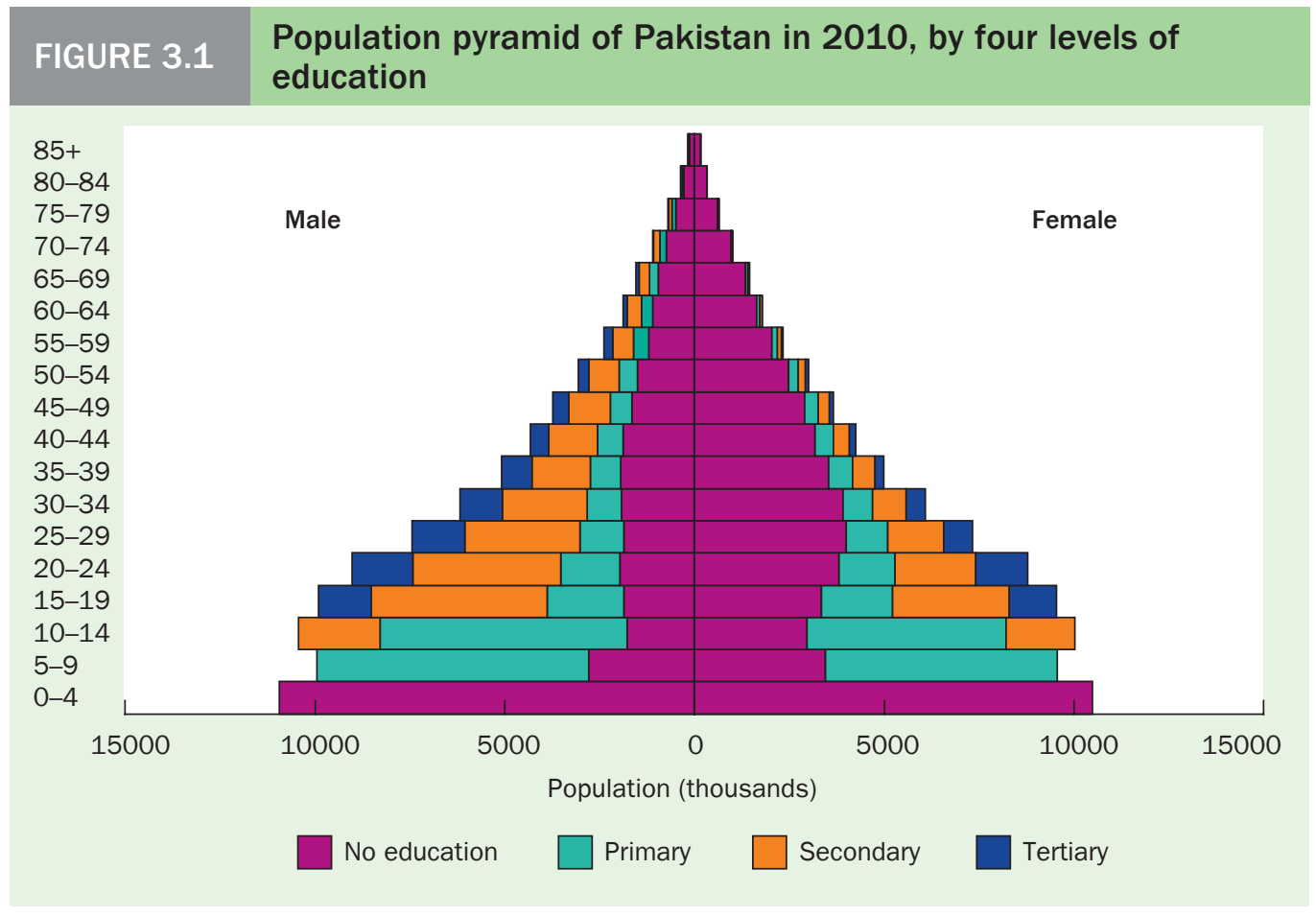

SOURCES: PDHS 2006-07; UN 2011. 


\section{The future path}

\section{Fertility trajectory by education}

The pace of fertility decline in Pakistan, which started in the early 1990s, has been very slow compared to other countries in South Asia. Recent evidence shows that Pakistan is in the midst of a demographic transition, and further fertility decline is expected in the future (see Sathar and Casterline 1998; Sathar 2007; Ali and Hussain 2001 for details about fertility levels and trends in Pakistan). Future levels of fertility will also be determined by socio-economic and cultural changes. In this context, significant roles will be played by national policies and family planning programs and their integration with other government policies (e.g., on education and health). Another critical factor is whether socio-economic development has reached a point where a large segment of society considers limitations of family size to be advantageous.

Here we consider one scenario for fertility (Table 3.5), namely "PC2011" (see details in Chapter 2), where the TFR reaches the replacement level of 2.1 births per woman by 2050 . The fertility differentials by education are obtained by applying the relative ratios of different education-specific fertility levels estimated in the PDHS to the overall total fertility rate for 2005-10 as estimated by the United Nations (2011). For future differentials by education, we assumed convergence, meaning that fertility differentials by education tend to diminish as fertility declines, which is in line with the contemporary experience of countries with below-replacement fertility. We chose the relative ratios of the levels of educationspecific fertility observed in the Indian State of Andhra Pradesh, which had a TFR of 1.8 in 2005-06 according to the National Fertility and Health Survey 3 (NFHS) (IIPS and Macro International 2007).We assume that in 2045-50 Pakistan will have education-specific fertility rates relatively equivalent to those observed in Andhra Pradesh in 2005-06.

\section{Education trajectories}

We have defined two scenarios of educational attainment in Pakistan (Table 3.6). The assumptions are set in terms of age- and sex-specific transition probabilities between levels of education to model the age-specific proportion of young men and women (here between ages 5 and 24) who make the transition from no education to primary, from primary to secondary, and from secondary to tertiary education. ${ }^{8}$

\begin{tabular}{|c|c|c|c|c|}
\hline TABLE 3.5 & $\begin{array}{l}\text { Assessment and projectio } \\
\text { Pakistan to } 2050\end{array}$ & TFR by le & of education & \\
\hline Level & $\begin{array}{l}\text { Observed } \\
2006-07^{\mathrm{a}}\end{array}$ & $\begin{array}{l}\text { Base year } \\
2005-10^{b}\end{array}$ & $\begin{array}{r}\text { Andhra Pradesh } \\
2005-06^{c}\end{array}$ & $\begin{array}{r}\mathrm{PC} 2011 \\
2045-50^{d}\end{array}$ \\
\hline No education & 4.8 & 4.2 & 2.1 & 2.4 \\
\hline Primary & 4.0 & 3.6 & 1.9 & 2.2 \\
\hline Secondary & 3.1 & 2.8 & 1.8 & 2.0 \\
\hline Tertiary & 2.3 & 2.0 & 1.6 & 1.5 \\
\hline Total & 4.1 & 3.7 & 1.8 & 2.1 \\
\hline
\end{tabular}

SOURCES: (a) PDHS 2006-07; (b) United Nations 2011; (c) Andhra Pradesh-NFHS-3 (2005-06); (d) Chapter 2, this volume. 


\section{TABLE 3.6 Access to education among males and females (percent) in 2010, according to two education scenarios for 2030}

\begin{tabular}{|c|c|c|c|c|c|c|c|c|c|}
\hline \multirow[b]{3}{*}{ Level } & \multirow{2}{*}{\multicolumn{3}{|c|}{$\frac{2010}{\text { Base }}$}} & \multicolumn{6}{|c|}{2030} \\
\hline & & & & \multicolumn{3}{|c|}{ Trend } & \multicolumn{3}{|c|}{ Goals } \\
\hline & Boys & Girls & Total & Boys & Girls & Total & Boys & Girls & Total \\
\hline No education & 28 & 36 & 32 & 26 & 30 & 28 & 0 & 0 & 0 \\
\hline Primary & 83 & 70 & 77 & 85 & 77 & 81 & 100 & 100 & 100 \\
\hline Secondary & 61 & 45 & 53 & 51 & 37 & 44 & 66 & 55 & 61 \\
\hline Tertiary & 18 & 16 & 17 & 18 & 18 & 17 & 22 & 21 & 21 \\
\hline
\end{tabular}

NOTE: Access is based on the proportion of the relevant schooling age group achieving the relevant education level: 5-9 for no education, 10-14 for primary, 15-19 for secondary, and 20-24 for tertiary education.

SOURCE: Authors' calculations.

The Trend scenario projects the pace of change in the last two decades into the future. This business-as-usual scenario enables us to see whether Pakistan is likely to attain the national and international targets in terms of education and hence evaluate to what extent Pakistan has adopted the appropriate policies to attain the targets set by national and international agencies.

The Goals scenario assumes that the gains in educational access increase-for instance, as a result of a stronger government commitment or improved national and international programs. The increase is assumed to be faster for girls ( 25 percent increase in the transition to primary for girls and 18 percent for boys, respectively) in order to ensure equity in enrollment for boys and girls by 2020. Furthermore, we assume a 50 percent increase in enrollments for secondary education (age group 10-14) and a 20 percent increase in enrollments for tertiary education (for age group 20-24) for the whole projection period (until 2050) for males and females alike. These "artificial" increases, which per se are not substantial, illustrate what could be a more realistic and more attainable education goal for Pakistan.

Table 3.6 shows the access to education for boys and girls according to the Trend and Goals scenarios. According to the Trend education assumption, there would still be 28 percent of the 5-9 age group not attending school by 2030, with a significant gender gap as 30 percent of girls and 26 percent of boys aged 5-9 would not be in school. Gender disparities will be far from eliminated in either primary or secondary education in 2030, where girls would still have an 8 percent less chance than boys to reach primary education and 14 percent less to enrol in secondary education. With a modest increase in access as shown in the Goals scenario, universal entry into primary school for boys and girls could be achieved by 2030 .

Although educational improvements would be significant by 2050, the probability of girls enrolling in primary and secondary school would still be lower than for boys. Interestingly, gender disparities would be eliminated at the level of tertiary education, where the increase in the last few years has been substantial, especially for girls. In 2010, women still have a 2 percent lower chance than men to enter tertiary education, but by 2050 
more women than men would enroll in higher education. The projection also shows that despite the rapid increase at the secondary and tertiary level, the national goals at these levels would also be very difficult to reach by 2050 according to present pace.

\section{Results and discussion}

\section{The impact of women's educational attainment on fertility}

Figure 3.2 compares the output of the two scenarios in terms of the educational attainment of women of reproductive age (15-49 years). In 2010, the share of the illiterate women exceeded 50 percent of women in fertile ages. According to the Trend scenario, two significant improvements will occur in the future. The share of women with no formal education will decline from 55 percent in 2010 to 23 percent in 2050, while the proportion of primary-educated women will increase significantly, from 15 percent in 2010 to 39 percent in 2050 . The share of women with tertiary education will increase from 10 percent to 16 percent over these 40 years. If Pakistan were to embark on a faster educational development track (as indicated by the Goals scenario), the share of women with no formal education would be reduced to 6 percent by 2050. The comparison of alternative education scenarios shows the large potential impact of educational attainment of future mothers, and may serve as an input to estimate future levels of fertility and of infant and child mortality.

Figure 3.3 shows the difference in total fertility rates according to the two education scenarios, based solely on the difference in the education composition of women of reproductive ages. If Pakistan achieved the Goals scenario, the total fertility rate in 2050

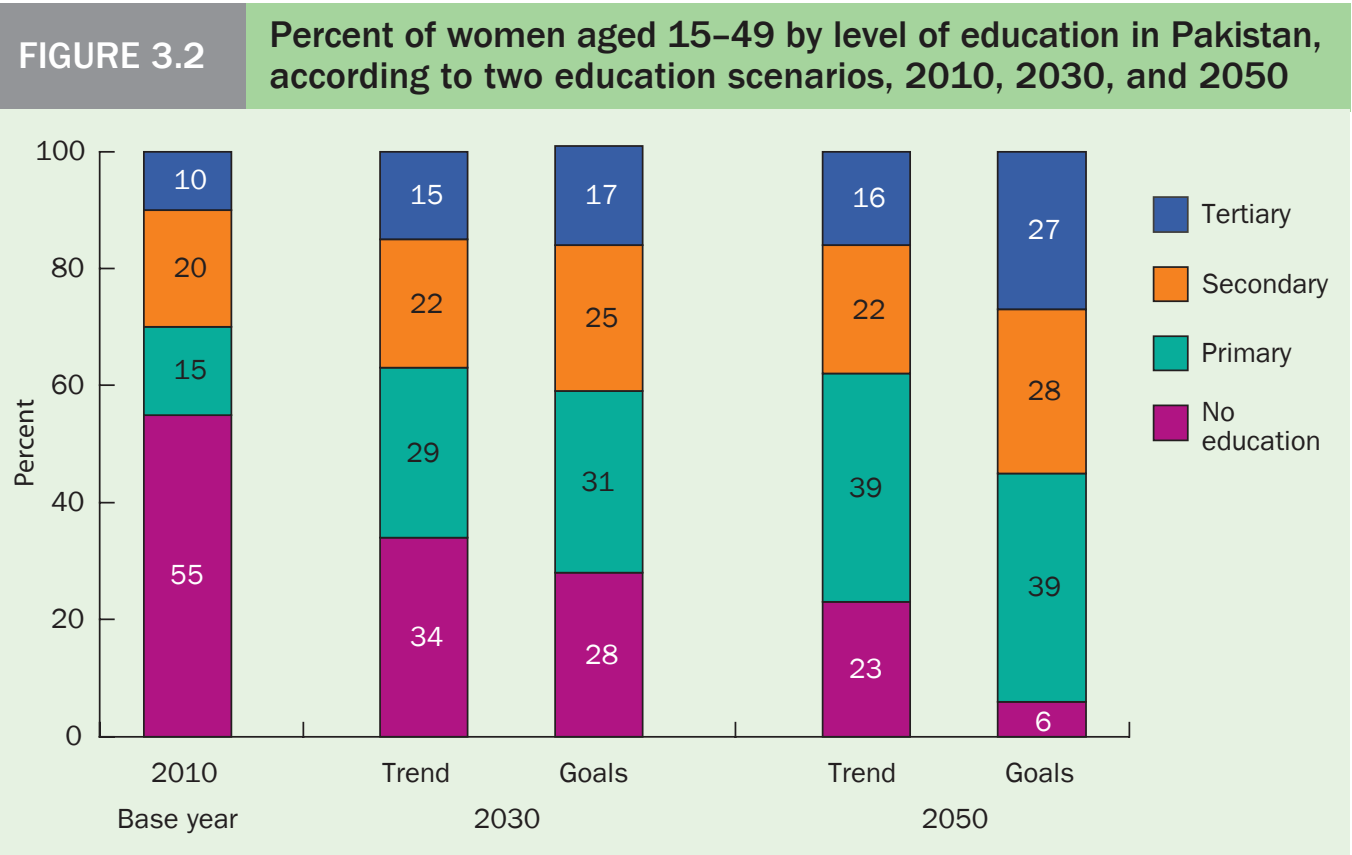

SOURCE: Authors' calculations. 


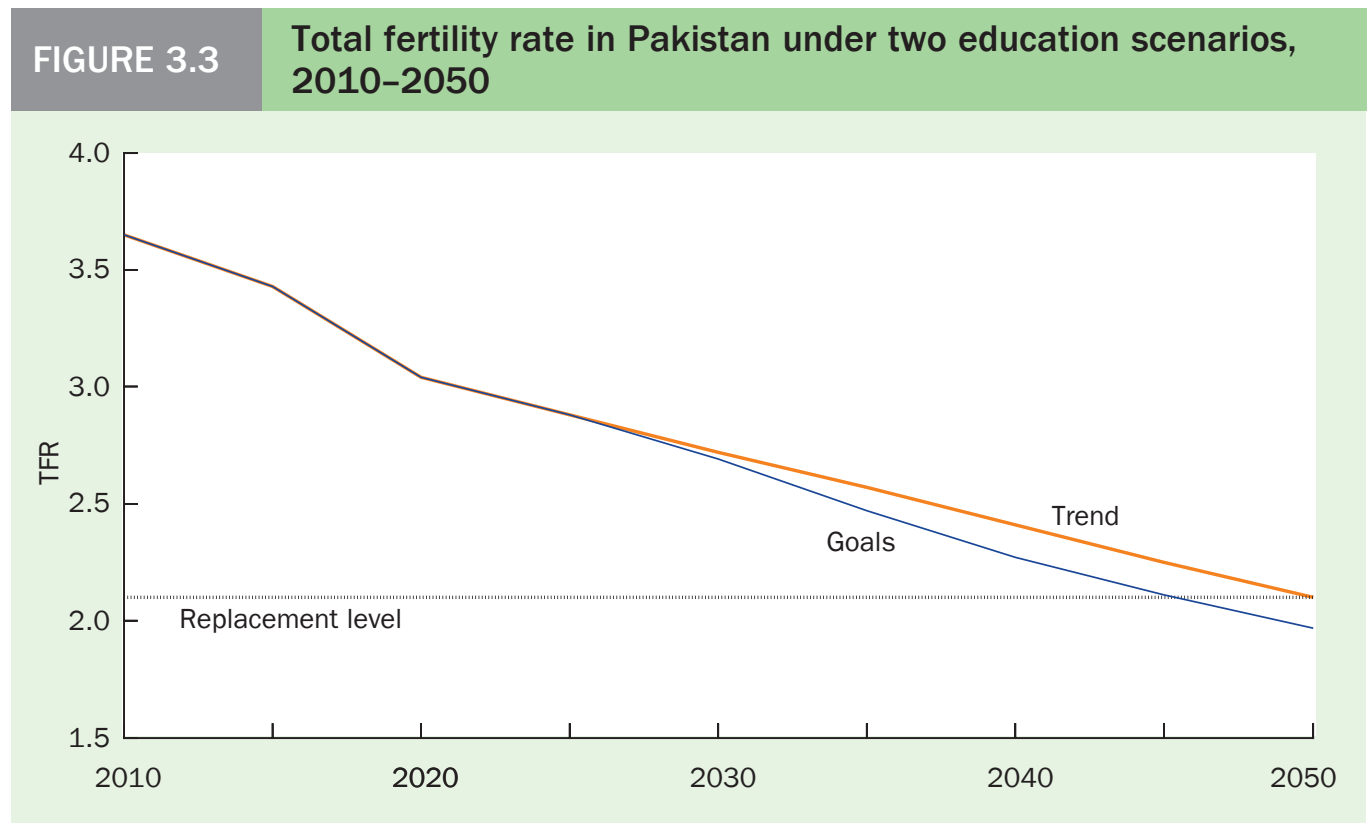

SOURCE: Authors' calculations.

would be 0.15 children per woman less than under the Trend scenario. It is worth noting here that the fertility-reducing effect of achieving higher educational goals increases with time and becomes stronger beyond 2050. The projection results show that if Pakistan achieved the educational goals defined in the Goals scenario, the concomitant effect of education on fertility would lead to the achievement of replacement fertility five years earlier than under the Trend scenario, which assumes replacement-level fertility in 2050. This is a purely mechanical effect that could in reality be reinforced by spill-over effects of the vanguard group on the rest of the population.

\section{Effect of education on total population}

Rapid population growth rate is inevitable in Pakistan, at least in the near future. Even if we optimistically assume that Pakistan will achieve replacement-level fertility and meet its national goals for education, the population would still grow significantly, from 174 million in 2010 to 293 million by 2050. In 2010, Pakistan was growing at a rate of 1.8 percent. The population is likely to continue growing at a rate of 1.4 percent per year from 2010 to 2050, a higher rate than elsewhere in the world except sub-Saharan Africa.

Table 3.7 shows the output of the two education scenarios on future population growth. Under the medium fertility scenario (PC2011), if national education goals are not met and education trends continue as they have during the past 15 years, then the total population in 2050 would be even higher at 299 million. A rather small difference of 6 million in 2050 is found in the total population between the unlikely scenario where Pakistan achieves its education goals over the next decades and the more realistic scenario where it follows the trend in education development: 299 million vs. 293 million. 

2050 , according to two education scenarios

\begin{tabular}{l|c|rr|rr} 
& & \multicolumn{3}{c}{ Education scenario } \\
\cline { 2 - 6 } & Base year & \multicolumn{2}{c|}{ Trend } & \multicolumn{3}{c}{ Goals } \\
\cline { 2 - 6 } Fertility scenario & 2010 & 2030 & 2050 & 2030 & 2050 \\
\hline PC2011 & 174 & 243 & 299 & 293 \\
\hline
\end{tabular}

SOURCE: Authors' calculations.

Pakistan has a remarkably young age structure, which has persisted during the last five decades and will continue into the future. The share of the school-age population (0-19 years old) in Pakistan was 47 percent (81 million) in 2010. Further, the schoolage population will continue growing significantly, to around 92 million by 2030 . This implies that until 2030, more children will need to be enrolled in school, more school will need to be built, and more teachers will have to be trained and hired, particularly in rural areas. The size of the school-age population would decline very slowly after 2030, to 90 million in 2050.

The share of the working-age population (20-64 years) in Pakistan, which has been growing over the past five decades, is estimated at 49 percent in 2010 (see Table 3.8). Within South Asia, Pakistan has the highest population growth rate and a very young age structure. The projection results show a significant increase in the working-age population-from 85 million in 2010 to 179 million in 2050. Pakistan will need to adopt highly effective labor force policies to absorb this population. This large labor force, if well educated, highly skilled, and sufficiently employed, could be a key asset for Pakistan both socially and economically.

Given the anticipated rapid fertility decline in the future, the size of the population aged 65+ will rise from 7.5 million in 2010 to 30 million in 2050, representing 10 percent of the country's population at the latter date. This rapid population aging poses many challenges for policy makers and for institutional adaptation, including the financing of pension and health care systems for the elderly. A large uneducated and unskilled young population along with a significant elderly population in the future would place an extreme burden on Pakistan's economy.

\begin{tabular}{|c|c|c|c|c|c|c|c|}
\hline \multirow[b]{4}{*}{ Year } & \multicolumn{7}{|c|}{$\begin{array}{l}\text { Total population of Pakistan by broad age groups from } 2010 \text { to } \\
2050\end{array}$} \\
\hline & \multicolumn{7}{|c|}{ Population in millions (share of total in parentheses) } \\
\hline & \multicolumn{2}{|c|}{$0-19$} & \multicolumn{2}{|c|}{$20-64$} & \multicolumn{3}{|c|}{$65+$} \\
\hline & Total & Female & Total & Female & & Total & Female \\
\hline 2010 & $80.8(47 \%)$ & $39.6(46 \%)$ & $85.3(49 \%)$ & $42.1(49 \%)$ & 7.5 & $(4 \%)$ & $3.6(5 \%)$ \\
\hline 2030 & $91.9(38 \%)$ & $46.1(38 \%)$ & $136.8(56 \%)$ & $67.6(56 \%)$ & 14.5 & $(6 \%)$ & $7.5(6 \%)$ \\
\hline 2050 & $89.9(30 \%)$ & $45.2(31 \%)$ & $178.5(60 \%)$ & $89.3(59 \%)$ & 29.5 & $(10 \%)$ & $15.5(10 \%)$ \\
\hline
\end{tabular}

SOURCE: Authors' calculations. 


\section{Effect of education on age and sex distribution}

As discussed before, although the pyramid for 2010 (Figure 3.1) clearly showed the improvements among cohorts in school enrollments over the last three decades, one-third of working males and two-thirds of working females remained uneducated. Figure 3.4 shows Pakistan's population pyramids by age, sex, and four levels of educational attainment under two alternative scenarios for education in 2030 and 2050, all under the assumption of the medium fertility scenario (PC2011). In 2010, the pyramid clearly shows the improvements in school enrollments over the last three decades: the younger cohorts of both sexes are better educated than the older ones. In 2010, one-third working-age males and two-thirds of working-age females were uneducated.

According to the Trend education scenario, which assumes that all future cohorts benefit from increases in enrollment ratios as observed in the recent past, the pace of change would not be sufficient to ensure that all children enroll in primary education. This can be seen from the share with no education in age groups 5-9 and 10-14. Consequently, even by 2050 Pakistan would not be able to achieve the goal of universal primary education set for 2015. The appropriate response is an intensification of investments in basic education to ensure that more children, particularly girls and children living in rural and remote areas, can enrol in school. This is what is projected under the Goals scenario. Based on that scenario, the proportion of the working-age population without education in 2050 would be reduced from 15 percent to 8 percent for males and from 22 percent to 15 percent for females.

\section{Impact on the educational levels of the labor force}

In 2050, according to the Trend education scenario, the working-age population with some secondary education would be 49 million ( 28 percent): 18 million ( 21 percent) for females and 28 million (34 percent) for males (see Figure 3.5). The future educational attainment of the population under the Trend scenario reflects the education policy orientations of the government of Pakistan in recent years. In 2010, the share of tertiary-educated women of working age was only 8 percent ( 3 million), and the corresponding share for men was 15 percent ( 6 million). The gender gap would be eliminated in 2050 according to the Trend scenario. The share of working-age females and males with a tertiary education would reach 17 percent (15 million) and 19 percent (16 million) respectively, reflecting the fact that women have benefited from increased access to tertiary education in the recent past. Still, the lack of past investments in female education will hamper the social and economic development of Pakistan far into the future as it is hindering the full participation of women in the labor force. In 2010, according to the Labour Force Survey, women accounted for only 22 percent of the active labor force.

\section{Gender gaps}

The Trend education scenario would not be enough to remove the gender gap, which persists at all levels. For example, the proportion of uneducated women aged 20-24 in 


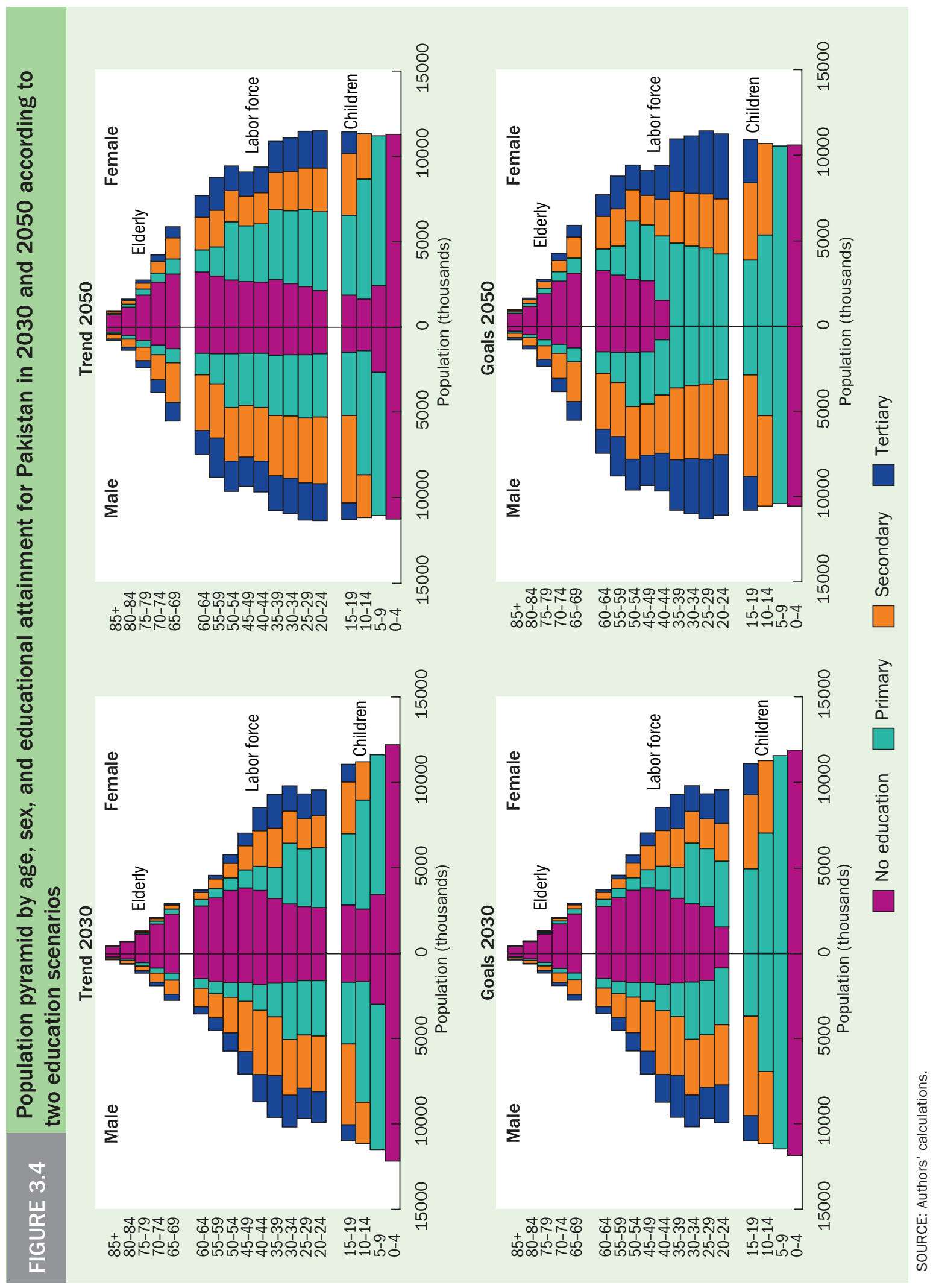




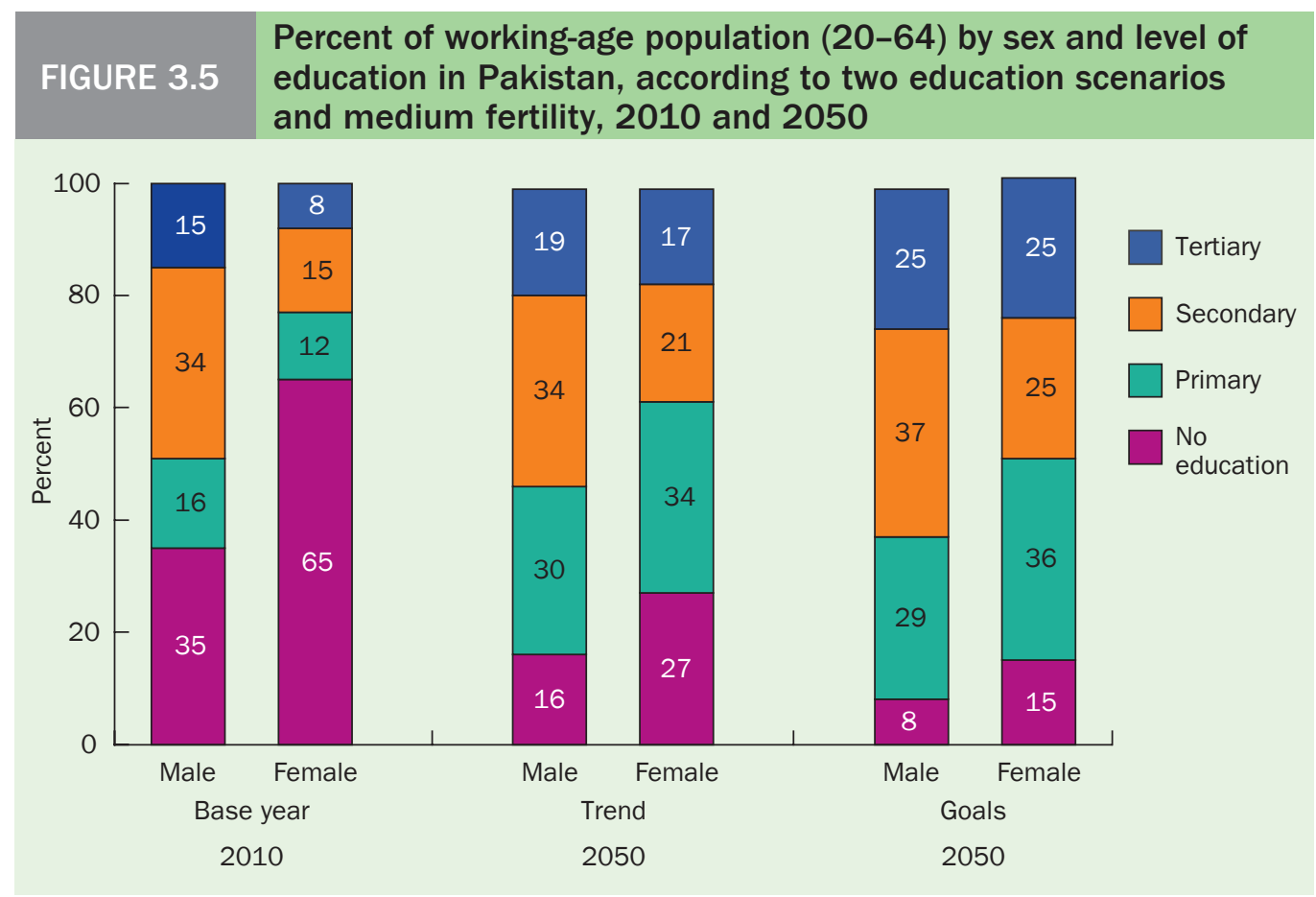

SOURCE: Authors' calculations.

2010 is twice the share of uneducated men. Around 25 percent of women aged 15 and above will not have been in school in 2050, while the proportion for men is around 16 percent. On the other hand, the Goals scenario shows that a more rapid closing of the gender gap could occur through an intensification of recent improvements in education trends. Even under the Goals scenario, however, the proportion of uneducated women aged 15 and over in 2050 would still be 20 percent, compared to 10 percent for men.

The gender gap in secondary education that was noticeable in 2010 will persist, although it will be attenuated. In 2050, 21 percent of women and 34 percent of men would have a secondary education according to the Trend scenario, compared to 15 and 34 percent in 2010. On the other hand, there will be a significant increase between 2010 and 2050 in the share of the working-age population with primary education, rising from 16 percent to 30 percent for males and from 12 percent to 34 percent for females, according to the Trend scenario. The impact of educational improvement is also clearly visible for secondary and tertiary education in the Goals scenario, which implements rapid improvements in education (i.e., universal primary education). Improvements will be significant for the proportion of the female population with tertiary education, which will more than triple over the projection period, from 8 percent in 2010 to 25 percent in 2050 under the Goals scenario, compared to a respective increase from 15 to 25 percent for the male population.

The projection results show the long time horizon needed to see the effects of the implementation of higher education in Pakistan. For instance, the Trend scenario shows 
a slight increase in the proportion of highly educated individuals (secondary and tertiary education) in the working-age population, from 36 percent in 2010 to 46 percent in 2050, while the corresponding proportion in the Goals scenario will be 56 percent in 2050. In general, however, recent trends point to a two-track system in the educational development of Pakistan, with most of the increase in enrollment occurring at higher levels of schooling rather than at the level of compulsory education.

\section{Conclusion}

The future of Pakistan is highly dependent on progress in educational attainment of the population. This chapter demonstrated that investments in education in the near future matter not only for the quality of human capital, but also for the future population growth of Pakistan. Only with strong near-term investments in education will Pakistan be able to significantly reduce its currently unsustainable high rate of population growth and harvest the fruits of long-term human capital development. Over the past decades, lack of investments in primary and secondary education, poor infrastructure, and political instability have contributed to Pakistan's failure to achieve satisfactory levels of education, especially for women. As a result, Pakistan will fail to achieve the Millennium Development Goals of providing universal primary education to boys and girls by 2015.

The scenarios examined in this chapter show that Pakistan needs to accelerate the pace of change in education. This is especially important now, since Pakistan is experiencing a demographic dividend-a relative increase in the size of the working-age population in comparison to the dependent population - which, in principle, is highly favorable to socio-economic development. This presents an opportunity to significantly increase the quality of human capital by 2050 . Strong political commitments are urgently needed for advancing through the demographic transition and achieving socio-economic development. Three main policy requirements are to invest in education as early as possible because of the lag between investments and benefits; add secondary education goals to those of universal primary education in setting future development priorities; and invest in family planning programs to lower fertility rates and thereby boost the effect of education on development.

\section{Notes}

$1<$ http://stats.uis.unesco.org/unesco/TableViewer/tableView.aspx?ReportId=210>.

2 As estimated by the UNESCO Global Initiative on Out-of-School Children and calculated as the number of children in the official primary school age range who are not attending either primary or secondary schools, expressed as a percentage of the corresponding population.

3 Measured as the stock of secondary school graduates and above in that particular study.

4 The gross enrollment ratio is the number of pupils (of any age) who are enrolled in a particular level as a percentage of the total children of official school age for that level. 
5 Detailed explanation of the multi-state population projection methodology is available upon request from the authors.

6 Developed at the International Institute for Applied Systems Analysis in 1993, it can be downloaded without charge from $<$ www.iiasa.ac.at/Research/POP/pub/software/pde/ pdesetup.zip $>$.

7 The shares of educational attainment obtained from the DHS were very similar to those found in the most recent Labour Force Survey (2010-11). We used the DHS 2006-07 for two main reasons: the DHS provides information on education for higher ages-the last age group in the LFS is 65+; and the DHS dataset contains information on fertility differentials by education that are not available in the LFS.

8 Transitions can in theory happen at any age-for instance, as in the case of individuals who become literate as a result of adult literacy campaigns. 
66 The demographic dividend must be viewed as an "opportunity" which, if realized, could lead to higher productivity and economic growth. But the same dividend could also turn into a demographic "disaster" if the large numbers of young people entering the labor market are not productively employed. 99 


\section{CHAPTER FOUR \\ Why Has Pakistan Not Reaped Its Demographic Dividend?}

\section{RASHID AMJAD}

A seminal article by Durr-e-Nayab (2006) showed that Pakistan was passing through a demographic transition, which in turn could yield a demographic dividend. The article marked a turning point in the way population and labor force issues were treated in the broader context of the country's development prospects, economic plans, and growth strategy. Until now the fast-growing size of the population and labor force were viewed mainly as a major impediment to Pakistan's economic growth prospects, absorbing precious resources and adding pressures to an already overcrowded labor market, with resulting rises in unemployment and poverty. Nayab's analysis shifted attention to how to take advantage of the window of opportunity that the demographic dividend now offered.

Nayab showed convincingly that starting in the late 1980s the growth rate of Pakistan's working-age population (15-64 years) was faster than the growth rate of the dependent population (less than 15 years and over 64 years). The resulting reduction in the dependency ratio and the increasing share of youth (15-24 years) in the labor force would stimulate growth in two ways. The first was through the "youth bulge." Young entrants were better educated and more highly skilled than the existing labor force and, 
if productively employed, would stimulate both productivity growth and overall growth in the economy. Second, the decline in the dependency ratio would reduce household consumption, resulting in increased household savings and investment. A smaller family size would also encourage women to seek employment in the labor market. A later study by the Population Council (2009) largely affirmed these favorable developments accruing from the demographic dividend.

Yet both Nayab and the Population Council study had struck an important word of warning. The demographic dividend must be viewed as an "opportunity" which, if realized, could lead to higher productivity and economic growth. But the same dividend could also turn into a demographic "disaster" if the large numbers of young people entering the labor market are not productively employed.

More than two decades have passed since the advent of the demographic dividend. The time has come to assess whether Pakistan has indeed benefitted from the demographic dividend, which is forecast to continue till 2040. And if not, what are the reasons for this failure? Most important, if Pakistan has so far not taken advantage of the opportunities the demographic dividend offers, what policy measures and steps are needed to enable it to do so?

\section{Economic performance and demographic change}

\section{Pakistan's macro-economic performance 1980-2011}

An analysis of Pakistan's macroeconomic experience post-1980, illustrated in Figure 4.1, shows no significant departure from the typical stop-go economic growth cycle

\section{FIGURE 4.1 Pakistan's macro-economic performance 1980-81 to 2011-12}

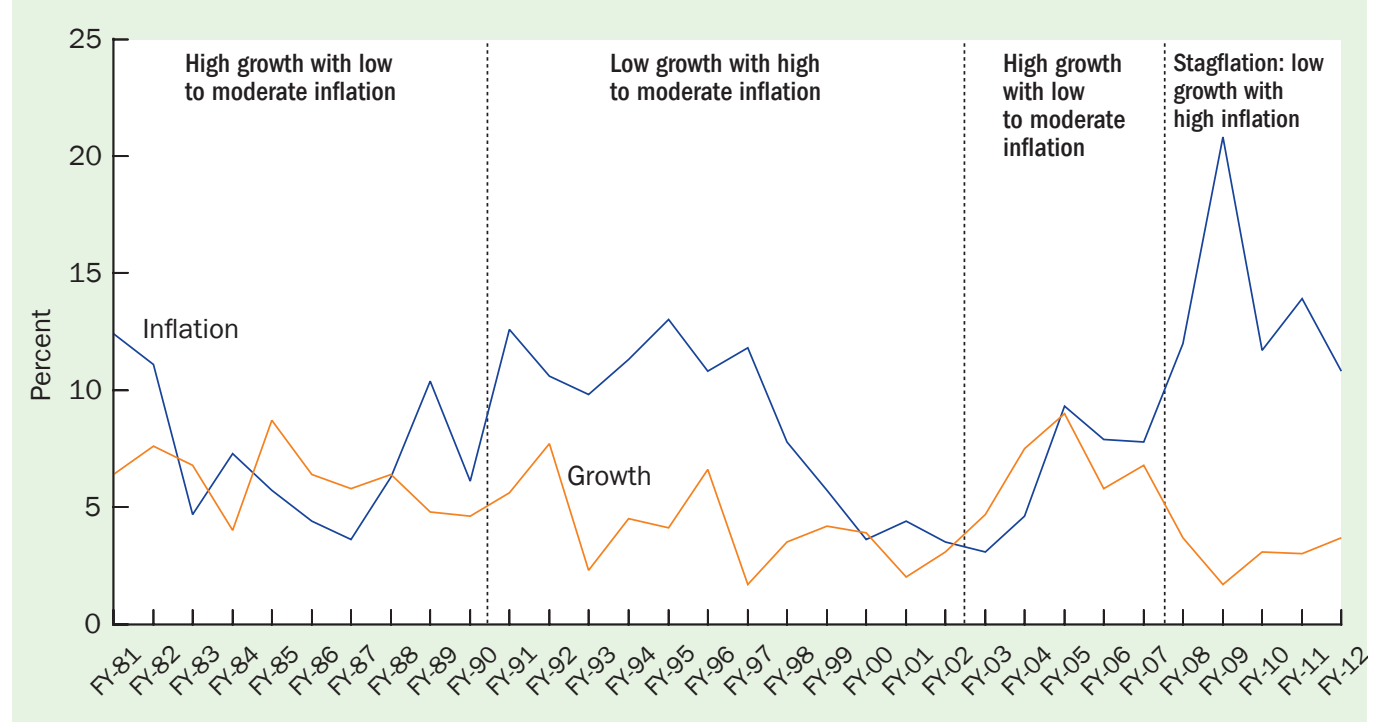

SOURCE: Amjad, Din, and Qayyum (2011), updated post-FY 2008 (Pakistan Economic Survey, 2011-12) 
that Pakistan has witnessed since the 1950s (Ahmed and Amjad 1984; Amjad, Din, and Quayyam 2011; McCartney 2011). The Planning Commission's (2011) Framework for Economic Growth in Pakistan points out that, between 1972 and 2010, Pakistan's economy grew at an average annual rate of 4.9 percent, but that this growth was sporadic and shows a declining trend (p. 18). It also reports that Pakistan's rates of investment and domestic savings are substantially lower than those of its neighbors, averaging only about 17 percent and 12 percent of GDP during 1971-2009, and that these rates also show signs of decline (p. 20).

The situation regarding productivity is similar. During the period 1960-2005 almost 80 percent of Pakistan's GDP growth was due to an increase in capital and labor inputs and only 20 percent to total factor productivity (TFP). ${ }^{1}$ TFP has also fluctuated, explaining 38 percent of GDP growth in the 1980s, a mere 18 percent in the 1990s, and around 22 percent during 2001-2005 (ibid., p. 38). Again, in the last five years it must have declined sharply given the rapid deceleration of economic growth (Figure 4.1). At the sectoral level, during the 1990s TFP in manufacturing grew by only 1.6 percent and over 1998-2007 by 0.9 percent, again pointing to the fact that growth was driven only by a rise in inputs (Chaudhry 2009).

On the basis of the economic growth experience post-1990, there is very little suggestion of any shift or sustained improvement in the key macro-economic indicators, as should have taken place if Pakistan had witnessed a demographic dividend. Indeed, actual performance suggests that except for a brief growth spurt during 2002-06 the overall trend of key macro-economic variables since the advent of the demographic dividend has been downward.

\section{Pakistan's delayed demographic transition and dividend}

Pakistan's most recent Population Census was held in 1998, and current population projections (including those in other chapters in this volume) are based on sample fertility and other related surveys. These also form the basis of projections of the population age structure under different scenarios (high, moderate, and low) of changes in the fertility rate.

In 2010, the government revised its estimates of the annual rate of population growth from around 1.8 percent to 2.1 percent as part of the analysis conducted for the preparation of the Tenth Five Year Plan (2010-15)2 (GoP 2012). The government also postponed the Population Census, originally planned for 2010, because of floods and security concerns. The pre-Census Enumeration Survey was conducted in early 2011, but the Census itself has been postponed again.

Figures 4.2 and 4.3 show the expected size and duration of the demographic dividend based on two alternative estimates. These include revised estimates by Nayab (2006) based on the UN 2010 Population Projection (UN 2011) and the Population Council estimates presented in Chapter 2. The updated projections show that the demographic dividend started not at the end of the 1980s, as Nayab (2006) earlier proposed, but was delayed to the early or mid-1990s. ${ }^{3}$ 

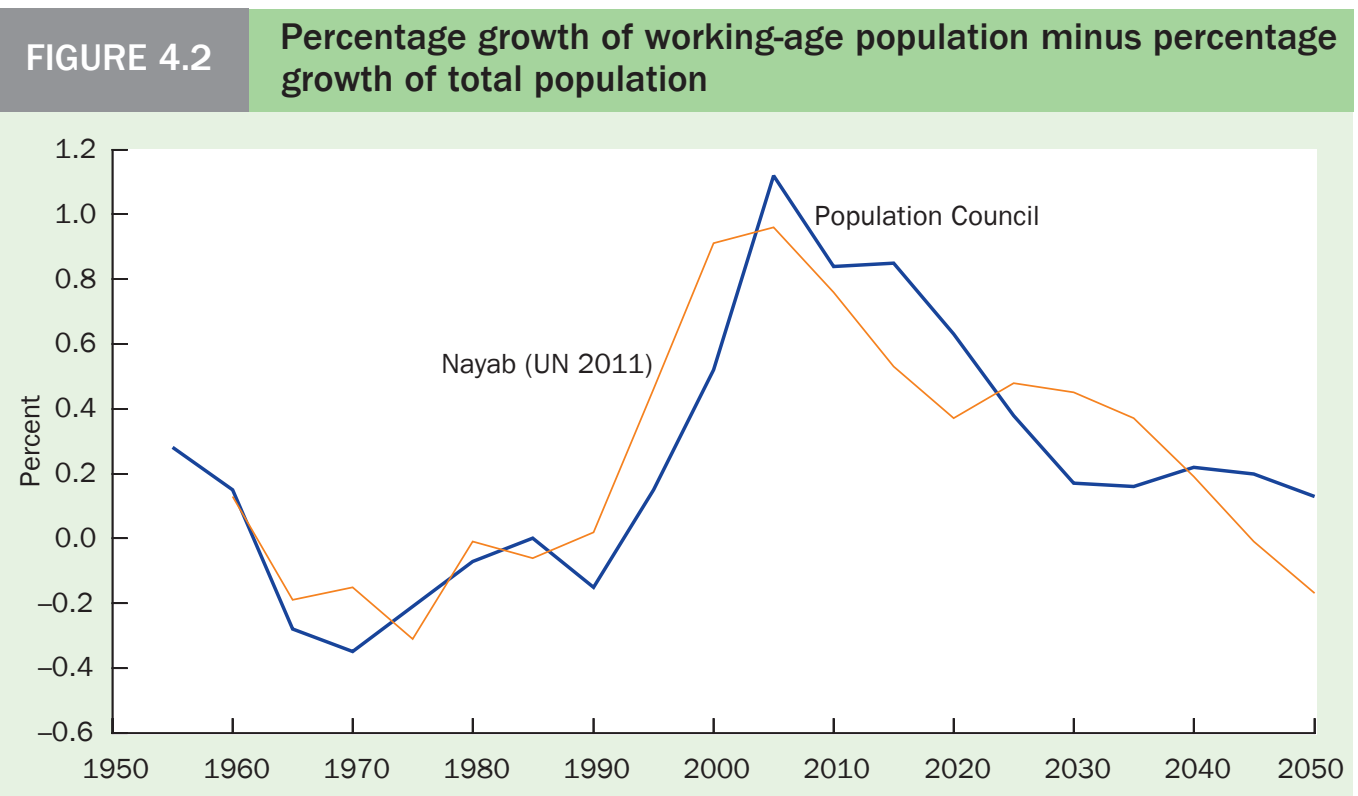

SOURCE: Population Council (2011): Chapter 2 in this volume; Nayab (2006) updated with UN (2011).

\section{FIGURE 4.3 Ratio of working-age population to non-working-age population}

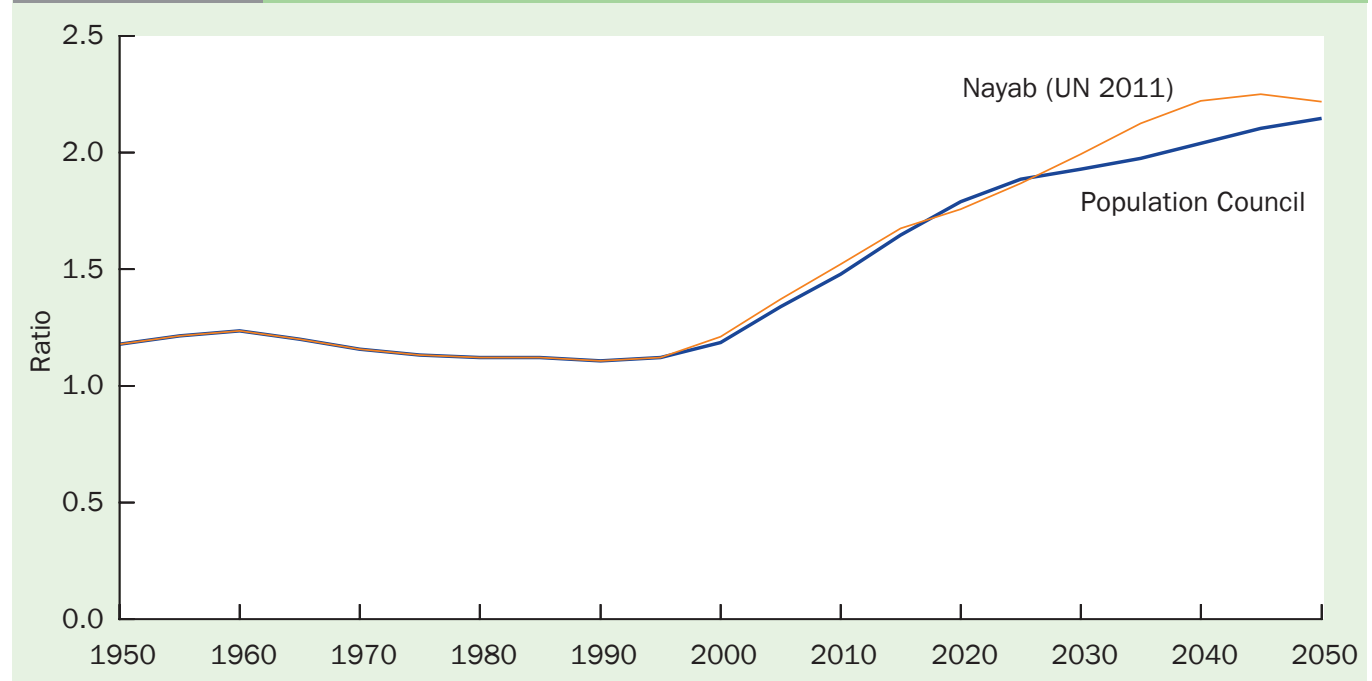

SOURCE: Population Council (2011): Chapter 2 in this volume; Nayab (2006) updated with UN (2011).

Is the demographic dividend sufficient for stimulating growth?

Is the effect of the demographic dividend on economic growth dependent on the prevailing economic conditions in a country? The literature on this appears divided. A recent IMF study on the demographic dividend based on evidence from Indian states by Aiyar and Mody (2011) states that, "unlike Bloom and Canning $(2004)^{4}$ we do not find the 
demographic dividend to be conditional on specific policies or social environments" ( $p$. 7). Their empirical analysis implies that a substantial fraction of the growth acceleration that India experienced since the 1980s-sometimes ascribed exclusively to economic reforms-was attributable to changes in the country's age structure. Aiyar and Mody further claim that the demographic dividend could add about 2 percentage points per annum to India's per capita GDP growth over the next two decades.

There is a growing realization that one needs to be careful in drawing conclusions from country experiences or from larger cross-country regression techniques that pool data. This is because, given such results, it is difficult to specify the conditions under which demographic variables contribute to economic growth. ${ }^{5}$ Therefore while Pakistan's neighbors, India and Bangladesh, appear to have reaped the demographic dividend in terms of higher economic growth, the question of why Pakistan has failed to do so becomes all the more pressing.

\section{Why has Pakistan not benefited from the demographic dividend?}

We now explore a number of possible reasons why Pakistan has not benefited from the demographic dividend.

\section{Sustained growth in employment is a necessary condition for realizing the demographic dividend}

From the early 1990s until now, Pakistan has been for the most part under the aegis of an IMF support program to overcome severe balance-of-payments constraints (leading to a possible default on foreign borrowings). The resulting stabilization programs severely constrained growth of aggregate demand, primarily through a combination of cuts in the federal PSDP (Public Sector Development Programme) and monetary squeeze through curtailing bank lending and high interest rates. These episodes of fiscal and monetary tightening, together with recent supply shocks (energy shortages), have resulted in low economic growth for most of the last 20 years. The exception has been the spurt of economic growth post-9/11, which peaked in 2005 before collapsing in 2008 (see Figure 4.1).

The last two decades witnessed a number of circumstances detrimental to Pakistan's economy. The nuclear explosion in 1997 led to a suspension of donor support, which resumed only in 2002. In 2010 Pakistan witnessed a flood of epic proportions that displaced 20 million inhabitants and caused an estimated loss of about US\$10 billion (almost 7 percent of GDP). The unprecedented increase in global commodity and oil prices in 2007, the global economic meltdown in 2008, and continuing global recession have also had a major impact on Pakistan's economy, as they did for many other developing countries. Severe energy shortages post-2007 have also shaved off 1.5 to 2.0 percent of Pakistan's GDP.

Can we therefore conclude that the combination of these factors explains Pakistan's failure to reap the demographic dividend? The World Bank (2012) supports this contention, stating that Pakistan's "growth has been volatile around a broad declining trend" (p. 54). This is in contrast to Bangladesh and India, which have grown rapidly as a result of improved policies and could continue to benefit from their demographic dividend. 
There is therefore merit in the assertion that Pakistan's poor economic performance in recent years has had an adverse impact on realizing the expected gains of the demographic dividend. These findings do not support the contention of the previously cited study for India (Aiyar and Mody 2011) which suggested that the demographic dividend alone can accelerate economic growth.

It has been rightly emphasized that for Pakistan to reap the gains of the demographic dividend, it is necessary to create productive employment opportunities for the new entrants into the labor force. An equally interesting question is whether the new entrants into the working-age population actually enter the labor force and find productive employment. With still only around 20 percent of females in the working-age population in the labor force, can one assume that more will enter the labor force if job opportunities were made available? The answer to this question is not obvious. Female labor market behavior needs to be examined in a much broader socio-economic context than simply the availability of job opportunities.

A study for the Asian Development Bank on competitiveness and structural transformation in Pakistan (Felipe, 2007) analyzed trends in per capita income by decomposing it into the product of the employment-to-population ratio and labor productivity. Its findings on the former were that Pakistan had experienced falling employment absorption capacity, as the ratio of employment to the working-age population had declined during 1973 and 2002 from 56 percent to 48 percent.

More recent data on the ratio of employment to the working-age population show that after remaining constant at around 47 to 48 percent between 1990 and 2004, the ratio increased to 51 percent post 2005-06 and remained around that level before declining slightly in 2010-11 (Figure 4.4). This improvement is mainly due to a doubling of the ratio of employment to working-age population of females from 11 percent in 1990-91 to 21 percent in 2010-11. While this increase is a positive development, it is primarily caused by an increase in non-agriculture employment post 2001-02 until 2005-06, the years of economic recovery and high growth, as males moved out of employment in agriculture. ${ }^{6}$ However, much of the increase in female employment was in the category of unpaid family workers, mainly in livestock.

Why do the majority of women continue to remain outside the labor market? A study conducted in Faisalabad district (Ministry of Labour and Manpower 2009), a prosperous region in Punjab province, provides some insights. The major reason given by females aged 15-29 for not entering the labor market was personal or family responsibilities (67 percent), while only 3 percent of males cited this reason. The next major reason was attending education or training ( 28 percent) while for males this was 91 percent. The proportion reporting the inability to find suitable work as the main reason was less than one percent for females. These results clearly suggest that it was not the lack of jobs but other personal and family factors that were responsible for females not entering the labor market. 


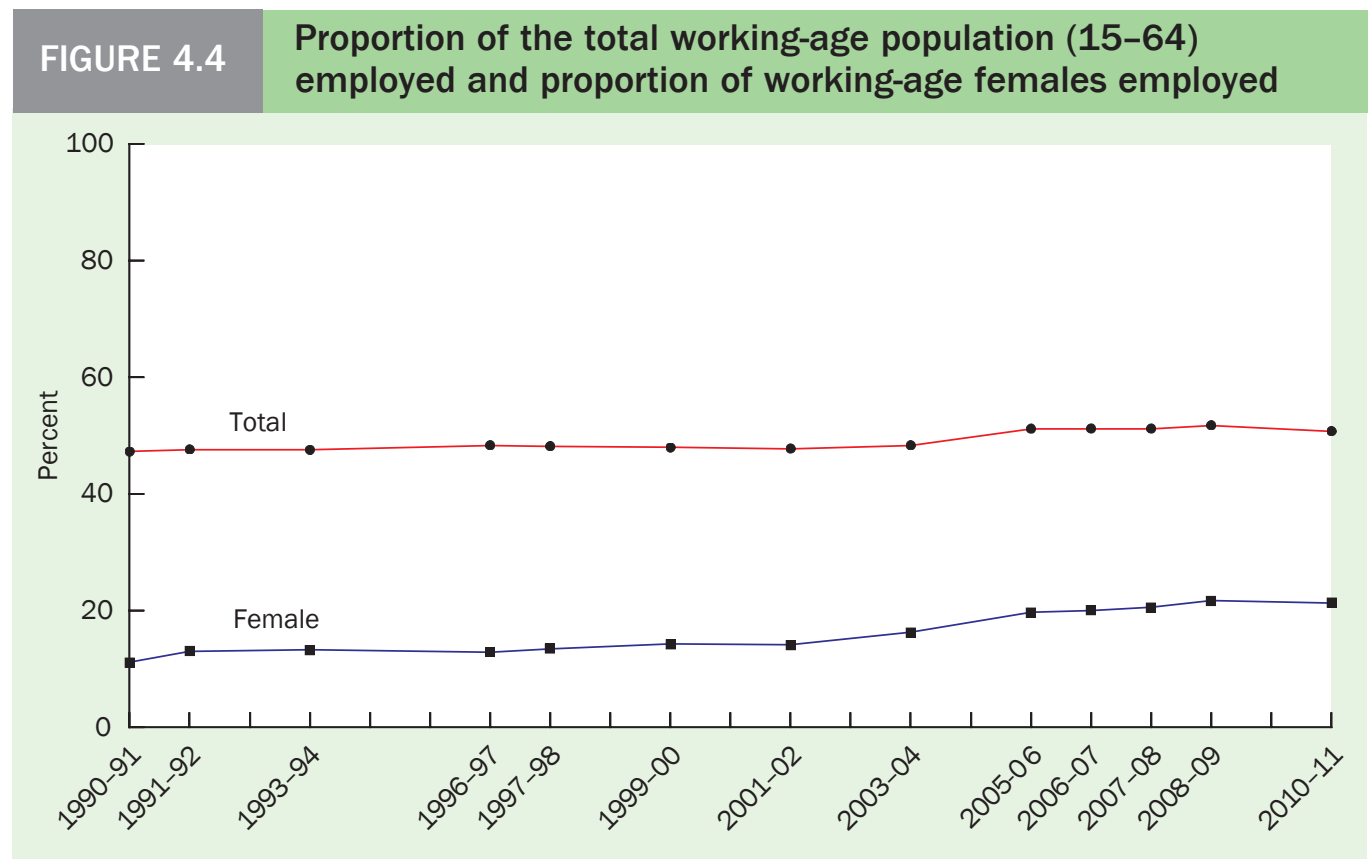

SOURCE: Labour Force Survey (various issues).

The continuing low ratio of employment to working-age population means that each working man and woman still had to provide for nearly two non-working persons in 2010. This dependency ratio is much higher than the South Asian average and will remain high in the absence of a substantial increase in female participation rates. The dependency ratio for low-income countries averaged 1.2 in $2005 .^{7}$

\section{Low re-allocation of labor to higher-value-added sectors}

After 2007-08, owing to crippling energy shortages, there has been little growth in the manufacturing sector, especially the labor-intensive small- and medium-size enterprises. However, growth has been stimulated in the rural areas owing to a strong pro-rural bias in government policies (e.g., substantial increase in procurement prices of wheat to reflect world prices). These developments have further setback movements to higher-valueadded sectors especially manufacturing.

A study by Felipe (2007) indicates that the share of industry in employment has remained flat (at around 20 percent) post-1980, implying that the higher-productivity sector of the economy had not generated sufficient new jobs to raise overall productivity. Industry's share of employment has continued to stagnate at around 20 percent between 1990 and 2010, with manufacturing also stagnating at around 12 percent over this period (see also Table 4.1).

These findings are reinforced by the World Bank (2012), which also analyses the contribution of labor movement across and within sectors to annual growth in total fac- 


\section{TABLE 4.1 Sectoral composition of GDP and labor force (percent)}

\begin{tabular}{lrrr|rrr|} 
& \multicolumn{3}{c|}{ GDP } & \multicolumn{3}{c|}{ Labor force (10 years and above) } \\
\cline { 2 - 7 } Sector & $1990-91$ & $1999-00$ & $2009-10$ & $1990-91$ & $1999-00$ & $2009-10$ \\
\hline Agriculture & 25.7 & 25.9 & 21.2 & 47.5 & 48.4 & 45.0 \\
Industry & 25.8 & 23.3 & 26.4 & 19.8 & 18.0 & 20.9 \\
Manufacturing & 17.5 & 14.7 & 18.6 & 12.2 & 11.5 & 13.2 \\
Services & 48.6 & 50.7 & 52.4 & 32.8 & 33.6 & 34.1
\end{tabular}

SOURCE: Pakistan Economic Survey and Labour Force Survey (various issues).

tor productivity in Pakistan and its South Asian neighbors. Table 4.2 shows that while re-allocation of labor across sectors played a role in driving TFP in Pakistan, its actual contribution was lower than in India. ${ }^{8}$ The table indicates not only that growth of TFP has been much lower in Pakistan as compared to India, but also that TFP growth in the services sector has been dominant in propelling this growth in India.

\section{Low levels of education and skills in the labor force}

A binding constraint on Pakistan's economic growth prospects has been the low level of education and skills of its work force. In 2010-11 one-third of the youth labor force was still illiterate and possessed very low levels of technical education (Table 4.3). Pakistan, it has been argued, is stuck in a "low-level skills equilibrium trap" which severely restricts its move into higher-value-added sectors essential to raising productivity and increasing economic growth (Amjad 2005). The continuing low level of investment in the education sector will have deleterious consequences for the education levels of the working-age population for years to come. Pakistan's very low level of investments in education and skills, which has fallen in recent years to less than 2 percent of GDP, the poor quality of education imparted, ${ }^{9}$ and lack of sustained growth act as important barriers to Pakistan's potential success in reaping the demographic dividend.

\begin{tabular}{|c|c|c|c|c|}
\hline \multirow[t]{3}{*}{ TABLE 4.2} & \multicolumn{4}{|c|}{$\begin{array}{l}\text { Sources of annual growth in total factor productivity in Pakistan } \\
\text { and India by sector and re-allocation effect }\end{array}$} \\
\hline & & $1990-2000$ & \multicolumn{2}{|c|}{$2000-08$} \\
\hline & Pakistan & India & Pakistan & India \\
\hline Re-allocation & 0.2 & 0.3 & 0.3 & 0.5 \\
\hline Services & 0.2 & 1.2 & 0.4 & 2.2 \\
\hline Industry & 0.4 & 0.3 & 0.4 & 0.6 \\
\hline Agriculture & 0.1 & 0.4 & 0.1 & 0.3 \\
\hline Total & 0.8 & 2.2 & 1.2 & 3.6 \\
\hline
\end{tabular}

SOURCE: World Bank: South Asia Development Matters - More and Better Jobs in South Asia, 2012, The World Bank, Washington D.C. 


\begin{tabular}{|l|lrrrrrrr}
\hline TABLE 4.3 & $\begin{array}{l}\text { Distribution of labor force by level of education (among those } \\
\text { aged 15-24) }\end{array}$ \\
\hline Years & Illiterate & $<$ Primary & Primary & Middle & Matric & $\begin{array}{c}\text { Inter- } \\
\text { mediate }\end{array}$ & BA+ & Total \\
\hline $1990-91$ & 53.0 & 5.0 & 16.7 & 10.9 & 9.6 & 3.0 & 1.7 & 100.0 \\
\hline $2001-02$ & 36.7 & 5.4 & 20.3 & 15.9 & 14.6 & 4.7 & 2.3 & 100.0 \\
\hline $2010-11$ & 35.3 & 4.6 & 21.4 & 16.4 & 13.8 & 5.3 & 3.3 & 100.0 \\
\hline SOURCE: Labour Force Survey (various issues) & & & & & & & \\
\hline
\end{tabular}

SOURCE: Labour Force Survey (various issues)

\section{Pakistan's poor youth profile ("youth bulge")}

In a world with a fast-growing aging population, Pakistan's large young population can prove to be a dynamic engine of economic and productivity growth. In 2005 almost 60 percent of the population was less than 25 years old-i.e., around 90 million people. Almost 40 percent of these were below 14 years of age, and nearly 30 percent of the labor force was in the 15-24 youth age group. ${ }^{10}$ Are the young entrants into the labor force contributing to the growth of the country's economy? Clearly the earlier discussion on the macroeconomic performance of the economy shows no evidence of this. Why is this contribution not taking place? Has the high unemployment rate among the young prompted potential workers to opt out of the labor market because available jobs do not match their expectations?

Youth unemployment in Pakistan, as is the case globally, is much higher than the average unemployment rate (ILO, 2010). Sparreboom and Shahnaz (2007) show that the share of female youth who are neither in education nor economically active was extremely high at 72 percent in 1999-2000. This proportion declined to 63 percent in 2005-06, but has increased slightly in subsequent years. Hou's (2010) study on challenges for youth employment in Pakistan makes the striking observation that not only is the unemployment rate much higher for better-educated youth, but "the initial earnings of better-educated youth are not very different from those of less-educated youth, as compared to wages for adults with similar education levels" (p. 209).

Have these difficulties in finding employment opportunities that match their expectations and the low returns on education led the young (especially females) to continue to join the ranks of discouraged and unemployed workers as well as to seek employment opportunities abroad? A recent study by the IMF (Kock and Sun 2011), which examined the rapid increase in remittances over the past decade (from just over US\$1 billion in 2000-01 to an expected US\$13 billion in 2011-12), finds for the period 1997-2008 that both the numbers of Pakistanis going overseas for work and the skill levels of these immigrants have increased. Since a large proportion of migrants are relatively young, one must ask whether better-educated and highly skilled young people are leaving the country in disproportionately high numbers. While evidence is scarce, this is a topic for further investigation. If true, then the expected spurt to economic growth from the "youth bulge" may be coming only in the form of much higher levels of remittances (in recent years around 5 percent of GDP) rather than in increasing economic growth. 


\section{How Pakistan can still reap the demographic dividend}

Pakistan has lost precious time in reaping the demographic dividend, which started some 15 to 20 years ago. But it is still not too late to do so, as the window of opportunity could last for another 40 years when the youth bulge gives way to an aging population. While the economic gains may so far be missing, there is an air of rising expectations as the young cohorts become more visible and assertive. The previous analysis clearly identifies and strongly dictates key areas where action is needed.

\section{Breaking out of stagflation and into sustained growth}

It would appear that in Pakistan the demographic dividend can serve as a "tail wind" that can accelerate whatever economic growth occurs. But such growth appears to be a necessary precursor to attaining the demographic dividend.

In the short term, key measures include overcoming or substantially reducing energy shortages, reducing the budget deficit to a more prudent level (to around 4 percent from the current 7 to 8 percent), raising revenues by introducing VAT (R-GST) ${ }^{11}$ and taxing untapped sectors, namely agricultural incomes and services, and exploiting new export opportunities to ensure a healthy trade balance.

The key, both in the short and medium term, is reviving business confidence to substantially increase investment levels, which have fallen to the extremely low level of 12 percent in 2011-12 (GoP 2012). This requires improving the security situation, ensuring better economic management, and reducing corruption. Political will, based on consensus among major political parties, is essential to undertaking economic and tax reforms, tariff reduction, and restructuring in major public-sector enterprises.

The federal PSDP has also been cut drastically in recent years to restore macro stability, from over 5 percent of GDP in 2005-06 to close to 2 percent in 2011-12, and this decrease is negatively affecting economic growth and job creation. To raise this to earlier levels requires increasing revenues from the low tax-to-GDP ratio of less than 9 percent in 2010-11 (the average for developing countries is almost double this amount) to 15 percent by 2015 and reducing non-development expenditure.

The bold steps being undertaken by the government to expand Pakistan-India trade can provide a much-needed outlet for economic growth. They will also have a positive impact on rebuilding confidence in Pakistan's economy. While estimates vary widely as to the potential trade gains if India were granted most-favored nation status by Pakistan and if India reduced non-trade barriers on Pakistan exports, the overall impact could be substantial. ${ }^{12}$

To enable the private sector to serve as the main engine of growth requires a conducive economic environment and an attractive incentive structure that eliminate or significantly reduce bureaucratic interferences. Only in such an atmosphere will entrepreneurship and business flourish.

\section{Creating more and better jobs for women and men}

Pakistan's labor force is currently growing at around 3.5 percent annually. Based on historical elasticity of 0.45 , Pakistan would need growth at around 8 percent per annum to 
absorb the increase in the labor force alone. ${ }^{13}$ It would need to grow faster if unemployment (6 percent in 2010-11) is to be also reduced.

Given Pakistan's lack of effective social protection systems or safety nets, many people are forced to seek employment at very low wages and under hazardous working conditions. The challenge is creating not just any jobs, but better jobs. A workable definition of such jobs in Pakistan is one adopted by the World Bank (2012), which calls for an increase in real wages and a decline in poverty of self-employed workers or family helpers.

Future engines of job creation in Pakistan will be: (i) the spread of urbanization, especially much-needed growth of medium-sized and new urban centers; (ii) modern services (especially ICT, banking, hotels, and restaurants); and (iii) agro-based manufacturing and food chains, given the enormous potential for productivity growth in the crop sector and the potential in the livestock sector. Growth of much-needed physical and social infrastructure (education and health sectors) will also pay a major role.

A key factor in ensuring remunerative and productive employment opportunities is ensuring mobility of labor both from rural to urban areas and across and within sectors. This requires a smooth-functioning labor market and availability of skills in demand, with better-educated and more skilled labor earning higher returns (World Bank 2012).

\section{Empowering women, reducing gender disparities, and increasing female employment}

For Pakistan to reap the demographic dividend, it is essential to increase the still very low labor force participation rate for women. As we have seen, most women in the working-age population do not seek employment in the labor market because of what they term personal or family responsibilities. To change this circumstance would require action and progress on three fronts: (i) increasing education levels starting at the primary and secondary level, especially in less developed regions; (ii) reducing the burden of household work, which adds on average an extra four to five hours of daily work for both non-working and working females (Saqib and Arif, 2012); and (iii) empowering women to reduce gender disparities and breaking down traditional mindsets through pro-active policies and interventions, including reservation of jobs in the public sector and higher grade positions.

Some positive signs are emerging in both rural and urban areas. As men move out of agriculture, women move in to take their jobs, especially in the livestock sector. In higher education, which has expanded rapidly post-2000 from around 300,000 total enrollment to just over 1 million in 2012, the female percentage is only slightly lower than that of males. Women are becoming prominent as entrepreneurs, in management positions, in the media, and in traditional education and social sectors. These changes are generating a momentum of their own-as prominent role models emerge-that will hopefully lead to a major increase in women's LFPR in coming decades.

\section{Profiting from the "youth bulge": Investing in education and skills}

Only an educated and skilled work force can allow Pakistan to reap the demographic dividend and to compete and prosper in a highly competitive global economy. Pakistan needs 
to invest far more in education. The public sector has failed to deliver the numbers and quality in both primary and secondary education. On the other hand, the performance of private-sector schools has been somewhat better. ${ }^{14}$ There is a need to identify how the government can support provision of primary and secondary education by the better-performing private schools, while ensuring access to children of poorer households through subsidies, including vouchers. The government still confronts the challenge of delivering quality primary and secondary education where the private sector is unwilling to do so.

Regarding formal skills training and skill certification, the lack of availability of skills in Pakistan is not just a supply-side problem. The increasing use of contract labor and the unwillingness of employers to pay higher wages for skilled workers are major demand-side disincentives.

\section{Conclusion}

It is perhaps overly optimistic to expect that economic gains will become visible at the very start of the demographic dividend. But in the case of Pakistan the dividend appears to be long overdue. Much time has been lost. But with better economic management and needed reforms that could re-ignite growth, the demographic dividend still holds the potential for Pakistan to enter a phase of much higher economic growth, which can also reduce poverty and improve living conditions. The "youth bulge" can usher in a "youth revolution" which can change the destiny of the country.

\section{Notes}

The author is grateful to Zeba A. Sathar, G.M. Arif, Durr-e-Nayab, Naved Hamid, and authors of this volume for their comments and ideas in the writing of this chapter.

1 Growth in productivity can be attributed to growth in physical capital per worker or labor (i.e., human resources including education). What cannot be explained by this increase in inputs alone is attributed to more effective use of these inputs, including through technical progress, and termed growth in total factor productivity.

2 The Tenth Five Plan (2010-15) being prepared by the Planning Commission was put on hold, possibly because of unsettled economic conditions. The Planning Commission (GoP 2011) came up with a growth framework for Pakistan in 2011.

3 These projections are based on the medium variant of both UN (2011) and Population Council (2011) projections. If we opt for the high variant of these projections, then the onset of the dividend would be later.

4 Bloom and Canning (2004), on the basis of a cross-country analysis for 1965-95, demonstrated a substantial impact of the working-age ratio on economic growth but only when the economy is "open", i.e., when incentives are in place to exploit their potential (as cited in Aiyar and Mody 2011).

5 For example, Rodriguez and Rodrik (1999), examining the relationship between trade openness and growth based on cross-country results, argue that, "Research aimed at ascertaining the circumstances under which open trade policies are conducive to growth (as well as those 
under which they may not be) and at scrutinizing the channels through which trade policies influence economic performance is likely to be more productive."

6 Labour Force Survey, 2010-11.

7 Based on World Development Indicators and cited in Amjad and Havers (2007: 7).

8 The contribution to total factor productivity of re-allocation was significantly higher in China and other South-East Asian economies as compared to South Asia (World Bank 2012).

9 See the most recent report on the state of education in Pakistan (ASER 2013).

10 See UN Population Prospects: The 2010 Revision, Population Division UN (2011) and Economically Active Population 2006 (ILO 2011).

11 Revised-General Sales Tax, as the Value-Added Tax is termed by the Ministry of Finance.

12 See Khan (2011).

13 This elasticity of employment is used in the Interim Report of the Panel of Economists (GoP 2008).

14 The recent Status of Education Report (ASER 2013) points out that lower-quality private schools are also producing very poor results compared to those seen in public schools. 
66 At the micro level, household or family size has been documented as a determinant of chronic poverty, and age composition influences the dependency ratio and consequently the poverty trajectories of households. 99
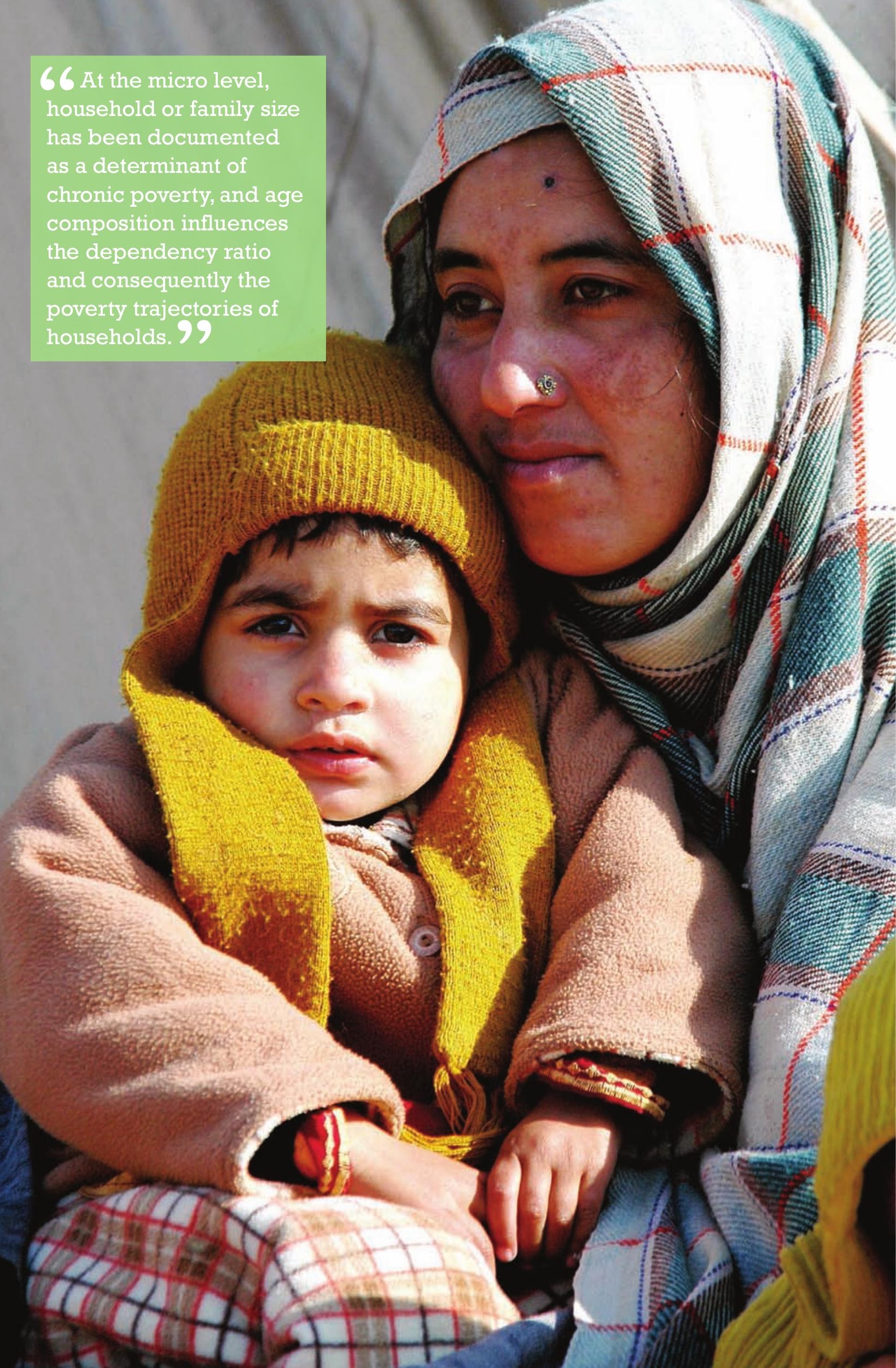


\section{CHAPTER FIVE}

\section{Population and}

Poverty Dynamics

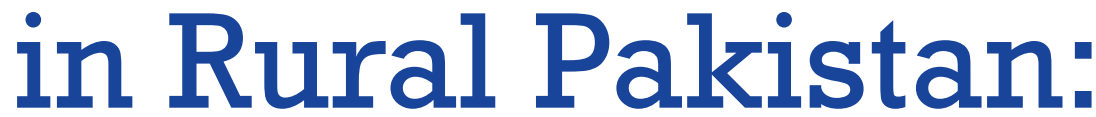

Evidence from

the Longitudinal

Household Survey

\section{G.M. ARIF}

The effect of population growth on poverty is neither obvious nor well established given the absence of a robust effect of population growth on economic growth (McNicoll 1999; Headey and Hodge 2009). However, a growing body of evidence shows that demographic trends are indeed important: population changes are part of the development story and are relevant to poverty at the macro and micro levels (Hobcraft 2003). For example, Headey and Hodge (2009) show from a meta-regression analysis of post-1980 international data that the "burden of higher population growth has been increasing over time." Moreover, the decline of poverty in East and Southeast Asia over the past few decades 
has been correlated with rapid fertility declines and lower rates of population growth (Kim et al. 2006), although drawing a causal relationship from such a correlation is risky (Jones 2009).

At the micro level, household or family size has been documented as a determinant of chronic poverty (Jayaraman and Findeis, 2005; Ssewanyana 2009), and age composition influences the dependency ratio and consequently the poverty trajectories of households. Changes in each age group (young, adult, and elderly) are also linked with poverty dynamics (movements into and out of poverty) because of their distinct economic consequences: "the young require intensive investment in health and education, prime-age adults supply labor and saving, and the aged require health care and retirement income" (Bloom, Canning, and Sevilla 2003).

The linkages between population and poverty in Pakistan are complex for several reasons. First, despite a decline since the late 1980s, fertility remains close to 4 births per woman, and consequently population growth is also still high at around 2 percent per annum. Second, Pakistan has not experienced sustained poverty reduction. Third, the relationship between economic growth and poverty in Pakistan has not always been in the expected direction. For example, poverty increased during a period of high economic growth in the 1960s and declined during the period of slow growth in the 1970s.

The gradual fertility decline in Pakistan has, however, brought a modest change in the age composition of the population. The share of young people in the total population has declined, while the share of the working-age population has increased. The question is the degree to which these demographic dynamics at the household level affect the transition into and out of poverty. The presence of a young population or child dependency can push families into poverty, while a larger adult population, through labor supply and earnings/savings, can help improve household well-being.

This chapter argues that population changes or demographic factors in Pakistan are relevant to poverty at both the macro and micro levels. Focusing on the micro level, the chapter examines the connections between demographic factors and poverty dynamics in rural areas of the country. Understanding these connections is important for refining poverty reduction strategies.

With respect to demographic factors, the focus here is on family size, change in the age composition of household members, and gender of the head of household. A key feature in rural Pakistan is the co-existence of landless and landowning households, the two distinct groups in the social and economic hierarchy (Hirashima 2009). These groups may differ in their demographic behavior, thus influencing poverty dynamics in different ways. This chapter also analyses the relation between demographic events and movement into or out of poverty while taking the asset position (particularly land ownership) of rural households into account. It uses data from a longitudinal household survey carried out in 2001 and 2004 in the same sampled households. 


\section{Demographic trends, poverty, and landholding: The macro context}

\section{Demographic changes}

This section reviews trends in selected demographic variables, poverty, and land ownership at the national level. For demographic trends, the last five decades can be divided into two broad periods: 1960 to the late 1980s and 1990 to 2010. In the former period, mortality declined steadily but fertility remained high, leading to a gradual increase in population growth. The latter period is characterized by the onset of fertility transition, which led to a modest decline in population growth.

The economic development that took place in the period 1960-89 appears to have strongly influenced the population growth rate through declines in death rates. The crude death rate declined from 23 to 10 per 1,000, and the infant mortality rate (IMR) declined from 150 to 100 per 1,000 live births between 1960 and the late 1980s. TFR remained high, around 6, until the 1980s. Thus, economic development in the 1960s through the 1980s contributed positively to population growth. Growth in per capita income remained modest; in fact in several years, it was negative.

Since the late 1980s fertility has declined gradually to 4 children per woman at present, resulting in a decline in the share of the very young and an increase in the share of the working-age population. GDP growth fluctuated during the post-1980 period: low in the 1990s, high during 2003-07, and low again in the last 4-5 years.

\section{Poverty}

Table 5.1 summarizes the poverty estimates provided by studies that used the calorific approach but used different threshold levels. Despite high economic growth, the 1960s witnessed high levels of poverty of around 40 percent, increasing mainly in the rural areas. One explanation for this unexpected relationship between high economic growth rates and the rise in poverty is that the initial beneficiaries of agricultural subsidies in the 1960s were generally large farmers. The benefits of high agricultural growth were thus not translated into reduced levels of poverty. Poverty declined rapidly during the $1970 \mathrm{~s}$ when the rate of GDP growth slowed to less than 5 percent. It appears that the growthpoverty relationship in the 1960s and 1970s was not in the expected direction.

Poverty declined steeply during the period of high GDP growth in the 1980s whereas it increased sharply in the 1990s when GDP growth slowed. Private investment in agriculture during the 1970s, improved performance of the agriculture sector in the 1980s, and inflows of foreign remittances associated with migration to the Middle East were the major reasons for declines in poverty during the 1970s and 1980s. The rise in poverty started in the early 1990s and continued until the beginning of the new millennium, when the headcount ratio was about 35 percent. In addition to the decline in economic growth, several other factors are responsible for the rise in poverty in the 1990s. The inflows of foreign remittances, which are believed to be one of the major factors for reducing poverty during the 1980s, also declined markedly during the 1990s. Poverty declined sharply again during the first half of the last decade, from 35 percent in 2000-01 to 22 percent in 2005-06-a decline of more than 12 percentage points in only five years. 


\section{TABLE 5.1 Trends in poverty (head count ratios) in urban and rural Pakistan}

\begin{tabular}{|lccc|}
\hline Period & Urban & Rural & Overall \\
\hline $1963-64$ & 44.5 & 38.9 & 40.2 \\
\hline $1966-67$ & 41.0 & 45.6 & 44.5 \\
$1969-70$ & 38.8 & 49.1 & 46.5 \\
1979 & 25.9 & 32.5 & 30.7 \\
$1984-85$ & 21.2 & 25.6 & 24.5 \\
$1987-88$ & 15.0 & 18.3 & 17.3 \\
$1990-91$ & 18.6 & 23.6 & 22.1 \\
$1992-93$ & 24.6 & 28.3 & 26.8 \\
$1996-97$ & 22.6 & 33.1 & 29.8 \\
$1998-99$ & 20.9 & 34.7 & 30.6 \\
\hline $2000-01$ & 22.7 & 39.3 & 34.5 \\
$2004-05$ & 14.9 & 28.1 & 23.9 \\
$2005-06$ & 13.1 & 27.0 & 22.3
\end{tabular}

NOTE: Poverty estimates in this table are not based on a consistent poverty line. SOURCE: Amjad and Kemal 1997; Cheema 2005; GoP 2009a.

The fraction of the population living below the poverty line in rural areas has declined from 39 percent in 2000-01 to 27 percent in 2005-06, while the corresponding decline in urban areas was from 23 percent to 13 percent. The sharp decline in rural areas, however, failed to narrow the rural-urban gap: rural poverty was more than double urban poverty in 2005-06. One of the main reasons for poverty reduction during 2000 to 2006 was the high economic growth recorded by most sectors. Other factors likely to have contributed to poverty reduction include increased public spending, especially on education, health, and infrastructure (rural electrification, roads, and irrigation improvements).

After 2006, no official statistics on poverty are available. Presently, the economy of Pakistan is facing severe challenges with a declining rate of economic growth, doubledigit inflation (particularly affecting food prices), power shortages, and rising oil prices. The ongoing war on terrorism has also diverted public expenditure from development to security. On the other hand, the inflow of foreign remittances through formal sources has increased to more than US\$10 billion per annum.

Regarding rural-urban poverty, three dimensions are noteworthy from Table 5.1. First, during the last five decades changes in poverty in rural and urban areas were mainly in the same direction: an increase or decrease in poverty was observed in both areas. Second, until the 1970s, the difference in poverty levels between rural and urban areas was modest, 5 to 8 percentage points. After the 1980s, this difference widened, and in 2005-06 rural poverty was double the rate of urban poverty. Third, poverty in Paki- 
stan is often considered a rural phenomenon not only because of the higher incidence in rural areas but also because of the high absolute number of the rural poor-two-third of the total population lives in rural areas.

\section{Landholding}

Only 37 percent of rural households owned some land in 1980 (Table 5.2). In 1972, 47 percent of the country's households owned less than five acres of land, and these households owned 5 percent of the total land. By contrast, only 3 percent of households had landholding of more than 50 acres, and owned 22 percent of the total land. The situation has hardly changed in three decades. In 2000 only 37 percent of rural households owned land and 61 percent of these owned fewer than five acres (15 percent of total land). Two percent of rural households owned 50 acres or more, accounting for 30 percent of the total land (World Bank 2007). Land in rural Pakistan is distributed far more unevenly than income (Hirashima 2009).

\section{Household size, dependency ratio, and poverty dynamics: The micro context}

Table 5.3 presents data on poverty dynamics by three demographic variables: household size, dependency ratio, and gender of the head of households. Poverty status is examined through change in the poverty status of the same households covered in two rounds of the Pakistan Rural Household Survey (PIDE 2001 and 2004): (i) poor in both rounds, (ii) poor in round-I and non-poor in round-II, (iii) non-poor in round-I and poor in roundII, and (iv) non-poor in both rounds. The first category is considered as the "chronic poverty," while the second and third categories are referred to respectively as "moved out of poverty" and "fell into poverty" between the two rounds. The last category is considered as the "never poor" or "non-poor in two periods."

The proportion of households that moved out of poverty was larger than those that fell into poverty between 2001 and 2004, resulting in a decline in overall rural poverty. In 2001, 33 percent of households were classified as poor; by 2004 the proportion had fallen

\section{TABLE 5.2 Distribution of land ownership in Pakistan}

\begin{tabular}{|c|c|c|c|c|}
\hline & 1972 & 1980 & 1990 & 2000 \\
\hline$\%$ of landless households & - & 63.0 & 62.0 & 63.3 \\
\hline \multicolumn{5}{|l|}{$\%$ share of holding $<5$ acres } \\
\hline Households & 47.3 & na & 54.4 & 61.2 \\
\hline Land & 5.4 & na & 11.4 & 14.8 \\
\hline \multicolumn{5}{|c|}{$\%$ share of holding $50+$ acres } \\
\hline Households & 3.3 & na & 2.8 & 2.0 \\
\hline Land & 22.4 & na & 34.0 & 29.7 \\
\hline
\end{tabular}

SOURCE: World Bank 2007. 


\section{TABLE 5.3 Household dynamics and change in poverty status in rural Pakistan}

\begin{tabular}{|c|c|c|c|c|c|}
\hline \multirow[b]{2}{*}{ Household dynamics } & \multicolumn{5}{|c|}{ Poverty status (percent in category) } \\
\hline & Chronic poor & $\begin{array}{l}\text { Moved out } \\
\text { of poverty }\end{array}$ & $\begin{array}{r}\text { Fell } \\
\text { into poverty }\end{array}$ & Never poor & All \\
\hline Overall & 11.3 & 21.2 & 11.0 & 56.5 & 100 \\
\hline \multicolumn{6}{|l|}{ Household size } \\
\hline$\leq 5$ members & 6.4 & 17.1 & 9.8 & 68.7 & 100 \\
\hline 6-8 members & 8.9 & 18.0 & 12.1 & 61.0 & 100 \\
\hline$\geq 9$ members & 18.5 & 28.9 & 10.8 & 41.9 & 100 \\
\hline \multicolumn{6}{|l|}{ Dependency ratio } \\
\hline Low & 6.3 & 14.3 & 9.6 & 69.8 & 100 \\
\hline Medium & 11.7 & 21.5 & 12.9 & 53.9 & 100 \\
\hline High & 16.1 & 28.2 & 10.6 & 45.1 & 100 \\
\hline \multicolumn{6}{|l|}{ Household headship } \\
\hline Male & 12.3 & 21.4 & 11.1 & 56.2 & 100 \\
\hline Female & 12.2 & 14.6 & 4.8 & 68.3 & 100 \\
\hline
\end{tabular}

SOURCES: Pakistan Rural Household Survey 2001 and 2004.

to 22 percent. Despite this decline in overall poverty, chronic poverty remains a problem: the 11 percent of households that are counted as chronically poor remained poor in two rounds of the PRHS. Another 11 percent of households fell into poverty between 2001 and 2004. Overall, more than half of the households (57 percent) remained in the nonpoor category in the two rounds of PRHS.

How are these poverty dynamics related to demographic variables? Table 5.3 indicates a positive relationship between household size and chronic poverty: the incidence of chronic poverty in larger households $(\geq 9)$ is three times the incidence in smaller households $(\leq 5)$. Demographic pressure is therefore a driver of chronic poverty. This finding is similar to the results of other studies (Islam and Shimeles 2007; Ssewanyana 2009). However, the table also shows that movement out of poverty was greater among large households than among smaller or medium-sized households. It is likely that some larger households have more earners than small households, and through their wages many of them were able to escape poverty. While there is no linear relationship between household size and falling into poverty, household size appears to be negatively correlated with the "never poor" category: the higher the household size, the less likely that the household remains "never poor." This demonstrates that larger families are not only more likely than smaller families to remain in chronic poverty, they are also less likely to retain the "never poor" status.

The relationship between the dependency ratio and poverty status shown in Table 5.3 is similar to that drawn for household size. The dependency ratio is positively related to chronic poverty while its relation with the "never poor" status is negative. 
There is no difference in chronic poverty between male- and female-headed households. However, households headed by a male are more likely both to move out of poverty and to fall into poverty. These observations point to greater stability in poverty status among female-headed households. This finding is supported by the fact that female-headed households are more likely than male-headed households to remain "never poor." Households headed by a female might be doing as well as those headed by a male because of money coming from a husband working elsewhere or from other family members. But the PRHS panel data do not have this type of information.

Table 5.4 shows data on poverty status while controlling for land ownership, household size, and the dependency ratio. Landless households, which constitute more than 50 percent of rural households, are under immense demographic pressure: as household size increases, the proportion of chronic poor increases while the possibility of retaining the "never poor" status declines monotonically. The overall poverty status of small landowners ( $<5$ acres land) is better than that of landless households; however, larger households are more likely than smaller households to be chronically poor and less likely to retain the "never poor" status in two rounds of the PRHS. The occurrence of chronic

\begin{tabular}{|c|c|c|c|c|c|c|}
\hline \multirow[t]{3}{*}{ TABLE 5.4} & \multicolumn{6}{|c|}{$\begin{array}{l}\text { Land ownership, household dynamics, and change in poverty } \\
\text { status in rural Pakistan }\end{array}$} \\
\hline & \multicolumn{3}{|c|}{ Household size (members) } & \multicolumn{3}{|c|}{ Dependency ratio } \\
\hline & $\leq 5$ & $6-8$ & $\geq 9$ & Low & Medium & High \\
\hline \multicolumn{7}{|l|}{ No Land } \\
\hline Chronic poor & 8.8 & 14.1 & 24.8 & 7.7 & 16.2 & 20.7 \\
\hline Moved out of poverty & 20.5 & 28.0 & 39.7 & 21.2 & 27.7 & 35.3 \\
\hline Fell into poverty & 13.1 & 11.5 & 7.9 & 9.7 & 12.8 & 11.0 \\
\hline Never poor & 57.6 & 46.5 & 27.6 & 61.4 & 43.4 & 33.0 \\
\hline \multicolumn{7}{|l|}{ Less than 5 acres } \\
\hline Chronic poor & 3.9 & 5.7 & 19.7 & 7.8 & 8.5 & 13.2 \\
\hline Moved out of poverty & 15.8 & 10.3 & 25.7 & 9.5 & 17.6 & 24.3 \\
\hline Fell into poverty & 6.3 & 12.9 & 9.9 & 11.2 & 13.4 & 5.9 \\
\hline Never poor & 74.0 & 71.1 & 44.7 & 71.5 & 60.6 & 56.6 \\
\hline \multicolumn{7}{|l|}{5 to 10 acres } \\
\hline Chronic poor & 2.9 & 0.0 & 14.6 & 3.2 & 9.8 & 5.7 \\
\hline Moved out of poverty & 11.8 & 10.2 & 21.8 & 11.3 & 17.7 & 17.1 \\
\hline Fell into poverty & 2.9 & 13.6 & 12.7 & 6.5 & 13.7 & 14.3 \\
\hline Never poor & 82.4 & 76.3 & 50.9 & 79.0 & 58.8 & 62.9 \\
\hline \multicolumn{7}{|l|}{ Greater than 10 acres } \\
\hline Chronic poor & 0.0 & 1.8 & 5.1 & 0.0 & 3.3 & 6.8 \\
\hline Moved out of poverty & 0.0 & 0.0 & 14.1 & 4.2 & 10.0 & 8.5 \\
\hline Fell into poverty & 2.7 & 10.9 & 17.2 & 8.3 & 11.7 & 18.6 \\
\hline Never poor & 97.3 & 87.3 & 63.6 & 87.5 & 75.0 & 66.1 \\
\hline
\end{tabular}

SOURCES: Pakistan Rural Household Survey 2001 and 2004. 
poverty among households that own more than 10 acres of land is negligible for smaller families, but 5 percent of larger families are chronically poor despite owning more than 10 acres. Moreover, there is a gradual decline in the proportion of the "never poor" category when the size of families increases. Finally, note the positive relationship between land ownership and falling into poverty for larger families. For these families, even 10 or more acres of land is not sufficient to retain their "never poor" status; rather the demographic pressure pushes them into the "chronic poor" status.

The right-hand portion of Table 5.4 shows data on land, the dependency ratio, and change in poverty status. Both the dependency ratio and land ownership seem to have an independent association with poverty dynamics. Chronic poverty has a negative relation with land ownership while it is positively related to the dependency ratio. The reverse is the case for the "never poor" status, which increases with a rise in land ownership and declines as the dependency ratio increases. The dependency ratio has an impact on poverty dynamics even after controlling for land ownership. For example, in households that own 10 or more acres of land, chronic poverty is non-existent in households with a low dependency ratio, while for households with a high dependency ratio it is around 7 percent. Similarly, the proportion of households moving into or out of poverty increases as the dependency ratio rises. The proportion of households in the "never poor" status declines as the dependency ratio increases.

These statistics show that demographic pressures in the form of large household size and high dependency ratios influence the standard of living even of those families who own 10 or more acres of land. It is difficult for them to retain the "never poor" status, and they have a greater possibility of falling into poverty. The fact that a quarter of landless households having large families are in chronic poverty indicates their inability to escape poverty even over the longer term.

\section{Socio-demographic correlates of poverty: A multinomial logit analysis}

This section examines the socio-demographic correlates of the change in poverty status between the two waves of the PRHS by using multinomial logit models. The dependent variable is one of three mutually exclusive categories of change in poverty status between the two rounds of this longitudinal survey. The categories are: chronically poor (poor in both round-I and round-II); "transitory poor" (moved out of poverty or fell into poverty between round-I and round-II); and "never poor" (remaining non-poor in both rounds). The last category is the reference category.

Two types of explanatory variables are used. The first are socio-economic characteristics of both the sampled household and head of household, including ownership of residential house, its structure, ownership of livestock, land ownership, access to credit, electricity, farm status of household, working status of the household head, health expenditure, and dummies for regions (Sindh and Southern Punjab, with central and north Punjab as the reference category). Second, the demographic variables included in the models are age of the head of household, household size, gender of the household head, 
and dependency ratio. The difference in selected variables between the two waves of the PRHS is also included in the regression analysis to examine the effect of change in these variables on poverty dynamics. The difference in household size and in educational level of the household head is computed and included in the regression analysis. To indicate the effect of change in age composition on poverty dynamics, three dummies are used in the model. The first dummy takes the value one if the population of young people $(<18$ years) increased between 2001 and 2004. In the second dummy, the value of one was assigned if the adult population (18-59 years) increased between the two periods. The third dummy is used to show the increase in the elderly population.

Three equations have been estimated. In model 1, only socio-economic variables are used, while model 2 adds demographic variables to assess their impact on poverty dynamics. Variables showing change in selected socio-economic and demographic characteristics are included in the model 3. All the regressors for the PRHS are measured on the basis of 2001, when its first round was carried out. For variables that show change, data from two rounds are used. The independent variables used in the multinomial logit models help explain how various socio-demographic factors keep people poor or allow them to escape poverty. Results, shown in the form of relative risk ratios, are presented in Table 5.5.

In model 1 , as expected, land ownership is negatively associated with both chronic and transitory poverty, showing that landowners are more likely to be in the "never poor" category. House ownership was not significantly associated with poverty dynamics, probably because of almost universal ownership in rural Pakistan. The better structure of a dwelling unit (pacca or cement house), however, has a significant and negative association with chronic poverty. The same is the case for electricity. Assets in rural Pakistan, particularly land, are surely the principal explanation for why households are in the category of "never poor," since they protect households from negative shocks.

Literacy and work status of the household head are also included in model 1 . While literacy has no significant association with poverty dynamics, the head's work status has a significant association: those in agriculture are less likely to be in the category of transitory poor, whereas construction workers are more likely to be in this category. Employment opportunities in construction may not be available year round, increasing the probability of seasonal unemployment and transitory poverty.

Per capita health expenditures show a significant negative association with both chronic poverty and transitory poverty (model 1). This finding suggests that large health expenditures are an obstacle to making the transition from being poor to being nonpoor. But the negative association between per capita health expenditures and chronic poverty indicates the ability of "never poor" households to afford such expenditures. The results of the regional dummies show the persistence of chronic and transitory poverty in Sindh and South Punjab.

Model 2 adds four demographic variables-age and sex of household head, household size, and dependency ratio-while retaining all socio-economic factors included 


\section{TABLE 5.5 Effects of socio-economic and demographic characteristics on the change in poverty status (relative risk ratios)}

\begin{tabular}{|c|c|c|c|c|c|c|}
\hline \multirow[b]{2}{*}{ Characteristics } & \multicolumn{2}{|c|}{ Model 1} & \multicolumn{2}{|c|}{ Model 2} & \multicolumn{2}{|c|}{ Model 3} \\
\hline & $\begin{array}{c}\text { Chronic } \\
\text { poor/ } \\
\text { never } \\
\text { poor }\end{array}$ & $\begin{array}{r}\text { Transitory } \\
\text { poor/ } \\
\text { never } \\
\text { poor }\end{array}$ & $\begin{array}{c}\text { Chronic } \\
\text { poor/ } \\
\text { never } \\
\text { poor }\end{array}$ & $\begin{array}{r}\text { Transitory } \\
\text { poor/ } \\
\text { never } \\
\text { poor }\end{array}$ & $\begin{array}{c}\text { Chronic } \\
\text { poor/ } \\
\text { never } \\
\text { poor }\end{array}$ & $\begin{array}{r}\text { Transitory } \\
\text { poor/ } \\
\text { never } \\
\text { poor }\end{array}$ \\
\hline \multicolumn{7}{|l|}{ Socio-economic } \\
\hline Land ownership (acres) & $0.948^{*}$ & 0.994 & $0.914^{*}$ & $0.971^{*}$ & $0.902^{*}$ & $0.969^{*}$ \\
\hline Farm status of household & 0.765 & $1.594^{* *}$ & 0.768 & 1.476 & 0.737 & 1.428 \\
\hline Ownership of residential house & 0.795 & 1.261 & 0.696 & 1.175 & 0.776 & 1.178 \\
\hline Pacca structure of residential house & $0.512^{* *}$ & 0.816 & $0.504^{* *}$ & 0.788 & $0.450^{* *}$ & 0.766 \\
\hline Electricity & $0.118^{* *}$ & 0.935 & $0.549^{*}$ & 0.801 & $0.506^{*}$ & 0.783 \\
\hline Literate head of household & 0.762 & 0.816 & $0.623^{* *}$ & $0.682^{*}$ & $0.610^{* *}$ & $0.674^{*}$ \\
\hline Working in agriculture & 0.996 & $0.697^{* *}$ & 0.804 & $0.664^{* *}$ & 0.816 & $0.676^{* *}$ \\
\hline Working in construction & 1.131 & $2.174^{* *}$ & 1.237 & 2.061 & 1.226 & 1.973 \\
\hline Health expenditure per capita (Rs.) & $0.999^{*}$ & $1.000^{* *}$ & $0.999^{* *}$ & $1.000^{* * *}$ & $0.999^{* *}$ & $1.000^{* * *}$ \\
\hline Access to credit & 0.849 & 1.110 & 0.804 & 1.050 & 0.749 & 1.042 \\
\hline South Punjab & $1.837^{* *}$ & $1.759^{*}$ & 1.139 & 1.286 & 1.079 & 1.253 \\
\hline Sindh & $4.779^{*}$ & $4.062^{*}$ & $3.171^{*}$ & $2.888^{*}$ & $2.887^{*}$ & $2.777^{*}$ \\
\hline \multicolumn{7}{|l|}{ Demographic } \\
\hline Age of household head & - & - & 1.058 & 0.987 & 1.030 & 0.980 \\
\hline Age squared & - & - & 0.999 & 1.000 & 1.000 & 1.000 \\
\hline Household size & - & - & $1.304^{*}$ & $1.206^{*}$ & $1.425^{*}$ & $1.225^{*}$ \\
\hline Female-headed household & - & - & 1.726 & 0.626 & 1.759 & 0.628 \\
\hline Dependency ratio & - & - & $1.452^{*}$ & $1.199^{* *}$ & $1.348^{*}$ & $1.190^{* *}$ \\
\hline \multicolumn{7}{|l|}{ Change } \\
\hline Difference in household size & - & - & - & - & $1.194^{*}$ & $1.059^{* *}$ \\
\hline Difference in education & - & - & - & - & 1.000 & 1.004 \\
\hline Increase in child population & - & - & - & - & 0.732 & 0.811 \\
\hline Increase in adult population & - & - & - & - & $0.663^{* * *}$ & 0.912 \\
\hline Increase in elderly population & - & - & - & - & 0.743 & 0.846 \\
\hline Log Likelihood & & -1125.999 & & -1030.884 & & -1016.025 \\
\hline$(\mathrm{N})$ & & 1279 & & 1279 & & 1279 \\
\hline LR chi ${ }^{2}$ & & 262.61 & & 452.84 & & 482.56 \\
\hline Prob > chi ${ }^{2}$ & & 0.000 & & 0.000 & & 0.000 \\
\hline Pseudo $\mathrm{R}^{2}$ & & 0.104 & & 0.180 & & 0.192 \\
\hline
\end{tabular}

\footnotetext{
${ }^{* * *}$ Significant at $p<0.01,{ }^{* *} p<0.05,{ }^{*} p<0.10$.
}

SOURCES: Pakistan Rural Household Survey 2001 and 2004 
in model 1. Inclusion of these variables has improved the overall explanatory power of the model; pseudo $\mathrm{R}^{2}$ almost doubled from 0.1044 to 0.1801 , suggesting that the demographic variables are strongly correlated with poverty dynamics.

The significance of economic variables, particularly land ownership and structure of the residential house, for poverty dynamics in model 2 is similar to model 1, except that literacy became statistically significant in model 2 . Households with literate heads are less likely to be chronically poor or transitory poor than they are to be non-poor. Education is thus the critical pathway out of poverty because it improves the quality of labor as an asset and is the key element in contexts where access to material assets is highly constrained (Chronic Poverty Research Centre 2005). The results of the multinomial logit model show a significant and negative association between literacy of the household head and chronic poverty.

Regarding the demographic factors, Table 5.5 shows that the effect on poverty dynamics of two key variables, household size and the dependency ratio, is statistically significant (model 2). The positive association of household size with both chronic poverty and transitory poverty indicates that large households are more likely to stay longer in poverty or to be vulnerable to poverty than they are to be "never poor." Smaller families are more likely to remain "never poor." Thus, even if poor rural households choose larger size for additional earning potential, they may not necessarily escape poverty. The significance of the dependency ratio in the model reinforces this finding. A higher dependency ratio increases the risk of being in chronic poverty or transitory poverty.

The effect of demographic factors on poverty dynamics is further explored in model 3, where dummy variables showing an increase in child, adult, and elderly populations were also included. Results are in the expected direction. An increase in the adult population shows a negative and significant relation with chronic poverty. In other words, an increase in the supply of labor contributes to household well-being by reducing the risks of being in chronic poverty.

The above-noted association of age composition (dependency ratio and increase in adult population) with poverty dynamics supports the view that:

Each age group in a population behaves differently, with distinct economic consequences. The young require intensive investment in health and education, adults supply labor and savings, and the elderly require health care and retirement income. When the relative size of each of these groups in a population changes, so does the relative intensity of these economic behaviors. This matters significantly to a country's income growth prospects. (Bloom, Canning, and Sevilla 2003: 20-21)

\section{Finding linkages with economic growth and development}

In view of the persistence of poverty in developing countries, it seems clear that development can only take place when poverty is reduced. Sustained economic growth, creation of job opportunities, and income-transfer programs are considered the main 
ways through which the incidence of poverty can be lowered. As shown in this chapter, the association between poverty dynamics and various demographic factors, including family size, the dependency ratio, and change in age composition, has implications for economic growth and development. For example, a low dependency ratio, associated with a smaller number of children per family as a result of fertility decline, can contribute to economic growth through increased household savings. Domestic saving rates, a necessary condition for investment, have been consistently low in Pakistan. Further declines in the dependency ratio can increase saving rates and contribute to economic growth through investment. Similarly, the negative association between the size of the working-age population and chronic poverty shows the importance of fertility decline for labor market growth: a more active and skilled population is a key resource for economic growth and poverty reduction.

\section{Conclusions and policy recommendations}

The following conclusions can be drawn from the analysis in this chapter.

First, household size increases the risk of remaining in chronic poverty or of moving into or out of poverty. The implication of this relation between household size and poverty dynamics is that larger families are less likely to stay in the desired status of "never poor." Because of demographic pressure, they are more likely to live either in chronic poverty or in transitory poverty.

Second, a high dependency ratio is also associated with long-term (chronic) poverty and transitory poverty. A high dependency ratio, or a higher proportion of younger and elderly persons in relation to persons of working age, is probably associated with lower saving rates. Household resources are mainly used to meet family consumption requirements, leaving little for investment.

Third, the common perception is that if a high proportion of the population is of working age, then households should have a high rate of earnings and savings, improving household well-being. The analysis in this chapter shows that while an increase in the working-age population has a negative association with chronic poverty, it plays no significant role in helping households to escape poverty.

Fourth, the statistical significance of literacy and health expenditure shows that unless efforts are made to improve both the health status and educational level of the poor and vulnerable, their prospects for escaping poverty are dim.

Finally, household assets, particularly landholdings, keep households out of chronic poverty. However, the independent effect of household size and age composition on poverty dynamics shows that despite the importance of assets for household well being, demographic pressures may push many families into poverty and make the movement out of poverty difficult. 
Three recommendations are as follows:

First, Pakistan's fertility decline since the late 1980s has led to declining trends in child dependency and a rise in the working-age population. This is the right time for Pakistan to pursue the small-family norm, particularly in rural areas. This will lead to low dependency ratios, greater household savings, and a reduction in poverty.

Second, Pakistan needs to reap the benefits of the demographic dividend by investing in its younger as well its adult population. The young should be the focus of investments in health, education, and nutrition. Adults and youth should both be targeted for their skill development. Otherwise, a rise in the working-age population will not automatically lead to the desired outcome of socio-economic development and poverty reduction.

Third, asset creation seems to be a necessary condition for poverty reduction, particularly to achieve the status of "never poor." In resource-poor rural households facing demographic pressures, access to micro-credit can play a crucial role in asset creation. 
66 Demographic change in Pakistan requires accelerated employment generation, improved coverage and quality of education and health, and changes in the institutional structure for inclusive growth. 99

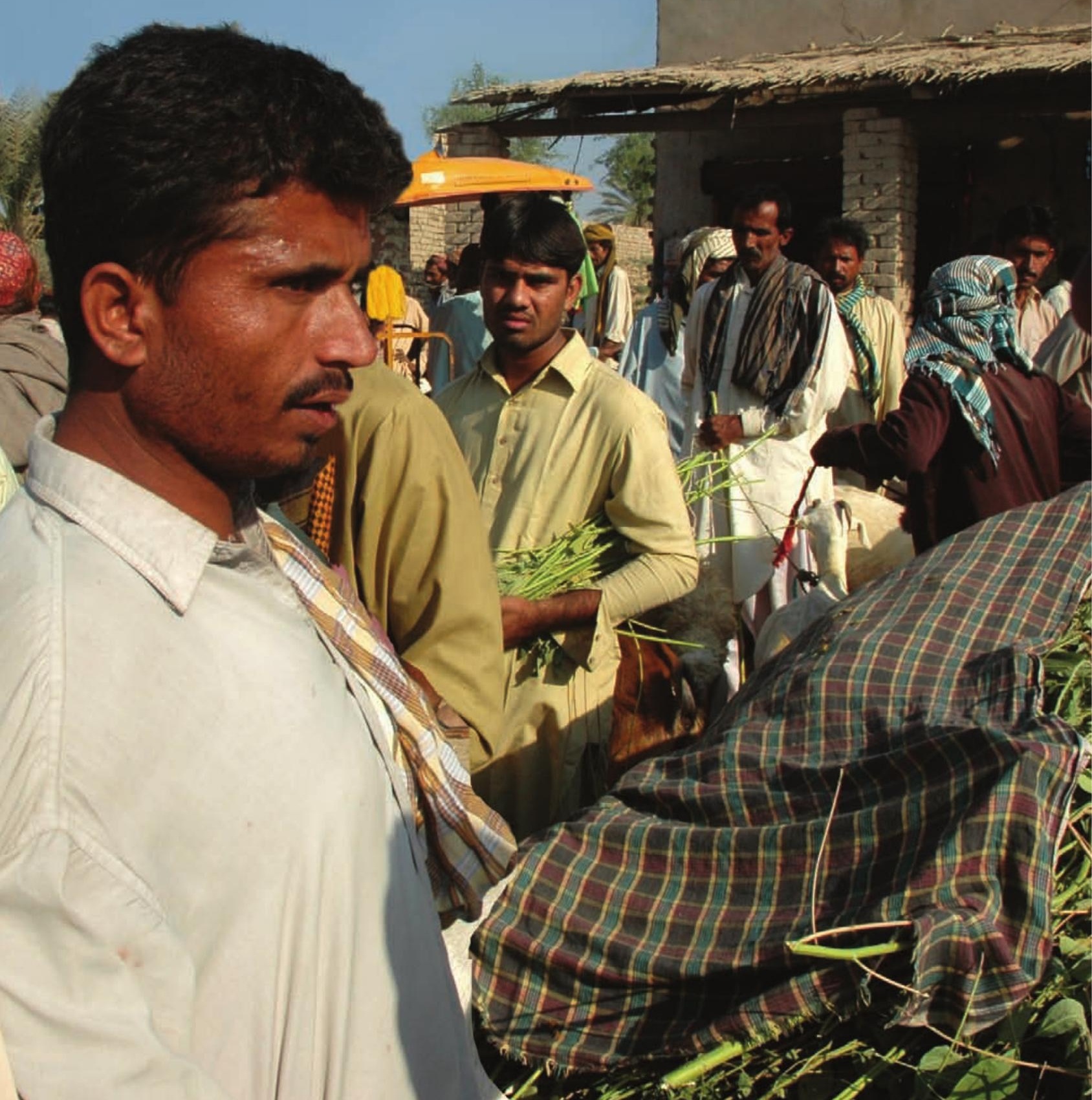




\section{CHAPTER SIX \\ Meeting the Challenge of Demographic Change through Equitable Development}

\section{AKMAL HUSSAIN}

Pakistan is undergoing a demographic transition as fertility rates decline and the percentage of the working-age population increases. If the young population achieves higher levels of education with access to opportunities for investment and high-wage employment, Pakistan can look forward to rapid economic growth. Failure to fully involve youth in the process of economic growth can lead not only to a loss of growth potential but to increased violence in society. Addressing the twin challenges of demography and development will require a change in the institutional structure of economic growth and public policy. This chapter describes the elements of the demographic challenge and identifies the paradigm shift that is required in pursuing growth and reducing poverty. It then addresses the employment challenge, analyzes the sectoral composition of employment, and identifies the institutional changes required to accelerate employment generation. Finally, it outlines some of the major features of a new path to development: a path sustained by realizing the capabilities of an increasingly youthful population. 


\section{The challenge of the demographic transition}

Census data show a change in the age structure of Pakistan's population: the growth rate of the labour force has been faster than the overall population growth rate. Consequently the working-age population (ages 15-64) as a percentage of total population increased from 54 percent in 1998 to 57 percent in 2005. At the same time, the dependency ratio (the population below 15 and over 64 divided by the working-age population) declined from 0.86 to 0.75 . These trends are expected to continue over the next two decades, and the dependency ratio will reach its lowest level by 2030 (GoP 2011b: 26).The falling dependency ratio means more working people taking care of fewer dependents. Therefore it constitutes a window of opportunity for higher economic growth if individuals of working age have access to productive employment. The data suggest that this so-called demographic dividend in Pakistan will last until 2050 when the growth rates of population and the labor force are projected to merge (GoP 2011b).

It has been estimated that over 60 percent of Pakistan's population is below age 30 . The labor force in the age group 15 to 49, estimated at 96 million in 2010, is projected to increase to 181 million by 2050 , while the total labor force is expected to increase from 110 million to 235 million over the same interval. This means that 3.1 million persons, of which 2.1 million will be young, are expected to enter the labor force every year over the next four decades. Unless they are provided with adequate education, health, and livelihoods, this demographic change can have explosive social and political consequences.

\section{Changing the paradigm of economic policy: Growth through equity}

The pattern of economic growth in the past suggests that the structure of Pakistan's GDP growth has three features:

Unsustainable growth. The problem of unsustainable growth is indicated by the fact that relatively high GDP growth has occurred only during periods when large capital inflows were available, and has declined sharply when foreign aid fell. For example, in the 1960s during the military regime of Ayub Khan, large foreign aid flows became available as Pakistan joined the SEATO and CENTO pacts to become part of the US alliance against the Soviet Union. GDP growth reached about 6 percent during this period. In the subsequent period 1973 to 1978, when the government of Prime Minister Z.A. Bhutto adopted a more independent foreign policy, aid fell and so did the GDP growth rate, averaging 4.9 percent annually. in the decade 1978-88 during the regime of General Zia ul Haq, foreign aid inflows increased sharply and GDP growth accelerated to 6.6 percent annually, as the military regime positioned Pakistan to play a front-line role in the American-sponsored 'Jihad' against Soviet troops in Afghanistan. Again during the subsequent democratic interlude 1988-98, foreign aid flows fell sharply and the GDP growth rate declined to an annual average of about 4 percent. In the subsequent Musharraf regime (1998-2008) large foreign aid inflows again became available as Pakistan began to play a key role in the war against terrorism, and GDP growth accelerated sharply to 6.3 percent annually. In the following period of the democratic government (2008-11), GDP growth declined sharply once again to 2.6 percent (Hussain forthcoming b). 
Growth with inequality. Economic growth has been accompanied by increasing income inequality. Burki (2011) estimates that the richest 18,000 members of the population have an average income of US\$72,700 per capita compared to the overall per capita income of US $\$ 1,050$.

Low employment elasticity of growth. The elasticity of GDP growth with respect to employment and poverty reduction is relatively low. The evidence for the period 19992011 shows that the unemployment rate did not fall substantially with higher growth. At the same time, during low-growth years, as those who became unemployed in the formal sector shifted into employment in the informal sector, the overall unemployment rate did not rise substantially. During 1999 to 2001, the unemployment rate remained at about 6 percent, and gradually increased to 8.3 percent in 2004 (Hussain 2008), reaching 10.3 percent in 2011. These figures of course do not include that portion of the underemployed labor force whose length of employment and wage rates are so low that their income is below subsistence levels. If such underemployed persons are included, then the unemployment figure may be substantially higher.

Given the existing structure of growth with low employment elasticity, 5 percent GDP growth has been generating employment for less than 1 million persons per year. At the same time, even after six decades of growth, as much as 40 percent of the population may be below the poverty line. The policy challenge is to substantially reduce poverty and generate employment for the more than 3 million people who on average will be entering the labor force annually over the next four decades. What is required is to: (a) sustain a higher rate of GDP growth of 7 to 8 percent, and (b) enhance the growth elasticity with respect to employment and poverty reduction.

Meeting these strategic objectives requires an inclusive growth paradigm. This involves changing the present institutional structure that generates rents for a small elite by restricting competition and excluding the middle class and the poor from investment and high-wage employment (Hussain forthcoming a). Generating higher and sustained GDP growth with high elasticities for employment and poverty reduction will require institutional changes for inclusive growth. This will involve enabling the middle class and the poor to acquire productive assets and equitable access to credit and markets for goods and services. Specifically such an inclusive growth strategy would include four elements: (i) localized capital accumulation in the micro-enterprise sector through participatory development; (ii) a small and medium farmer strategy for accelerated agriculture growth through the provision of land ownership rights to the landless and institutionalized support for land development and technologies for increasing yields per acre; (iii) an institutional framework for accelerated growth of smalland medium-scale enterprises by increasing their production and exports of high-valueadded products in the light engineering and automotive sectors; (iv) an institutional framework for providing productive assets to the poor through equity stakes in large corporations which are owned by the poor and managed by professionals. These large corporations could be initiated through public-private partnerships in the livestock, milk products, and fisheries sectors (Hussain forthcoming b). 


\section{The employment challenge and achieving employment generation}

\section{Employment and labour productivity}

Given the existing structure of economic growth, the employment-generation capacity relative to the growth of the labour force is unacceptably low. As indicated in the preceding section, the employment elasticity of GDP growth with respect to both employment and poverty reduction is relatively low. While the unemployment rate does not fall significantly during high-growth years, during low-growth years unemployment in the formal sector is accompanied by a shift of the labour force to the low-wage informal sector. Consequently poverty is accentuated even among those employed in the labour force. Because over 91 percent of the labour force is unskilled, a large proportion of those who are employed have such low levels of productivity and wages that they are unable to support their households.

The employment challenge therefore is two-fold: (a) Change the sectoral composition of GDP growth so as to increase the weight in GDP of sectors with high employment elasticities. (b) Create an institutional framework for providing technical training and credit so that employed workers can increase their productivity and hence wage levels, while at the same time a larger percentage of the labour force can achieve productive self-employment.

\section{Employment growth by sector: the actual and the possible}

The evidence on employment growth by sector during the last decade indicates both the challenge and the potential of increased employment generation in the economy. Table 6.1 shows that employment growth rates during the period 2001-02 to 2009-10 for most sectors are quite low. In the case of agriculture the low employment growth rate of

\section{TABLE 6.1 Growth in employment by sector, 2001-02 to 2009-10}

\begin{tabular}{lrrr} 
Sector & $\begin{array}{r}\text { Employment } \\
\text { growth rate (\%) }\end{array}$ & $\begin{array}{r}\text { Value added } \\
\text { growth rate (\%) }\end{array}$ & $\begin{array}{r}\text { Employment } \\
\text { elasticity }\end{array}$ \\
\hline Agriculture & 1.7 & 3.8 & 0.45 \\
Manufacturing and mining & 4.1 & 7.8 & 0.53 \\
Electricity and gas & -0.3 & 3.9 & -0.07 \\
Construction & 2.9 & 4.8 & 0.60 \\
Wholesale and retail trade & 6.5 & 4.8 & 1.35 \\
Transport and communication & 2.5 & 3.9 & 0.64 \\
Finance and insurance & 18.7 & 17.9 & 1.05 \\
Public administration and community services & -2.6 & 6.7 & -0.39 \\
Total & 2.3 & 5.5 & 0.42
\end{tabular}

SOURCES: Labour Force Survey (various years), Federal Bureau of Statistics, Government of Pakistan; Pakistan Economic Survey (various years), Government of Pakistan, Finance Division; State of the Economy: Devolution in Pakistan, Fourth Annual Report 2011, Institute of Public Policy, Beaconhouse National University, Lahore, 2011, Table A-5, page 138. 
1.7 percent suggests the potential for achieving higher employment by accelerating the growth and productivity of the small farm sector (less than 25 acres). At the same time the evidence shows high employment growth in sectors such as finance and insurance (18.7 percent), wholesale and retail trade (6.5 percent), and manufacturing and mining (4.1 percent). Clearly, accelerating employment growth in the future will involve accelerating the growth of these sectors.

Accelerated growth in the manufacturing sector will require provision of adequate electricity, trained personnel, and improved communication infrastructure. The considerable employment potential in the mining sector will require establishing transparent institutional mechanisms for combining foreign and domestic enterprise to utilize the world's largest copper deposits and second-largest gold deposits in Balochistan, as well as the considerable coal deposits in Sindh.

Growth in the services sector, such as wholesale and retail trade, will require an institutional framework for accelerating the growth of entrepreneurship in the burgeoning urban centres of Pakistan. Dr. Nadeem ul Haque, currently Deputy Chairman of the Planning Commission, has identified the potential of domestic commerce in urban Pakistan and outlined the institutional changes that can utilize this potential. Some of the key initiatives in this regard are measures for increased mobility, competition, and innovation amongst wholesalers and promotion of value chains by enabling free entry of both foreign and domestic investment in this sector (GoP 2011b). (Value chains are the various interlinked processes involved in producing goods and services and bringing them to consumers.) In spite of substantial liberalization in the financial sector, the private-sector credit-to-GDP ratio is the lowest amongst emerging economies. Realizing the employment potential of this sector will require further deregulation, reduced government borrowing from commercial banks (to prevent crowding out of the private sector), development of public bond markets, and lower real interest rates (GoP 2011b).

\section{Employment generation through small farms and small- and medium-scale enterprises}

Although most of the burden of employment generation will be borne by the manufacturing and services sectors, agriculture still has a significant potential for employment generation and productivity increase. My earlier estimate of annual employment demand for major crops (plus fodder and pulses) is 1361 million person days. Given crop production cycles whereby farmers are employed for about 200 days per year, this figure translates into an annual employment demand of about 5.4 million persons per year in the crop sector (Hussain 1999). My estimates of employment generation in the crop sector by type of crop and size class of farm suggest that farms below 25 acres are generating more than twice as much employment on average as large farms for all crops. The employment generation by small farms, in the case of HYV, rice is three times higher and for maize five times higher compared to large farms (Hussain 1999: 6).

These estimates suggest that if the yield and output potential of small farms could be realized, a significant increase in crop-sector employment generation could be achieved. The magnitude of this potential can be judged by the fact that 45 percent of 
the employed labour force is engaged in agriculture (GoP 2011a: 161), while the smallfarm sector constitutes 60 percent of the farm area and 94 percent of all farms (Hussain forthcoming b). Using this potential will require a new small-farmer-based agriculture growth strategy in contrast to the elite farmer strategy that has been pursued over the last five decades (Hussain 2008). This strategy would involve: (a) a policy of land to the tiller by providing state-owned land to small tenants in 5-acre packages as well as credit to other small tenants to enable them to purchase ownership rights; (b) institutionalized mechanisms for providing small farmers access to high-quality seeds, fertilizers, and pesticides; (c) access to new agriculture technologies for improving on-farm water management (such as laser-based land leveling and drip irrigation), and production of high-value-added crops (such as tunnel farming and green houses).

Employment generation from the agriculture sector can be substantially increased by accelerating growth of the off-farm sector through (a) livestock development such as meat and milk production, (b) off-farm micro enterprises such as processing and packaging of fruit and honey production, (c) production of local construction material, and (d) Industrial Support Centres (ISCs) located in industrial clusters for the accelerated development of small- and medium-sized manufacturing enterprises in the field of light engineering, such as automotive and electrical parts and products (Hussain 1994).

The ISCs could be initially established through public-private partnerships in the small and medium sized light engineering industry. They would provide the following services to individual entrepreneurs: (a) specialized fabrication facilities such as forging, heat treatment, and surface treatment required for the manufacture of high-value-added products; (b) raw material banks to enable small entrepreneurs to acquire high-quality raw materials which they cannot individually afford to buy in bulk; and (c) technical training in production management, quality control, advanced mill work, and precision welding.

\section{Education and the demographic dividend}

If the aforementioned opportunities associated with the demographic dividend are to be utilized for achieving higher GDP growth and avoiding social unrest, it is necessary to make a substantial increase in the coverage and quality of education.

\section{The present situation and future trends}

The gross primary school enrollment rate in 2010-11 was 92 percent, while the net primary school enrollment rate in the same year was only 56 percent, suggesting a high dropout rate. Secondary school education is essential to prepare girls and boys for vocational, technical, and higher education. Here the situation is dismal. The net secondary school enrollment rate stands at 20 percent overall. Achieving a 100 percent net primary school enrolment rate in the next five years will require both a massive increase in financial allocations and major improvements in the organizational structure for translating the increased allocations into the targeted outcomes. Unless a radical 
change occurs in public-sector resource allocation priorities, this objective is unlikely to be achieved in the foreseeable future. Even more unlikely over the next decade is the achievement of a 100 percent enrollment rate in secondary education, let alone improving quality and relevance of the courses taught. It appears therefore that a significant proportion of the young people entering the labor force will have limited or no education and skills.

Apart from the low enrolment rates, there is a serious problem with respect to both the curricula and the quality of instruction. A World Bank study on education in the Punjab shows that in 1999 only 41 percent of public school students who took the matriculation examination obtained a passing grade. Given that only 16 percent of the 15-to-19-year age group reached the 10th class, the low pass percentage makes the problem of achieving quality and coverage more difficult.

Even more disturbing is the fact that for most of the students who pass the matriculation examination, what they obtain cannot be called education in any meaningful sense. Textbooks in most cases induce a narrowing of the mind, distort history, and inculcate prejudice. The emphasis on rote learning restricts students' spirit of inquiry and constrains their creative imagination (Hussain, Mumtaz, and Arif 2010). Those who pass the intermediate examination by and large have inadequate reading and writing skills and in most cases are not equipped to benefit from higher education even in the small proportion of cases where they gain admission to a university.

Given the poor quality of high school and intermediate-level education, it is not surprising that the majority of the students who enter university in Pakistan are not equipped for advanced studies. This is quite apart from the fact that, with few exceptions, universities in Pakistan do not have the quality of staff and facilities to provide university-level education at an international standard. Therefore university students, in spite of investing a significant amount of their family's financial resources and 2 to 4 years of their lives, in most cases face no intellectual challenge, remain oblivious to the debate and research in their respective fields of study, and do not have the understanding of their subject and the skills necessary to reach even the minimum international standards. Thus most university graduates are unable to obtain high-wage employment, even where it is available.

Present trends suggest that by the year 2030, enrollment rates for the age group 10-14 may increase to a maximum of 55 percent for males and 45 percent for females. This means that the population-education gap will be 37 million for males and 41 million for females over the next two decades. Clearly young people entering the labor force, if they have missed school or failed to complete secondary education, would be unable to earn the income necessary for a middle-class standard of living. The present tendency towards extremism, intolerance, and violence could acquire an explosive potential if the expected 52 million young persons (aged less than 49 years) entering the labor force over the next two decades are poorly educated and incapable of earning a decent living. 


\section{The education for development and democracy programme}

A major initiative is required to reach the scale of coverage and level of quality standards in education that are consistent with establishing the social and economic basis of democracy and development. In this context the following objectives can be specified:

\section{Schools: New institutional mechanisms}

(1) After passage of the $18^{\text {th }}$ Amendment, education is now essentially within the domain of provincial governments. However, provision of education at a high standard is also central to the task of building a better future for the country. Therefore the federal government needs to: (a) facilitate capacity building in the education sector of each province, for resource mobilization, project formulation, monitoring, and implementation; (b) create a forum where the relevant stakeholders at the provincial level can formulate education strategies as part of an inter-provincial process; the forum would also identify financial support requirements from the federal government and foreign donors within development strategies of each province; and (c) decentralize fiscal powers to provinces to permit mobilization of resources for the education programme.

(2) Achieve 100 percent net primary school enrollment rates in the next five years and 100 percent net secondary school enrollment rates within eight years. To achieve these enrollment targets will require coordinated efforts of public, private, and voluntary organizations.

(3) Improve the quality of education in the public and private sectors with the aim of developing the ability for reasoning, critical enquiry, and creative imagination.

(4) To reach these objectives of quality education, undertake measures to: (a) shift emphasis from rote learning to developing the ability for independent thinking based on logic and observation; (b) develop a large cadre of teachers who are trained in modern teaching methods and who can adopt the proposed new approach to learning. This may require teacher training institutes in each division. Such institutes at the provincial level should be adequately funded and staffed by world-class teacher trainers.

(5) A vital element in improving the quality of education is to review the curricula with a view to bringing them in line with international standards. In this regard, it is important to remove distortion of facts and falsification of history. It is equally important to remove indoctrination and bigotry from the curricula. The curricula should enable students to use facts and reasoning to understand the world around them and to objectively analyze historical processes.

(6) An Education Council could be established in each province to facilitate public and private education with a view to maintaining high-quality standards, adequate facilities for students, and safety of buildings. It could also become a resource centre for information on the latest techniques in teaching and educational management, and for IT-based learning which schools in the province could access as required. 


\section{Vocational training for a skilled labor force}

It ought to be a matter of urgent concern for policy makers that roughly 92 percent of the rapidly growing labor force is unskilled. Many of those classified as "skilled" have inadequate skills by international standards. To use the "demographic dividend" for development, it is necessary to rapidly develop a wide range of skills that will be required in a growing and diversified economy. Creating the organizational basis for skill training will also provide access to vocational training centres for high school graduates who are disinclined or unable to enter university.

The Planning Commission in 2009 developed an imaginative programme for creating a market-driven organizational base to develop a skilled labor force. This programme, titled "Investing in People," (GoP 2009b) ought to be implemented to begin developing a skilled labor force that can make use of employment opportunities and provide an inducement for entrepreneurs to invest in a more diversified economy.

\section{Higher education for development}

A university can be defined as a place where new knowledge is produced by the faculties in various disciplines and where students are trained to produce new knowledge. Teachers are expected to develop new perspectives, conduct cutting-edge research in their fields, inspire their students, and impart the necessary training to pursue them. Through university experience, the creative imagination is developed as students are trained to conduct creative work in the arts, humanities, and natural sciences. Such centres of learning influence modes of thought and social action, develop the professionals who drive private enterprise, lay the knowledge base for improved public policy and governance, and become catalysts in the development process. In this sense, most universities in Pakistan do not meet even the minimum international academic standards (Hussain, Mumtaz, and Arif 2010: 86). However, concerted efforts by the Higher Education Commission (HEC) to strengthen the institutional basis for improved teaching and research have led to improvement in a few universities. But there is still much work to be done.

A higher education base needs to be established if the demographic dividend is to be deployed for economic development and the building of a an educated and tolerant society. Towards this objective, it may be helpful to develop selected private and public universities for collaborative teaching and research at international standards. This would require adequate funds drawn from the private sector and the HEC in order to hire university teachers and researchers at internationally competitive salaries and provide research facilities to selected departments in fields relevant to national development. The objectives of such a university network for development (UND) could be to (a) develop world-class graduates and faculty to catalyze knowledge-based economic growth and the development of an enlightened society; (b) conduct research in priority areas of social and natural sciences and history, and make creative contributions to literature and the arts; and (c) establish institutionalized linkages to provide the research input for privatesector development and government policy formulation. The research input from the UND could stimulate the development of industrial products and processes, management systems, and public policy. 


\section{Health and the demographic dividend}

\section{Health and poverty}

My work on the UNDP Pakistan National Human Development Report showed that as many as 60 percent of the sample population of the poor in all four provinces of Pakistan were ill at the time of the interview, and were on average ill for 90 days in the past year (Hussain et al. 2003: 69-71). There is also a high prevalence of ill health in the population as a whole. In rural Pakistan, according to the National Health Survey of Pakistan, 80 percent of women above 45 years of age, and 60 percent of low-income men suffer from poor to fair health (Pakistan Medical Research Council 1998: 109, 129). Our study showed that ill health was a major trigger that pushed people into poverty (Hussain et al. 2003: 70), and the World Health Organization has identified poverty as a major threat to health (Hussain, Mumtaz, and Arif 2010: 67). People are pushed into poverty because the high costs of medical treatment in many cases oblige marginal households to sell whatever assets they have. At the same time, since the poor do not have access to safe drinking water and sanitation and face unhygienic living conditions, they are exposed to a higher risk of disease.

\section{Health problems and inadequate health service delivery}

Some of the health problems needing urgent attention are inadequate sanitation, unsafe drinking water, lack of immunization against polio and measles, and widespread prevalence of communicable diseases such as tuberculosis, hepatitis, and HIV. Moreover, 500,000 new cases of malaria occur annually.

Pakistan faces widespread inadequacy of coverage and quality of health care. This is due both to insufficient public-sector expenditure and to inefficient health care delivery. Although total public-sector expenditure on health has increased significantly in absolute terms, it has actually declined as a percentage of GDP. A large proportion of public-sector health facilities suffer from a severe shortage of competent medical staff, have inadequate diagnostic facilities, lack medicines and in some cases provide spurious medicines which cause the death of patients, lack waste disposal facilities in hospitals, and treat patients under dangerously unhygienic conditions (Hussain, Mumtaz, and Arif 2010: 67).

\section{Major health hazards}

(1) Unhygienic drinking water and unsafe food. One of the most important factors in the widespread prevalence of disease in Pakistan is that most of the population is exposed to unsafe drinking water. The country also lacks an effective institutional mechanism for ensuring health safety standards in the supply of raw food items and cooked food in restaurants, tea shops, and roadside cafes.

(2) Poor sanitation and lack of waste disposal facilities. Inadequate sanitation facilities combined with lack of waste disposal, particularly in hospitals, create a hazardous environment for health for most Pakistanis. 
(3) There is a widespread illegal practice of supplying spurious medicines in Pakistan. They are either substandard counterfeits of well-known brands or are supplied under substitute brand names that are also substandard (Hussain, Mumtaz, and Arif 2010: 77). This fact was tragically manifested in the deaths of hundreds of patients in the Punjab Institute of Cardiology, in Lahore, in January 2012.

\section{Institutional mechanisms for addressing health hazards}

The following institutional initiatives could be undertaken to address the major health hazards indicated above (Hussain, Mumtaz, and Arif 2010: 78-79).

(1) Establish a national food and drug administration in collaboration with provincial governments to establish and maintain safety standards in the supply of raw and cooked food and the provision of medicines. This organization could work in partnership with local governments and community organizations to ensure conformity to specified health standards.

(2) Establish a provincial-level waste disposal authority. This should be done in collaboration with local governments, community organizations, and private waste disposal companies. Waste treatment plants should be established for each locality to enable both safe disposal of waste and its conversion into socially useful products such as fertilizer.

(3) Undertake a national campaign for safe drinking water and sanitation with the support of the federal government. The campaign should mobilize knowledge and technologies for the production of safe drinking water in each locality. Community organizations can collaborate with Union Councils of local government, development NGOs, private-sector firms, and a multilateral donor support group working with provincial governments to provide access to knowledge, technologies, and finance.

\section{Conclusion}

Demographic change in Pakistan requires accelerated employment generation, improved coverage and quality of education and health, and changes in the institutional structure for inclusive growth. If these steps are taken, then the country could be placed on a new trajectory of high economic growth and equity and could become an enlightened society where the young become the architects of a better future. However, if the burgeoning young labor force remains uneducated, unskilled, unemployed, subjected to health hazards, and deprived of access to quality health facilities, then the potential demographic dividend could become a demographic disaster for the country. 


\section{Since women's empowerment is integral to}

all measures of success in population policy and other social policies, women's rights to reproductive health, education, livelihood, mobility, and freedom from violence must be addressed comprehensively. 99

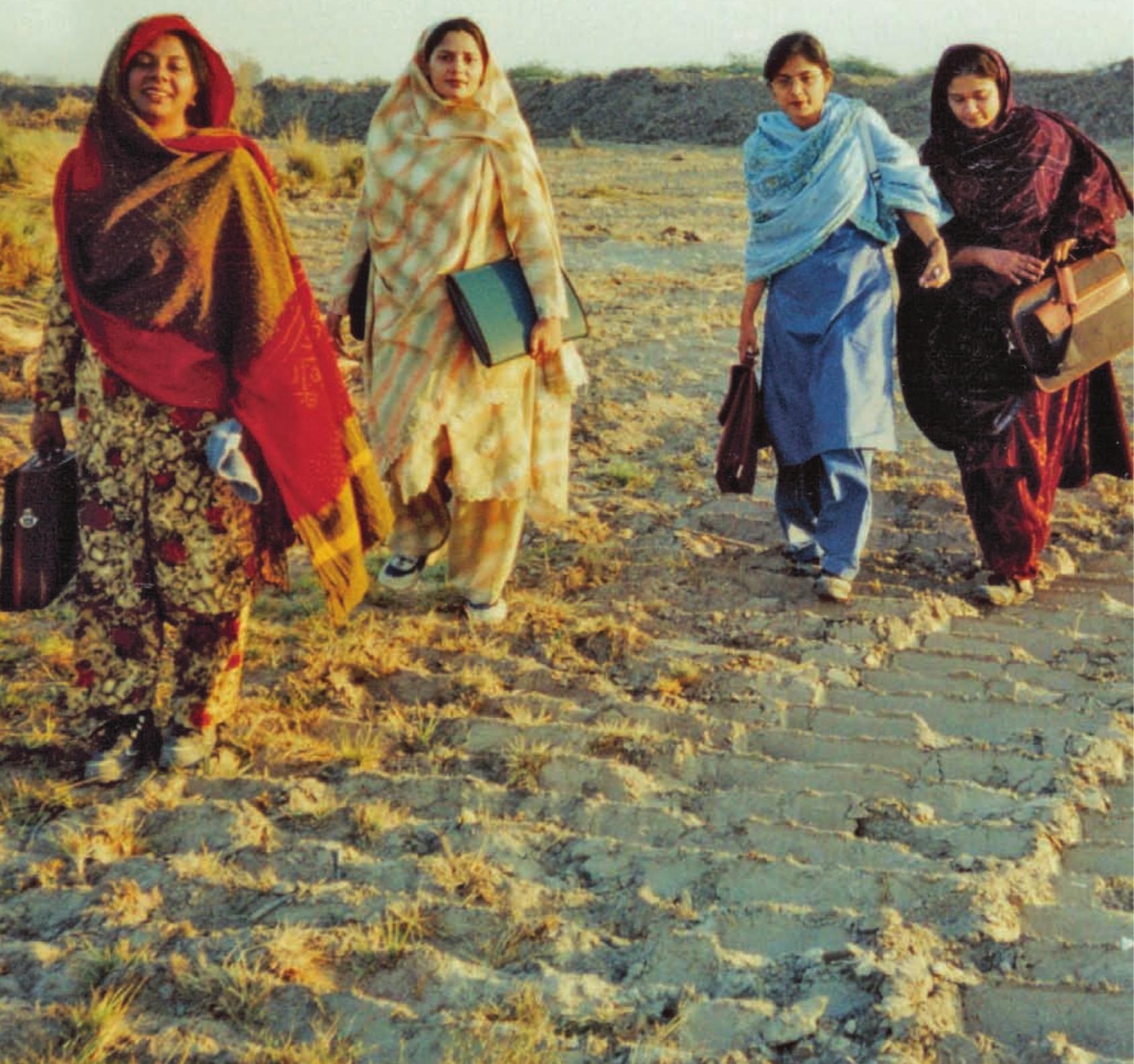




\title{
CHAPTER SEVEN
}

\section{What Hampers Population Policy in Pakistan? The Crossroads of Women's Empowerment and Development Agendas}

\author{
SABA GUL KHATTAK
}

As population trends become salient national and global concerns, the need to influence and control numbers, movement, distribution of resources, and provision of services becomes paramount. Because controlling the number of births encompasses societal trends and patterns within which individual behavior is ensconced, population policies typically focus on creating conditions that induce behavioral change in patterns of reproduction. Therefore, controlling women's bodies in the reproductive context to ensure a balance between resources and population numbers has often been central to population welfare programs.

This chapter asserts that population policy goals alongside an internalized women's empowerment agenda must inform wider social, political, and economic measures. It places both population welfare priorities and women's empowerment issues within the context of social development and maintains that population policy should be strategically conceptualized to achieve holistic outcomes in cohesion with health, education, and labor policies. It also argues that a segmented approach to policymaking across various social, political, and economic spheres results in parallel policy objectives and strategies. Such segmentation forms the base for a dysfunctional interlocking grid that spurs across-the-board development policy failure. Such approaches are endemic to development policy globally. 
This chapter advances two major themes that examine the links between population policy and women's empowerment on the one hand, and the links between population censuses, political constituency demarcation, and resource distribution between provinces and the federal government on the other hand. The first section analyzes population policy objectives in the context of women's empowerment and social development in Pakistan. It underscores the tensions within parallel approaches to achieving social policy goals and women's empowerment. It asserts that population policy in particular and social policies in general at best partially empower women; also, they curb and reverse women's empowerment when they rely upon retrogressive cultural norms in the pursuit of narrow policy objectives.

The second section looks at the linkage of population policy with Pakistan's political and economic policies for resource-sharing and underscores the need for cohesion across a broad spectrum of state policies and guidelines. It discusses population policy objectives vis-à-vis the specific arrangements for resource distribution across provinces, the National Finance Commission (NFC) Award, and the arrangements for political constituency formation in relation to elections and representative government. In doing so, it highlights the propensity for political parties and provincial bureaucracies to vie for more resources and seats in legislative assemblies on the basis of population size. The greater the number, the higher the gains.

The final section discusses the factors that are critical for a successful population policy in Pakistan. It asserts that a successful population policy must have women's empowerment as an intrinsic feature; and that together with women's empowerment, it should be integrated with other social policy goals and with political and economic arrangements that influence demographic trends.

\section{Women's empowerment, population, and social policy tensions in Pakistan: Challenges of pragmatism and justice}

To the question, what ails population policy, this chapter asserts that selective integration of women's empowerment issues in population policy, including the tensions resulting from its reliance upon culture, is an important arena to investigate; in addition, examining linkages with other social policies, especially policies for women, education, health, and labor, also serves to demonstrate the limitation of social policies when they are not integrated to produce holistic results. The main challenge for a cohesive social policy comes from the inability of social policies to overcome issues of insularity. This makes it difficult, if not impossible, to usher in meaningful and just social change associated with balancing resources and population numbers. Worries about a rapidly expanding population and issues of inadequate resources and infrastructure have plagued Pakistan's population policy and planning debates since 1947 . These concerns gained significant attention by the early 1960 s when it became evident that Pakistan was lagging behind other South Asian countries, ${ }^{1}$ whether in the context of literacy rates, average caloric consumption, or availability of and access to health services. Pakistan's Five-Year Plans from 1960 onward have referred to "demographic transition" and over the years have reflected the introduction of different strategies and interventions based on international good practice and local experience of successful approaches to lowering population growth rates. ${ }^{2}$ Analysts continue to debate the possibility of capitalizing on the potential demographic dividend, and they worry about the rapid pace of urbaniza- 
tion, the changing age profile of Pakistanis, the large numbers of women of reproductive age, and the need to curtail population growth rates.

More recently, in trying to achieve its overall objectives, the population policy $(2002)^{3}$ focused on population stabilization through declines in both fertility and mortality. The shortterm goals were to reduce the population growth rate to 1.9 percent per annum by 2004 and reduce fertility through enhanced voluntary contraception to 4 births per woman by the same year. The long-term objectives were to reduce the population growth rate to 1.3 percent by 2020; reduce fertility to the replacement level of 2.1 births per woman by 2020; and achieve universal access to safe family planning methods by 2010. Among the seven areas of policy focus, the first area, "Population mainstreaming in national planning and development program," refers to women's status, though not necessarily empowerment, by stating: "The connectivity of population with poverty, status of women and sustainable development will be established because they are intrinsically interrelated and progress in any component can catalyze improvement in others." Women are mentioned in two other instances as well: in the context of poverty and with regard to their involvement in local management committees for family planning and reproductive health.

The population policy proposed to reduce fertility by giving women reproductive rights through addressing unmet need for contraception, maternal health, and education so that women can make informed decisions about the number of children they wish to have. ${ }^{4}$ However, the answer to the question of who decides women's choice is not straightforward. It is unclear whether it is women themselves, their husbands and extended families, or community norms. The issue of reproduction appears to contain competing discourses for control. In the policy context, community and religion clearly receive significant attention.

Policymakers and donors are only too willing to provide funds to and rely upon the mosque as a critical site for advocating family planning to make it culturally acceptable. There are two ways of looking at culture and its relationship with policy, especially with regard to women. The first posits that since culture often negatively affects women as equal citizens, policy should challenge culture rather than reinforce it. The second position argues that policy needs to respond to local arrangements; policy failure is often ascribed to insensitivity to local culture and traditions. Thus, religion and culture become central features of policy for controlling women's bodies, especially their ability to give birth. "Motivational aspects" are also followed by the government to promote family planning practices by providing the clergy employment in the population program in return for their support. ${ }^{5}$ Although this may buy limited legitimacy for the program, it also indicates that the matter of choice is not for the woman to make, but that sanction for it comes from the community in general and the religious lobby in particular.

The discourse of religion also permeates the education policy (1998-2010), whose aim is to "train better practicing Muslims" based on Islamic teachings and integrate verses from the Holy Quran into primary and middle schools. None of its salient features ${ }^{6}$ addresses women's equality directly, although the policy emphasizes that literacy, enrollment, completion rates, and gender parity indices must improve for women. Education is considered key for reducing the population growth rate, since once women can access information and understand the advantages and disadvantages of particular choices, they can make informed decisions. Although 
some improvements in literacy and completion rates have occurred, women still lag behind in literacy rates (male 69\%, female $45 \%$ in 2011), primary enrollment (male 60\%, female 53\% in 2011), and primary completion rates (male 59\%, female 39\% in 2011). Given this situation, it becomes obvious that a sense of urgency about reducing population growth rates through improving women's educational attainment is missing from Pakistan's education policy.

The lack of integration with health policy (2001) is also problematic At the level of policy formulation, the policy promised "health for all," and gender equity is one of its ten focus areas. However, its implementation is focused almost entirely on reproductive health services to childbearing women and safe motherhood, and on nutrition interventions for women of childbearing age and pregnant women. ${ }^{7}$ The emphasis on women of reproductive age, rather than all women, reconfirms the instrumentalist view propagated by mainstream development economists, who consider people solely in their human resource dimension rather than as citizens with rights. Similarly, the policy claims that, at the community level, family health services provided by lady health workers (LHWs), and employment opportunities for women as LHWs, nurses, and midwives shall be strengthened (doctors and health management cadres are ignored). Furthermore, the health departments are hesitant to take on family planning services as part of their mandate, reinforcing the preference for institutions and policies to retain their insularities.

The inherent inadequacies of various policies produce only partially healthy and partially educated citizens with few employment prospects. Labor policy is primarily concerned with labor productivity, promotion of investment, maximization of employment, and workers' rights. While it is completely oblivious to population policy goals, it displays a limited focus on women through a small section on women's empowerment and gender equity (page 4) that includes gender-responsive data collection, gender equality in the private sector, and minimum and above-minimum wages for women. It states that the government shall "radically improve participation of women in income generation economic activities" (page 11) and further that "women are Pakistan's least utilized human resource. Women's labor force participation depicts a gloomy picture" (page 15). The policy does not include women in its skill development plans nor in manpower export. The policy states that women's labor force participation rates need to increase and that their wages should be equal to or in some cases higher than those of men. However, by omitting mention of women from skill development and manpower export, the subtext indicates that women are seen in their traditional role, whose vulnerability prevents them from accessing employment abroad. Adhering to ideas of the sexual division of labor on the one hand and treating women as workers in their own right on the other hand depicts an inherent tension in labor policy that is also seen in other policies.

Given the above, two sets of views emerge. The first looks at women in their traditional gender roles resulting from sexual division of labor based on cultural and religious precepts; the second, based on mainstream economic policy logic, looks at human beings as vehicles for promoting national economic well-being. Both views suffer from an inbuilt deficiency and limitation vis-à-vis women, and therefore they limit the effectiveness of any social policy. They negate the issue of justice by providing state-centered reasons for social development, completely disregarding the issue of inherent rights that constitute state obligation.

The foregoing discussion demonstrates that different policies target different aspects of women's bodies and lives. For example, education policy targets their minds, population poli- 
cy is concerned with their reproductive system, health policy focuses on their physical bodies and longevity, labor policy explores how to make women more productive contributors to the economy, and welfare policies concentrate on women's roles as mothers and caregivers. Such an approach has the advantage of looking intensively within a particular category by filtering it from others, but it simultaneously prevents a view of the issues in their entirety. Even if most of these policies are put together under the rubric of social policy-a somber challenge for policymakers, as many cannot overcome issues of turf and territoriality-they are still incapable of addressing women's subordination and equality, as the latter requires much more than providing women education, health, choice in reproduction, and employment.

Diverging from instrumentalist mainstream approaches, the National Policy for Development and Empowerment of Women (GoP 2002) represented the first clear-cut policy commitment to gender equality and the social, political, and economic empowerment of all women. It addressed not only education, health, women's work, and poverty but also issues of violence against women, and it proposed increasing women's power in decision making within the family, the community, public institutions, and policy implementation. Most importantly, it spoke of justice for women. Although it was enunciated in 2002, policymakers failed to incorporate it into other social development policies. Such failures come with a cost.

The achievement of population policy objectives depends upon empowering women to take decisions about the number of children they wish to bear. For this to be possible, the policy has to respond to women's empowerment in a holistic manner. Segmented policies always provide fragmented results. Piecemeal solutions-making some progress on one count and losing on another while yet another slips through the cracks-will not deliver empowerment. In fact, empowerment cannot be segmented: one cannot empower the mind but keep the body imprisoned, or empower women socially but not economically. Translated into concrete policy terms, one cannot empower women's hands fully but not their reproductive choices to the same degree, or empower women's minds maximally but curb their mobility for "their own good."

This chapter started with the premise that population numbers are critical for policy planning. The classical Malthusian debate about population outstripping resources spurs policymakers and analysts to renew efforts toward sustainability. The success of population policy is key for the success of other social policies and vice versa. Since women's empowerment is integral to all measures of success in population policy and other social policies, women's rights to reproductive health, education, livelihood, mobility, and freedom from violence must be addressed comprehensively. This means that population policy goals have to be complemented by other social policies that ensure women's autonomy in both the reproductive and productive spheres.

\section{The linkage of population policy with electoral politics and resource distribution}

This section looks at political and economic arrangements that influence the success of population policies. Indeed, social policies cannot consist solely of technocratic solutions for influencing social change, they must also recognize and respond to existing political and economic arrangements that provide incentives or disincentives for population planning. 
This section has two parts: the first discusses the implications of the census in the context of demarcating electoral constituencies based on population numbers; the second discusses the implications of the National Finance Commission Award formula for distribution of resources vis-à-vis incentives for population planning.

\section{Census: The linchpin for development policy and political arrangements}

Census data are vital for policy planning throughout the world. Understanding the rate of population growth and the demographic makeup of the population (e.g., sex, age, rural/ urban, provincial/district/tehsil breakdowns) helps address emerging opportunities and concerns appropriately. This section discusses two political arrangements that influence population targets and outcomes: the close links between the census and democratic/electoral arrangements, and the relationship between the census/population size and resource distribution in the country.

Political arrangements in Pakistan, including electoral constituency demarcation and distribution of resources, are based upon population size. The message at the macro level for political parties and for provinces is that the larger the number of people in their vote-bank and in a province, the greater their chances of winning and gaining resources.

The household census, the basis of population headcount, is overdue as it was last conducted in 1998. Initiated in 2011, it had to be postponed for multiple reasons ranging from resource constraints to political interference in Sindh and Balochistan that would prevent a transparent census. For example, ethnic minorities in both provinces have incentives to manipulate an increase in their numbers, while ethnic majorities have incentives to underrepresent ethnic minorities, especially when elections can be won on the basis of numbers (votes), and new electoral constituencies (seats in the provincial and national assemblies) can be created on the basis of population.

There is general consensus in Pakistan that electoral districts should be compact for reasons of representative government. As a result, new districts are formed when the population of a district reaches a particular size. The delimitation of constituencies is loaded with political interest that can translate into ethnic, regional, and geographical gains for particular groups. The increase in the number of districts in Pakistan's four provinces has meant that more resource allocations would need to be made to the districts, and political representation/total number of seats in the three tiers of government-the local councils and the provincial and national assemblies - would increase. In fact, the number of National Assembly seats increased from 217 to 357 in 2002 when the Election Commission of Pakistan redrew electoral constituencies on the basis of the 1998 census. Once the new census is held, the total number of seats in provincial and national parliaments could increase further. Various political parties, which generally have assured vote-banks in different geographic areas (rural/urban/provincial), would like to see increases in their vote-bank. The census data collection is therefore a highly charged process. Additionally, the politicization of the census jeopardizes development planning. Demarcating electoral districts on the basis of population negates the fundamental objective of population policy as it is a disincentive for population planning.

The census provides the basis for guiding resource allocations; therefore a dated census would not yield appropriate resource distribution and effective policy implementation. The 
current National Finance Commission (NFC) Award, for example, is constrained by the absence of the latest census figures, as the formula for calculating provincial shares is still based upon the 1998 census whereas realities may be significantly different. Aside from provincial breakdowns, rural/urban population ratios, and sex and age profiles, the census also provides a basis for the design and direction of development policy. Population policy goals cannot be strategically targeted if on-the-ground information is skewed, dated, or both.

\section{The NFC Award}

Constitutional arrangements for the distribution of resources among the federal government and the provinces have undergone various changes. Until 1971, resource distribution between the former East Pakistan and West Pakistan was primarily determined on the basis of landmass. However, this arrangement generated a sense of alienation and exploitation across the former East Pakistan, which had a much larger population than that of West Pakistan. The inability of the state to redress this inequitable distribution of resources played a critical role in the secession of East Pakistan in 1971.

Post-1971, the formula for distribution of resources was re-examined. The 1973 Constitution introduced the National Finance Commission Award under Article 160 (1), which changed the formula for resource distribution from landmass to population numbers as the primary criterion for determining the transfer of resources from the federal to provincial governments. Until recently, such a policy created resentment among those provinces with smaller populations, especially Balochistan, whose large landmass and sparse population have prevented equitable development from reaching the people. For example, the per-unit cost of delivery of contraceptives is much higher in Balochistan than in the Punjab owing to the long distances across Balochistan. In addition, there is little incentive for the provincial government to promote family planning programs, as the small population of Balochistan represented a disadvantage in terms of resource distribution.

The demands of the less populous provinces have been accommodated to a limited degree through the 7th NFC Award, valid from 2010 to 2015. This NFC increases the share of the "divisible pool" in favor of provincial governments, with the understanding that the provincial share of revenues will increase from the current level of 56 percent to 57.5 percent during the Award period. Providing greater resources to the provinces would ensure more effective policy implementation.

In addition to the revision of federal and provincial governments' shares, multiple criteria for distribution of resources across provinces were finally introduced. This meant that population size, which had been the sole criterion, would now be accompanied by three other criteria as the basis for distribution of resources. Although population remains the dominant criterion (82\%), the addition of poverty/backwardness $(10.3 \%)$, revenue collection/generation (5\%), and inverse population density (2.7\%) served to appease Sindh, Balochistan, and Khyber-Pukhtunkhwa. Balochistan would now suffer less in terms of resource allocations for having a sparse population and huge landmass - a point that the leadership of the province underscored in terms of an interest in family planning programs.

Changing from a single criterion to multiple criteria is an important shift in policy, as it translates into recognition by the state that low population density should not be a disad- 
vantage for a province. However, the weight assigned to the additional criteria needs to be re-examined. To preserve and maintain their shares, provinces have perverse incentives to continue to have fast-expanding populations in order to secure their NFC Award shares in resources.

Although not usually associated with population policy, the NFC Award and electoral politics act as disincentives for the provincial governments and political forces to effectively implement population planning. Despite the fact that provincial governments now realize that their population has outstripped any public-sector ability to provide service delivery, they also realize that the trend whereby the federal government could monopolize the bulk of resources has been reversed. As such, additional resources at their disposal would also mean that provinces would shoulder responsibility for an increasing number of areas, including population planning programs. The urgency of an expanding population on the one hand, and the apathy of state institutions and scarcity of resources on the other, may generate some degree of readiness within provinces to redress the situation. However, before that can happen, a systematic assessment of the anomalies within policies needs to occur, as different policies provide contradictory signals to stakeholders. In brief, as long as population remains the dominant criterion for resource distribution, provinces will continue to harbor an interest in maintaining their shares and, therefore, incentives for curtailing population growth rates will continue to be ignored or remain ineffective.

\section{Conclusion}

This chapter examined population policy, its relationship to issues of women's empowerment and equality, and the need to align population policy with other social policies. The success of population policy vis-à-vis women's empowerment and development is dependent upon a reconceptualization of state policies which ensures that women's equality is an objective rather than a tool of policy. Instrumentalist logic cannot be effective in the long term. In other words, it is the function of policy to aim for women's equality as a goal, rather than advocating for women's equality as a means of achieving particular policy objectives.

In addition to population policy linkages with the broad agenda of women's empowerment, social development policy in general needs to discard its own segmentation so it can form a cohesive whole that would complement population policy. Until this happens, small changes here or there continue to be insufficient for obtaining effective outcomes in terms of population policy and gender equality. Furthermore, these policies are part of larger societal arrangements that have a symbiotic relationship with state policy. Thus, different social policies such as labor, education, health, and population need to be finely calibrated to avoid failures.

At the practical level, the government needs to establish an institution that examines and coordinates social policy objectives. Such an institution should ensure that population policy priorities inform social policy goals and that policy strategies are translated into projects that are accountable for delivering results. The institution can also track expenditures in terms of value for money as well as quality of social service delivery. For far too long, Pakistan's social-sector priorities and their limited achievements have failed to justify the investments made in various areas. Equally important, such an 
institution needs to be staffed by people with a full understanding of the importance of gender equality and of justice in its multiple contexts. Finally, the institution must have the power to assert its positions vis-à-vis effective policy formulation, coordination, and implementation.

To conclude, the answer to the question, what hampers population policy in Pakistan, is not a simple or straightforward one. This chapter has attempted to go beyond the usual policy prescriptions of investing more in population policy, women's reproductive rights, and greater coverage across the country. It advocates for greater integration and cohesion across all the crosscutting arenas that interact with population policy in one context or another. These include reconceptualizing social policy in a manner that would assimilate social policies together with women's empowerment in its multiple contexts, and move toward larger systemic integration of political and economic arrangements so that the logic of justice permeates social, economic, and political development and informs social policies.

\section{Notes}

1 See, for example, W. Parker Mauldin, "Population and population policy in Pakistan," Marriage and Family Living 25(1): 62-68.

2 For an overview, see Mehtab S. Karim, "Pakistan's demographic scenario, past and present: Population growth and policies, with lessons from Bangladesh and Iran," in Michael Kugelman and Robert M. Hathaway (eds.), Reaping the Dividend: Overcoming Pakistan's Demographic Challenges, 2011, pages 121-144.

3 There is no discussion in this chapter of the draft Population Policy 2010. The policy is shelved as a draft since it could not be approved by the Cabinet owing to passage of the 18th Constitutional Amendment, which shifted major responsibility of population issues to the provinces.

4 Unmet need is around 25 percent, implying that one in four women would like to limit or space the next birth but lacks access to a family planning method. One out of three pregnancies in Pakistan is unplanned; around 900,000 abortions are estimated to take place annually; most of the women resorting to unsafe abortions are 30 years old or above and already have three or more children (Qazi 2011).

5 This stance receives support from external multi- and bilateral donors as well.

6 The areas are: aims and objectives; literacy and non-formal education; elementary, secondary, and higher education; teacher education; information technology; and private-sector education.

7 Progress in achieving health outcomes even for women of reproductive age continues to be below expectation. Maternal mortality ratios (death due to maternal reasons) were at 450/100,000 mothers in 2000 and reduced to 320/100,000 in 2010 (Human Development Reports 2001 and 2011). Similarly, nutrition data (Draft National Nutrition Survey 2011) indicate that 45 percent of women of childbearing age receive less than 80 percent of the recommended daily allowance (RDA) of food, and therefore low-birth-weight babies (40 percent) and stunting among children under five years of age persist. 
66 New population policies must be broad based, emphasizing an inter-sectoral approach to lower fertility and harnessing the potential of a youthful population. 99

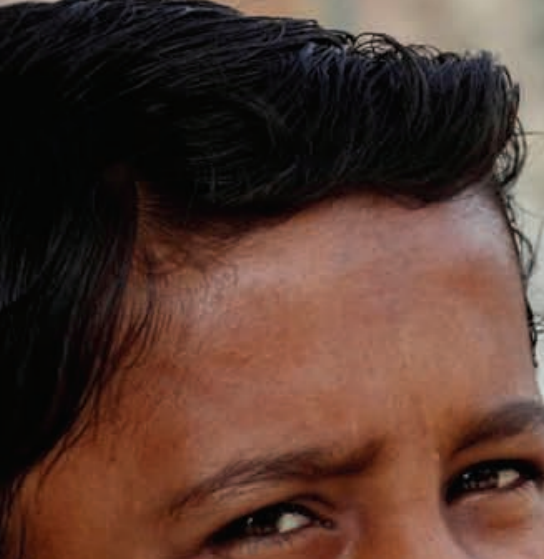

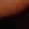

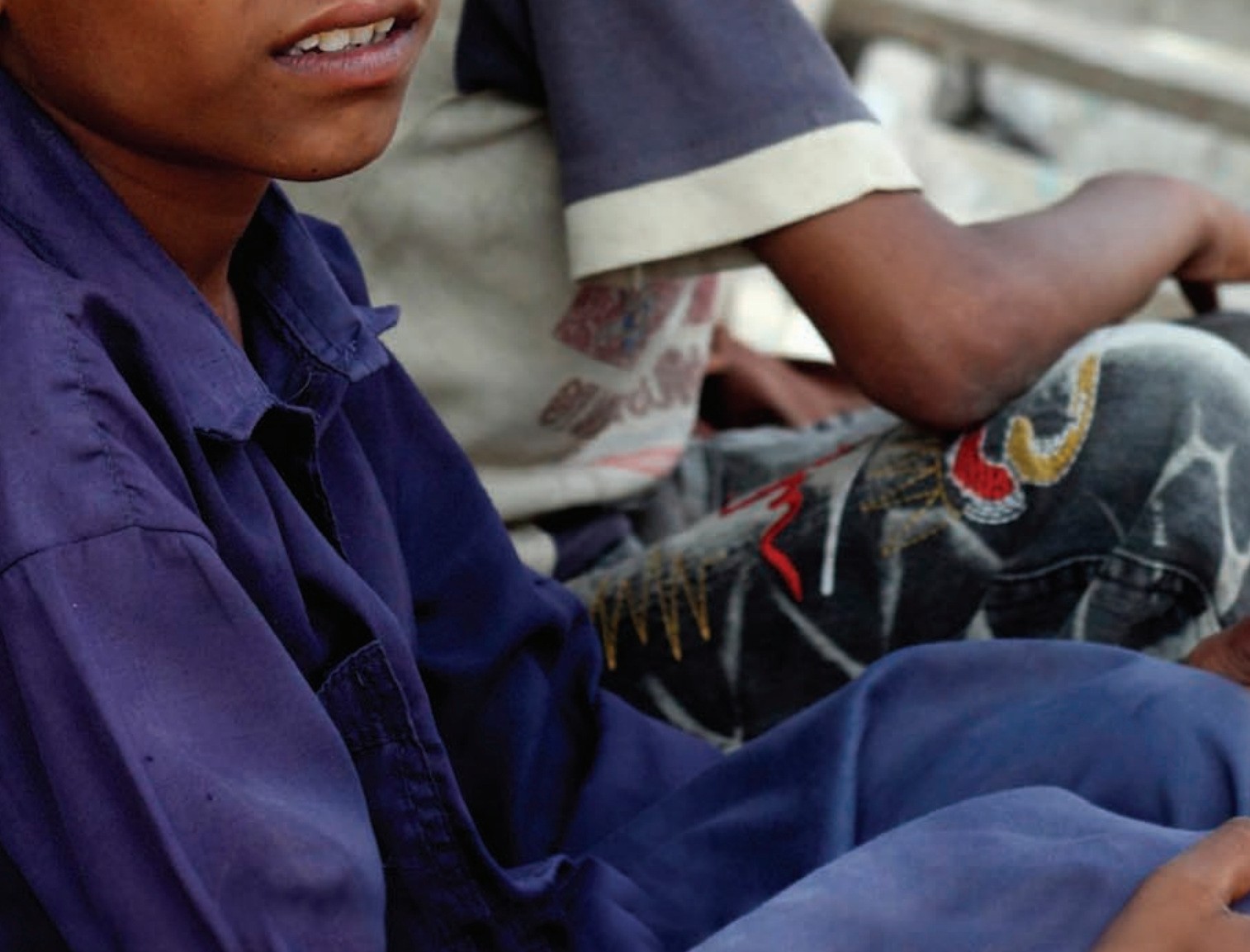




\section{CHAPTER EIGHT \\ Policies for Capturing the Demographic Dividend in Pakistan}

\section{JOHN BONGAARTS, ALI MOHAMMAD MIR, and ARSHAD MAHMOOD}

Immediately after the creation of Pakistan in 1947, the new government realized that a rapidly growing population would impede development by creating an imbalance between people and resources. The first five-year plan of Pakistan (1955-60) earmarked funds for supporting family planning through the non-governmental sector. In 1965 the government initiated an autonomous national family planning program. The key concern then was that economic gains from industrialization would be diluted by a rapidly growing population. Reducing this growth by curtailing fertility was an implicit policy pursued by successive governments. Political commitment and resources were scarce, however, in part because Pakistan lacked an explicit policy with a clear articulation of the linkage between population dynamics and people's well-being and a persuasive explanation of the rationale for family planning.

In 2002, nearly four decades after the launch of the family planning program, the government announced a population policy which articulated a goal of achieving 
population stabilization by 2020 . The policy emphasized individual rights and provision of accessible and better-quality services to meet the needs of individuals. After the limited statements of earlier plans, Pakistan finally had a policy that followed principles articulated at the 1994 International Conference on Population and Development held in Cairo. The policy was beset with a number of inherent weaknesses, however. For instance, while it mentioned collaboration between ministries as a prerequisite for achieving the overall goals, it did not elaborate how these linkages were to be formed. Furthermore, the ambitious targets set out in the policy to achieve social and economic gains by curbing population growth remained unachievable in the planned time frame. Toward the end of 2009 the need to develop a new population policy was strongly felt.

The National Population Policy of 2010 was developed but remained in draft form as of 2012, owing to the disbandment of the Ministry of Population Welfare after the 18th Constitutional amendment. The delay in drafting a new policy allows for a realignment of the strategy for achieving universal access to family planning services and related objectives. The 2010 policy focused on repositioning family planning as a health intervention, emphasizing the critical role of birth spacing in saving mothers' lives and increasing child survival. Priority was given to improving access to family planning services by consolidating and upgrading service outlets of all major stakeholders and by increasing provision of services to those who need them most. The policy mentions improving the status of women as a means to lower poverty and achieve sustainable development, yet it is silent as to how women will be empowered to enhance their status and social standing.

\section{Current policy imperatives for Pakistan}

There is currently a clear opportunity to broaden the canvas on which the new national and provincial policies are framed. Post-devolution, the provinces are developing their own policies reflecting local priorities and realities. Once it is completed and approved, the National Population Policy will provide guidance to provincial policymakers.

The new policy will need to have short-, medium-, and long-term goals and expand its scope to encompass broad development goals. Progress, prosperity, and well-being cannot be attained with a one-dimensional focus on fertility reduction alone. The policy must emphasize the need for close collaboration between the health and population sectors in providing services; for the education sector to support and benefit from population-sector goals; and above all for interventions to boost the economy. It must focus on the factors influencing fertility, such as improving the status of women, reducing maternal and infant mortality, enhancing access to family planning services, and changing societal fertility behaviors and norms. The policy must further reconsider procedures for distributing federal financial resources among the provinces. The provincial shares are now linked to population figures. The aim should be to prevent provinces from exaggerating population sizes by manipulating census results to enhance federal funding.

In short, for the new policy to succeed, it must be based on a well-articulated vision and on well-conceived goals, objectives, and strategies incorporated into an implementation plan that translates the vision into reality. To ensure that the policy reflects people's 
aspirations, policy development must have a bottom-up approach facilitated through community dialogues. The process must also be evidence-driven, based on an objective assessment of what has and has not worked in the past both nationally and internationally.

Finally, the policy must be supported by strong political commitment and have popular support and endorsement of all key stakeholders, including politicians, religious groups, women's groups, civil society, and NGO representatives.

\section{New directions}

In this section we highlight the two major strategies that are essential components of any future population policy: 1) strengthen family planning programs to expedite the fertility transition by reducing unwanted pregnancies, enhancing access to high-quality family planning services, and using the extensive health infrastructure for the delivery of family planning services and outreach; 2) invest in human capital development to ensure that the increasing numbers in the work force are suitably educated and skilled, thus allowing maximum realization of the demographic dividend.

These strategic goals must be framed in the context of women's empowerment and social development in Pakistan. The family planning program should assist women in achieving their reproductive goals through strictly voluntary means. By reducing unplanned pregnancies, the program also improves the health of women and children and increases standards of living of women and their families. Further, investments in schooling should emphasize girls' education, which will improve the status of women in their families and communities and will enable them to take advantage of employment opportunities.

\section{Strengthening family planning programs to expedite the fertility transition}

Family planning programs aim to fulfil the demand for contraception by providing access to a range of birth control methods. In addition, they provide information about methods and their benefits through IEC programs that reduce obstacles to contraceptive use.

Persuasive evidence that unfulfilled demand for contraception is substantial and that family planning programs can reduce it comes from successful programs in many countries over the past 40 years. The most decisive evidence is found in actual field experiments, such as the one undertaken in the Matlab district of Bangladesh. In 1977, the study divided Matlab's population of 173,000 into experimental and control areas of roughly equal size. The control area received the same limited family planning services as the rest of the country, whereas in the experimental area, high-quality family planning services were provided aimed at reducing the costs of using contraception (monetary, social, psychological, and health). The intervention provided free services and supplies of a range of methods (pills, condoms, injectables, intrauterine devices, and sterilization), home visits by educated and well-trained female family planning workers, regular follow-up to address any health concerns, comprehensive multimedia communication, and menstrual regulation services (a simple medical procedure that extracts the uterine contents shortly after a missed menstrual period). Outreach to husbands, village lead- 
ers, and religious leaders addressed potential social and familial objections from men (Cleland et al. 1994).

The impact of the new services was large and immediate. Contraceptive use rose from 5 percent to 33 percent among women in the experimental area. As a result, fertility declined more rapidly in that area, and a difference of about 1.5 births per woman was maintained through the 1980s until services in the rest of the country were also improved. The Matlab experiment demonstrated that family planning programs can succeed even in highly traditional societies. The lessons from Matlab were used to strengthen the national family planning program of Bangladesh, and application of those lessons is one of the main reasons why fertility declined more rapidly in Bangladesh than in Pakistan (see Figure 8.1).

In Pakistan, the family planning program did not have a significant impact on lowering fertility until the 1990s, largely owing to lack of access to services for a majority of the population (Rukanuddin and Hardee-Cleveland 1992) as well as a lack of demand for smaller families. According to Rosen and Conly (1996) family welfare centers at the time were accessible to only 10 percent of the population. The fall in fertility that occurred during the 1990s was mainly the result of a rise in the demand for smaller families, as well as a reduction in the social, psychic, and cultural costs of contraception (Sathar and Casterline 1998). New efforts were also made to reach rural communities through programs such as the Village Based Family Planning Workers Scheme and the Prime Minister's Program for Family Planning and Primary Health Care. The latter was an ambitious program employing initially nearly 30,000 lady health workers. Around the same time, social marketing programs made their debut

\section{FIGURE 8.1 Total fertility rates for Bangladesh and Pakistan}

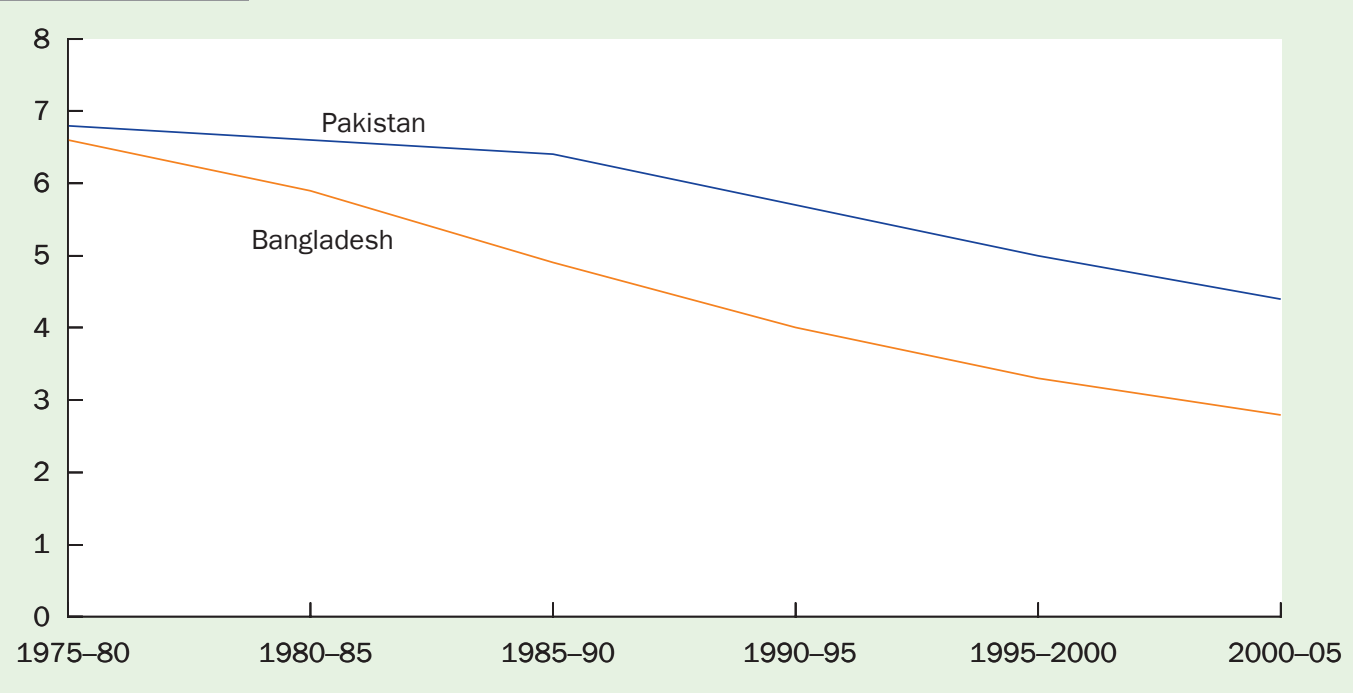

SOURCE: Bongaarts (2011), page 39. 
in Pakistan. It is reasonable to attribute the onset of the fertility decline in the 1990s to these interventions.

In 2007, however, the Pakistan Demographic and Health Survey found that the speed of the fertility decline had slackened and contraceptive prevalence was stagnating. Nearly a quarter of women of reproductive age had an unmet need for contraception. Clearly the high demand for family planning services was not being met, primarily because of the uneven and unsustained impact of the various interventions underway in the country. In particular, the Village Based Family Planning Workers Scheme had been disbanded and the workers were subsumed in the LHW program. Although social marketing activities continued, they remained focused within urban centers, having failed to make inroads into rural areas.

As late as 2006, the provision of family planning services was seen as the sole responsibility of the Population Welfare Department. ${ }^{1}$ In the past the health sector, with its large network of some 13,000 facilities (as compared to the 3,000 facilities of the Population Welfare Department), was not involved in delivering services. This represented an opportunity lost and an inherent weakness of the family planning program. But change is underway. There is now increasing recognition that the Departments of Health and Population Welfare have to collaborate more closely. At the London Family Planning Summit in July 2012, Pakistan made a new national commitment to raise contraceptive prevalence to 55 percent by 2020. This goal is based on clear evidence of a high level of unmet need for contraception, which makes this change possible in a period of eight years, provided the effort is well funded.

A persuasive demonstration of the potential for successful implementation of family planning services in Pakistan is provided by the Family Advancement for Life and Health (FALAH) project recently implemented by the Population Council. The project aimed at improving access to family planning services and lowering unmet need in 20 mostly rural districts of the country, covering nearly 20 percent of Pakistan's population. ${ }^{2}$ Much like Matlab, the intervention has shown that change in fertility intentions and behaviors of the magnitude achieved in Bangladesh is possible in rural Pakistan.

The project, described as a "game changer" for Pakistan by key policy makers, succeeded in meeting the rising demand for family planning in its project districts in the four major provinces of the country (Capps et al. 2012). Its success can be attributed to improving communication and quality of service delivery in family planning. Unlike in the past the project did not focus its messages on limiting family size, because this was often seen by couples as an infringement of their decision-making authority. Instead, the emphasis was on introducing the concept of birth spacing - an intervention that helps save maternal and child lives and improves family well-being. The project sought to enhance the social acceptability of birth spacing by engaging with policy makers and religious leaders and with men and women at the community level through interpersonal communication.

At the same time, the project increased women's access to services and improved the quality of care offered by the public health system. Providers were trained in offering family planning services to ensure higher acceptance and continuation rates of modern 
contraceptives. Enhancing the capacity of the community-based lady health workers was at the core of these efforts (Oxford Policy Management 2009). Behavioral change training of LHWs and clinic staff improved their communication skills and made them proficient in using the client-centered tools developed by the Population Council for enabling providers to assess and meet clients' reproductive health needs. The training also included updates on contraceptive technology and a component on Islam and family planning. Nearly 14,000 LHWs and 6,000 male and female providers were trained in this client-centered approach. A third-party evaluation found that the frequency and quality of household visits by LHWs increased significantly. The public health facilities where trained providers were available attracted almost 60 percent more clients compared to facilities with untrained providers. A statistical analysis of the evidence demonstrated that household visits by LHWs were the crucial element in influencing clients' family-size preference, husband's approval of family planning, and current use of and future intention to use contraceptive methods (Mahmood 2012).

This approach was successful largely because unmet need was already high and the strengthened facilities were able to meet this need. A comparison of the baseline and endline surveys carried out to evaluate FALAH revealed that contraceptive use had increased from 29.0 percent to 37.5 percent, an 8.5-percentage-point increase overall, and by 9.1 percentage points in rural areas in the project districts. Unmet need for birth spacing fell from 14.2 percent in the baseline to 10.8 percent in a matter of four years. FALAH has demonstrated that, as in Bangladesh earlier, family planning use rises once obstacles to use are reduced by giving couples appropriate information, by bringing services to their doorstep, and by equipping referral facilities to meet clients' needs.

Any program-induced fertility decline changes the future trajectory of population growth and the population age structure. As noted in Chapter 2, even a small change in fertility can have a large impact on future population size. According to the standard (medium variant) UN projection, the population of Pakistan will grow from 174 million to 302 million between 2010 and 2050. This projection is based on the assumption that fertility will continue its fairly rapid decline over the next few decades. The projection also implicitly assumes some strengthening of the Pakistan's current family planning program.

If no further investment in family planning is made, however, the fertility trajectory could easily be a half a birth higher. In that case Pakistan's population would reach 342 million in 2050. On the other hand, if a strong new investment in family planning is made, the future fertility trajectory could easily be a half birth below the medium variant, or a population of just 266 million by 2050. In short, the difference between a weak and a strong program scenario is 76 million Pakistanis by 2050 .

\section{Invest in human capital development}

Strengthening Pakistan's education policies is imperative for a host of reasons, including their impact on some critical population outcomes. Given the extensive literature on education policy and how to implement needed changes, here we simply identify three critical population-education interlinkages. 


\section{Higher education leads to lower fertility.}

The preceding section focused on the role of family planning programs in reducing unmet need for contraception and unwanted fertility. But it is important to remember that even if unwanted fertility could be eliminated, overall fertility would remain quite high in Pakistan because many individuals and couples continue to want and have large families. The reasons include fears of infant and child mortality and the need for children to support parents in family enterprises and in old age. Countries in which wanted fertility is high will need declines in preferences to complete their fertility transition to the replacement level. Such declines usually occur with improvements in socioeconomic conditions as rising levels of income, education, and urbanization reduce the benefits and increase the costs of childbearing. Evidence indicates that desired fertility is most responsive to improvements in human development, in particular in female education and child survival (Caldwell 1980; Jejeebhoy 1995; Sen 1999). This conclusion is further supported by the fact that low fertility has been achieved in some very poor societies such as Sri Lanka and the state of Kerala in India. Although poor, these populations have high levels of literacy and female empowerment and low levels of infant and child mortality.

As shown in Chapter 3, education of girls is a powerful driver of fertility decline and reduces both wanted and unwanted fertility. Educated women have below-average desired family size (in part because the opportunity costs of childbearing are higher for these women). Educated women are also more capable of overcoming obstacles to use of family planning and thus have lower unwanted fertility (Jejeebhoy 1995; Lutz 2009).

We emphasize that family planning programs not only address the existing unmet need but also raise demand for contraception and reduce desired family size. Countries with strong family planning programs typically have lower wanted fertility than countries with weak programs. For example, wanted fertility in Pakistan is 3.2 births per woman, compared with 1.8 births per woman in Bangladesh. Among the reasons for this effect on fertility preferences is that programs often have communication campaigns that extol the benefits of smaller families (Bongaarts 2011).

\section{Education reduces population momentum by delaying childbearing.}

Pakistan's very young age structure is the cause of large population momentum. The population age structure cannot be changed directly, but one option to offset momentum has received little attention in past policy debates. Further reductions in population growth can be achieved by raising the average age at which women begin childbearing (by delaying the first birth) and through wider spacing between births. For example, increasing the average age at childbearing by five years could reduce future population size by $15-20$ percent. Of course, this would be a formidable ask since the mean age at marriage is already quite high in Pakistan, in particular among women with higher levels of education. However, it is likely that as female education levels rise in the general population, the average age of first birth will increase.

The longer girls stay in school, the later they marry and the more influence they will exert in a marriage to delay or space childbearing. Young women in Pakistan often 
have little choice about when or whom to marry, and whether to defer childbearing. An early onset of fertility and the close spacing of births present health risks to girls and young women, limiting their education and livelihood prospects. Delaying the onset of childbearing by keeping girls in school longer will therefore not only reduce population growth, it will also significantly improve personal well-being and the quality of family life, especially for women. One approach to encourage parents to send their children to school is through incentives such as issuance of national identity cards or passports only upon proof of completion of secondary education.

\section{Education is necessary to take advantage of the demographic dividend.}

Fertility decline is a precondition for the demographic dividend, but to realize the economic boost from a changing age structure, the labor force has to be well trained and widely employed. Pakistan is experiencing rapidly growing demand for education which is pervasive across income class and among both males and females. It has been further amplified by the wide reach of the mass media, including social media and the internet. As noted in Chapter 4 there is a great need to facilitate the entry of young people, especially young women, into the job market and to secure and retain their employment in both the formal and informal sectors. Pro-employment industries should be encouraged, and strategies will have to be quickly devised to extend incentives. For promoting women's employment more generally, Chapter 4 suggests that within the public sector, jobs may be reserved for females. Another approach is the creation of employment opportunities, especially for women, in the hospitality, hotel, and garment industries.

For girls, who cannot leave their homes, microcredit schemes could be launched along with short-term training in entrepreneurial skill development. At the same time, the attitudes of employers need to be changed to avoid gender-based discrimination against women. Standing committees of the national and provincial assemblies, the National Commission on the Status of Women, and similar groups must become involved in facilitating the creation of women-friendly work environments.

\section{Conclusions}

To capture the demographic dividend, Pakistan needs new policy directions. An economic turnaround and a doubling of economic growth are prerequisites to increasing employment opportunities so as to take advantage of the demographic expansion of the working-age population. Ensuring a rapid fertility transition by strengthening the quality of family planning programs is another necessary condition, but a policy intended to achieve long-term reduction in population growth has to broaden its scope to include intersectoral issues. The two most closely related sectors are gender and education: girls and women must be the focus of attention because gender inequities will hamper progress in education and employment. Finally, population policy is dependent on improvements in the education system, because success or failure in education and the creation of favorable demographic trends are intertwined with prospects of a dividend. 


\section{Notes}

1 Annual Plan 2007-08, Planning Commission, Government of Pakistan.

2 Through sustained advocacy, the Department of Health came to realize the centrality of lowering fertility in influencing health outcomes. Nearly 25,000 health professionals were trained in proactively providing client-centered family planning services. With contraceptive availability ensured and trained staff available, district-level health systems began to offer family planning/birth spacing services. FALAH's advocacy efforts prompted the Prime Minister in 2011 to make the provision of birth spacing services at all health facilities mandatory. 


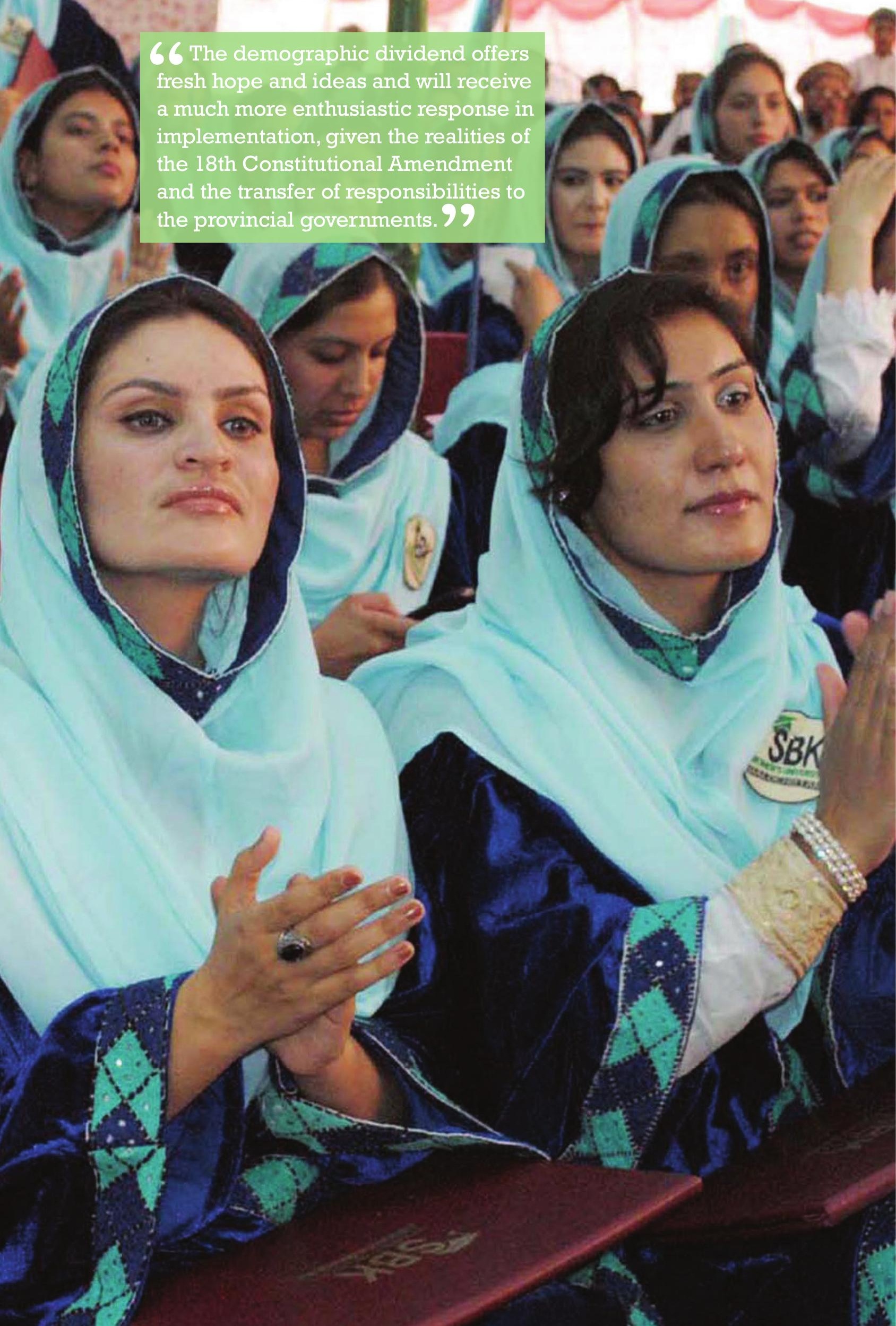




\title{
CHAPTER NINE \\ Conclusions
}

\author{
ZEBA A. SATHAR AND RABBI ROYAN
}

Pakistan's current phase in the demographic transition presents some stark challenges for the country's future. This volume presents evidence to support the need to reformulate the country's population policy. Given the failure to achieve progress in reducing population growth and improve social and economic well-being (Sathar and Miller 2012), this new approach of using the demographic dividend offers fresh hope and ideas, and will receive a much more enthusiastic response in implementation. Given the realities of the Constitutional Amendment and the transfer of responsibilities directly to the provincial governments, a national population policy is less relevant now than it was in 2010. In light of past weaknesses of population policy, there is a strong case for a policy that takes a broader approach to population issues.

In this final chapter we outline a population and development policy that builds on the draft 2010 Population Policy. The new policy, we argue, must take into account the linkages across several sectors of government, and it should form the umbrella under which provincial policies are framed. This is effectively a call for investing in human de- 
velopment that has lagged so far behind in Pakistan. Population is the centerpiece while the spokes of the wheel are health, education, employment, gender, and youth policies.

The population and development policy dialogue must make clear that the potential effects of the demographic dividend, even once fertility begins to falls more rapidly, are not automatic. The fact that countries in East Asia and elsewhere experienced the dividend does not guarantee other countries will follow suit (Bloom and Canning 2004). We present major recommendations for capturing the demographic dividend in Pakistan that involve six major sectors: population; health; education; employment and labor; youth, women, and development; and economic growth.

Developing population policies at the province level will be all the more challenging because each province must now highlight its own priorities. This volume and its recommendations can be used as a springboard for the discussion that must precede the framing of population policies in the provinces.

\section{Population}

Given the lack of a Population and Housing Census since 1998, future population-driven scenarios are based on the population projections presented in this volume. According to these projections, the population in 2050 may reach as high as 395 million if no further fertility decline occurs, and as low as 266 million if fertility decline is more rapid. In this regard, a strong family planning program is essential for achieving a more rapid fertility decline and for capturing the benefits of a demographic dividend. At the London Family Planning Summit in July 2012, Pakistan set a target for raising its current contraceptive prevalence rate of about 30 percent to 55 percent by 2020 and reducing its total fertility rate from 3.6 to 2.6 by 2020 and achieving replacement fertility by 2045 .

The starting point for a new population policy will be to emphasize the high levels of unmet need for family planning services. Satisfying unmet demand through full access to quality services would considerably increase contraceptive prevalence. While clearly ambitious in view of stagnation in the impact of family planning programs in the last decade, this is an achievable objective based on comparisons with other countries of the region, and on national programs that have succeeded in raising prevalence in a short period of time. This volume points out recent demonstrations of a rapid increase in family planning use in response to improvements in public-sector service delivery quality and performance.

No obstacles should prevent Pakistan from doubling its contraceptive prevalence rate, even in rural areas and among the poor and uneducated (Mahmood 2012). As a start, the new population and development policy has to be framed in terms of meeting unmet need and encouraging birth spacing for the purpose of improving the health of mothers and children rather than for achieving demographic targets. This approach is consistent with the ICPD Programme of Action. Two sectors will have to contribute most immediately: population and health. Post-18th Amendment, these two sectors fall entirely within the responsibility of the provinces. Provincial programs will therefore have to revise their objectives and increase their efforts to achieve the desired results. The provinces 
will also have primary responsibility for ensuring coordination and monitoring of trends to track progress on policy implementation. This will require improved population data on fertility and contraceptive prevalence trends, including urban and rural breakdowns. Household surveys to measure changes in essential demographic behaviors will have to be conducted. The newly formed provincial branches of the Pakistan Bureau of Statistics will have to coordinate this effort alongside the development of vital statistics systems.

\section{Health}

The Federal Government will collaborate with the provinces to coordinate implementation of the Prime Minister's directive in 2011 asking for the provision of birth spacing services at all health facilities. To achieve the objectives set at the London Summit, the health sector will have to take full responsibility for providing 100 percent coverage of family planning services. The main advantage of having the health sector do so is that its larger infrastructure and its wider reach can deliver family planning services much more effectively than Population Welfare departments. The health sector's greatest shortcoming is that it has yet to make family planning a priority. It will do so only if there is greater functional integration between health and population welfare services.

The health sector in general and the health departments in particular must recognize the close connections between family planning levels and use and improved maternal and child health. Only this recognition and associated monitoring of performance in the achievement of increases in family planning will motivate the health sector to fulfill its potential. In particular, the health departments will require that designated female staff be trained and equipped to provide family planning services. Such training is now readily available through the Regional Training Institutes. Some master trainers have also been trained through FALAH and other projects. A systematic assessment of training needs is required to fill gaps in the health outlets. Service provision is also contingent upon the uninterrupted availability of a range of contraceptive choices. While significant improvements have been made in the contraceptive supply chain through the DELIVER project, stock outs still occur at health facilities and ultimately the health department may have to develop its own systems of procurement and supply.

The 90,000 lady health workers whose mandate is to deliver family planning and primary health care will have to prioritize family planning, which over time has fallen as a priority in their long list of duties. LHWs are the first point of contact and referral for the communities they serve. They must be given the training and supplies needed to increase family planning use. This includes provision and use of communication materials, contraceptive updates, and above all an updated list of facilities in the public and private sector that provide family planning by method of choice, so that they can refer clients appropriately.

Improved access to family planning will have to include greater access to services in the private sector. Partnerships between public and private-sector services are essential to ensure full access to family planning, including vouchers schemes, cross-referrals, and contracting-out mechanisms. While there is increased reliance on the private sector for 
reproductive health needs, private-sector facilities, including Greenstar, Marie Stopes, and FPAP clinics, may not be optimally located to meet the needs of rural and poor communities. Quality of private-sector services is quite uneven, and costs are certainly higher except in very low-level services where standards may be compromised. A minimal standard package for family planning services needs to be established. Once accepted, these standards should be enforced through improved regulatory mechanisms.

\section{Education}

The strongest policy imperative identified in this volume is the urgency of having all children enrolled in school by 2020 or preferably even earlier. According to the recent five-year trend of net primary enrollments, it will take around 13 more years (from 2010 onward) to achieve universal primary enrollment. At this pace, at least 35 years would be needed to achieve 100 percent enrollment rates at the secondary school level. The level of effort to ensure that all children attend school has to increase at least fivefold to achieve universal primary enrollment and 60 percent secondary level enrollment by 2020 . The net enrollment rate will have to rise by 4 percent per annum at the primary level and slightly more at the secondary level. The provision of education of requisite standards is not only in the interest of provincial development, it is also central to the task of building a better future for the country as a whole.

Each province will be required to introduce specific measures to improve its educational enrollments, especially those of poor households and rural areas and of girls who lag behind. Efforts to improve education are linked not just to the need for additional schools and teachers but to a focus on inequalities and the groups left behind. It is important to point out areas where special efforts are required. This would require a concerted effort from the education sectors to ensure that all parents are compelled to send their children to school, that schools achieve a particular standard of quality (Zaidi et al. 2012), that their location is accessible, and above all that all out-of-school children are targeted. In short, both quality of education and access have to be improved.

\section{Employment and economic growth}

A robust pace of growth in employment can be a consequence of the demographic dividend in Pakistan. The dividend is based on the bonus of having lower dependency ratios and higher numbers in the labor force, with some independent effect on savings and consumption. Perhaps the most basic question asked throughout the volume is whether Pakistan's economy is ready to capture the demographic dividend. It was pointed out that the country's working-age population is increasing at 3.2 percent per annum. But the economy needs to grow at a rate above 6 percent in order to absorb these potential entrants into the labor force. By 2030, the working-age population is expected to be around 67 percent of the country's total, compared to the current 55 percent, hence the demand for employment will grow substantially. A positive outcome of declining fertility is that women will be freed for employment, given lesser demands on their time for bearing and rearing children. 
A critical policy recommendation is for growth with equity that leads to wider availability of productive opportunities for both men and women. This growth is conceivable if the creation of jobs is the main driver of the Growth Strategy 2011. We recommend that only growth that generates employment and productive opportunities be promoted for the next four decades. Generating higher and sustained GDP growth with high elasticity for employment and poverty reduction will require institutional changes for inclusive growth. An inclusive growth strategy will require institutional changes to enable the middle class and the poor to acquire productive assets and equitable access to credit and markets for goods and services.

The policy discussion will have to evolve into provincial employment-generation strategies. The incentives to increase growth, to substantially reduce poverty, and to generate employment for over 3 million people who will enter working ages annually over the next four decades. What is required is to (a) sustain a rate of GDP growth of 7 to 8 percent, and (b) enhance the growth elasticity with respect to employment and poverty reduction.

Immediate priority should be given to employment planning that takes into account the number of jobs required and the sectoral breakdown of employment opportunities. Decisions about how to achieve these goals will have to be made. Once decisions are taken, it is also important to achieve consensus across the public and private sectors. The private sector in particular generates most new job opportunities, and a three-way discussion among industry, the commercial sector, and government will be required to achieve legislation or standards to ensure that growth produces employment opportunities. Two sectors that have high labor elasticity are Finance and Insurance and Wholesale and Retail trade. Many more sectors can be tapped in the same way.

A strong educational base and reasonably advanced levels of education are particularly important for matching new job entrants and emerging employment opportunities. While improvements in the quality of the new entrants to the labor force are obviously desirable, the skills required for many jobs are not being developed by many universities and colleges in Pakistan. The matching of tertiary education with professional requirements and with the types of jobs that are becoming more numerous is an urgent priority. In addition, mentoring and apprenticeship programs should be formed between businesses and educational institutions. Attention should also be given to developing the skills required to enter jobs both nationally and internationally that are in greatest abundance. For instance, a basic education is a pre-requisite for most non-farm and non-agricultural jobs, yet 32 percent of youth are uneducated, and most lack vocational or life skills.

With increasing global linkages and movement toward regional integration, international migration may become an option, as many countries like China and Japan experience labor shortages as their populations age. Policymakers in Pakistan should plan for these opportunities for emigration to other regions. However, for this to be an option, the basic requirement is for young people to acquire the basic skills and technical and tertiary education to compete for available jobs in the receiving countries. 


\section{Poverty reduction}

The demographic dividend is an opportunity for ensuring increased economic growth through greater numbers in employment. The dividend can also advance an equally important objective of reducing poverty. This can only happen through the equitable distribution of opportunities across rich and poor households. The larger proportion of employed men and women can result in higher contribution to savings. Meeting these objectives requires changing the present elite-based institutional structure that generates rents for a small elite by excluding the middle class and the poor from the opportunity for investment and high-wage employment. The outcome of this inequality is seen in the perpetuation of high fertility and chronic poverty among the poor and in rural areas.

Lower fertility offers households an opportunity to escape poverty and for workingage members to contribute to family income. In contrast, if the opportunities for fertility decline and employment are limited to certain urban areas or rich households, they will result in even wider gaps in incomes and push families with fewer opportunities for productive work into poverty. The Population and Development policy has to have a pro-poor perspective to ensure that family planning services, educational opportunities, and job creation are available in particular to poorer women and households.

\section{Gender equity}

Women and girls will be at the center of the opportunities for capturing the dividend. While this may seem a platitude, this basic conclusion emerges from the chapters in this volume. The lack of investment in girls and women is perhaps the most overlooked reality in Pakistan. Universal primary education cannot be achieved when less than half of girls do not attend school, when only one out of five women works in the labor force, and when women who do work do not receive adequate remuneration. When women cannot choose the numbers and spacing of their children, half of society is being denied the opportunity to achieve its full potential. The overarching Population and Development policy being proposed must take steps to eliminate disadvantages faced by girls and women in Pakistan.

The first realistic step for eliminating or greatly reducing gender inequities is to rapidly increase the rate of entry of girls into primary schools, since they still lag far behind boys. Gender equality and a concerted effort to improve girls' education is pivotal for reducing the momentum of population growth through the beneficial effects of female education on age at marriage and fertility. Female education is also critical because of its close link to raising female labor force participation rates.

It is also important to raise rates of female enrollment in secondary and tertiary education. The gender gap in secondary education can be traced back to the gap at the primary level. In many countries, girls who complete primary education have the same probability as boys of entering secondary education. Once enrolled in secondary school, however, girls are more vulnerable to dropping out (UNESCO 2011). Poverty is one of the major causes of the gender gap in education, particularly for girls of secondary 
school age. Studies shows that, in poor households, about twice as many girls of secondary school age are not attending school compared to their better-off counterparts. Secondary schooling is more costly than primary, and poor households often choose to send only boys to secondary school. In addition, many girls' schools lack basic amenities, particularly in rural areas, and girls' schools are often far from their homes.

One of the most critical factors for capturing the demographic dividend is how fast women in Pakistan enter the labor force, especially in nonagricultural occupations. Representing half of the potential work force, they are currently barely one fifth of the labor force. It is hard to imagine any developing country reaping the full demographic dividend without a major proportion of its female work force taking part in the economy.

For this to happen, efforts will have to be made to improve the education and skill base of young women. Employers' attitudes will also have to change. In certain fields women will be at an advantage, particularly in education, health, and certain services sectors. Innovative, large public-sector programs such as the Benazir Income Support Program and the lady health worker program have had indirect effects on family income and on the status of women.

\section{Youth and the future}

While youth are not singled out, the policies recommended here should have a direct impact on the major life transitions of the young. Other aspects of youth can be emphasized, especially those that involve empowerment, ability to vote, and the potential for change represented by their large numbers.

Specific policies for youth may not be the appropriate approach, as they tend to compartmentalize the issues outlined above. In the past, youth policies have focused either on reproductive health needs or on sports and additional educational opportunities. What is required is that the emerging policy, with its focus on human development, recognize that one of the principal challenges facing Pakistan is to bring women and girls into the forefront of national development, as both actors and beneficiaries. Another challenge is to take advantage of the largest-ever cohorts of young people in Pakistan, on whom the course of the country's future depends, and to take their needs into account in all aspects of policymaking. 


\section{References}

Abadian, Sousan. 1996. "Women's autonomy and its impact on fertility," World Development 24(2): 1793-1809.

Abbasa, Qaisar and James Foreman-Peck. 2007. "Human capital and economic growth: Pakistan, 19602003.” Cardiff Economics Working Paper E2007/22. Cardiff, UK: Cardiff University.

Ali, Syed Mubashir and Jafar Hussain. 2001. "Fertility transition in Pakistan: Evidence from census," The Pakistan Development Review 40(4 Part II): 537-550.

Aly, Javed Hasan. 2007. “To debate and finalize the national education policy," a white paper of the National Education Policy Review team. <http://planipolis.iiep.unesco.org/upload/Pakistan/PakistanNational Education Policy Review WhitePaper.pdf $>$ Accessed 20 September 2011.

Ahmed, Viqar and Rashid Amjad. 1984. The Management of Pakistan's Economy 1947-82. Karachi: Oxford University Press.

Aiyar, Shekhar and Mody, Ashoka. 2011. “The demographic dividend: Evidence from Indian state," IMF Working Paper WP/11/38, Washington, DC: International Monetary Fund.

Amjad, Rashid. 2005. "Skills and competitiveness: Can Pakistan break out of the low level skills trap?" Pakistan Development Review 44(4): 387-409.

Amjad, Rashid and Julian Havers. 2007. "Jobs for Iraq: An employment and decent work strategy." Beirut: ILO, Regional Office for the Arab States.

Amjad, Rashid and A. Kemal. 1997. "Macroeconomic policies and their impact on poverty alleviation in Pakistan," Pakistan Development Review 36(1): 39-68.

Amjad, Rashid, Musle-ud Din, and Abdul Qayyum. 2011. "Pakistan: Breaking out of stagflation into sustained growth," Lahore Journal of Economics 16: Special edition.

Arif, G.M., Nasir Iqbal, and Shujaat Farooq. 2011. “The persistence and transition of rural poverty in Pakistan: 1998-2004," PIDE Working Papers. Islamabad: Pakistan Institute of Development Economics.

ASER. 2013. Annual Status of Education Report: Pakistan 2012 (Provisional 21 January 2013). <http:// www.aserpakistan.org/document/aser/2012/reports/national/National2012.pdf >. Accessed 1 February 2013.

Barkat-e-Khuda, John C. Caldwell, Bruce K. Caldwell, Indrani Pieris, Pat Caldwell, and Shameem Ahmed . 2001. "Determinants of fertility transition in Bangladesh," in Zeba A. Sathar and James F. Philips (eds.), Fertility Transition in South Asia. Oxford: Oxford University Press.

Behrman, Jere R., David Ross, and Richard Sabot. 2008. "Improving quality versus increasing the quantity of schooling: Estimates of rates of return from rural Pakistan," Journal of Development Economics 85(1): 94-104.

Behrman, Jere R., Shahrukh Khan, David Ross, and Richard Sabot. 1997. "School quality and cognitive achievement production: A case study for rural Pakistan," Economics of Education Review 16(2): $127-142$.

Bhat, P.N. Mari and S. Irudaya Rajan. 1990. “Demographic transition in Kerala revisited," Economic and Political Weekly 25: 1957-1980.

Birdsall, Nancy, Allen C. Kelley, and Stephen W. Sinding. 2001. Population Matters: Demographic Change, Growth, and Poverty in the Developing World. New York: Oxford University Press. 
Bloom, David E. and David Canning. 2004. “Global demographic change: Dimensions and economic significance,” NBER Working Paper No. 10817, Washington, DC: National Bureau of Economic Research.

Bloom, David E. and Jeffrey G. Williamson. 1998. "Demographic transitions and economic miracles in emerging Asia," The World Bank Economic Review 12(3): 419-455.

Bloom, David E., David Canning, and Jaypee Sevilla. 2003. The Demographic Dividend: A New Perspective on the Economic Consequences of Population Change. Santa Monica, CA: RAND Corp.

Bongaarts, John. 1994. "Population policy options in the developing world," Science 263(5148): 771-776.

2008. "The causes of educational differences in fertility in sub-Saharan Africa." Vienna Yearbook of Population Research 1: 31-50.

—. 2011. "Completing the fertility transition in the developing world: The role of educational differences and fertility preferences," Population Studies 57(3): 321-335.

Bongaarts, John and Judith Bruce. 1995. "The causes of unmet need for contraception and the social content of services," Studies in Family Planning 26(2): 57-75.

Bongaarts, John and Rodolfo Bulatao. 1999. “Completing the demographic transition," Population and Development Review 25(3): 515-529.

Burki, Shahid Javed. 2011. "How rich are the Pakistani rich?" The Express Tribune, 16 May.

Caldwell, John C. 1980. "Mass education as a determinant of timing of fertility decline," Population and Development Review 6(2): 225-255.

Caldwell, John and Peter McDonald. 1982. "Influence of maternal education on infant and child mortality: Levels and causes," Health Policy and Education 2(3-4): 251-267.

Capps, J.M., A.F. Qureshi, S. Israr, and M. Sultan. 2012. Family Advancement for Life and Health (FALAH) Evaluation Report. Management Systems International (MSI) under the Independent Monitoring and Evaluation Contract (IMEC).

Casterline, John B., Zeba A, Sathar, and Minhaj ul Haque. 2001. "Obstacles to contraceptive use in Pakistan: A study in Punjab," Studies in Family Planning 32(2): 95-110.

Casterline, John and Steven Sinding. 2000. "Unmet need for family planning in developing countries and implications for population policy," Population and Development Review 26(4): 691-723.

Castro Martin, Teresa and Fatima Juarez. 1995. “The impact of women's education on fertility in Latin America: Searching for explanations," International Family Planning Perspectives 21(2): 52-57.

Chaudhry, Azam. 2009. "Total factor productivity growth in Pakistan: Analysis of agricultural and manufacturing sector," Lahore Journal of Economics 14(Special edition): 1-16.

Cheema, Ali. 2005. "A profile of poverty in Pakistan." CRPRID Working Paper. Islamabad: The Centre for Research on Poverty Reduction and Income Distribution.

Chronic Poverty Research Centre (CPRC). 2005. The Chronic Poverty Report 2004-05. Manchester, UK: University of Manchester, CPRC.

Cleland, John. 2000. "Education and future fertility trends, with special reference to mid-transitional countries," in Completing the Fertility Transition. New York: United Nations Population Division, pp. 187-202.

Cleland, John, Stan Bernstein, Alex Ezeh, Anibal Faundes, Anna Glasier, and Jolene Innis. 2006. "Family planning: The unfinished agenda," Lancet 368(9549): 1810-1827. 
Cleland, John, James F. Phillips, Sajeda Amin, and G.M. Kamal. 1994. The Determinants of Reproductive Change in Bangladesh: Success in a Challenging Environment. Washington, DC: World Bank.

Coale, Ansley J. and Edgar M. Hoover. 1958. Population Growth and Economic Development in LowIncome Countries. Princeton, NJ: Princeton University Press.

Das Gupta, Monica. 1990. "Death clustering, mothers' education and the determinants of child mortality in rural Punjab, India," Population Studies 44(3): 489-505.

Federal Bureau of Statistics. 2009. “Pakistan Demographic Survey, 2007” Islamabad: Government of Pakistan, Statistics Division.

_- (various years). Pakistan Labour Force Survey. Islamabad: Government of Pakistan.

Felipe, Jesus. 2007. “Competitiveness and structural transformation in Pakistan,” Technical Assistance Report, Manila: Asian Development Bank.

Feeney, Griffith and Iqbal Alam. 2003. "Chapter 4: Fertility, population growth and accuracy of census enumeration in Pakistan, 1961-1998" in A.R. Kemal, Mohammad Irfan, and Naushin Mahmood (eds.), Population of Pakistan: An Analysis of 1998 Population Census and Housing Census, Islamabad: Pakistan Institute of Development Economics/UNFPA.

Fuchs, Regina, Elsie Pamuk, and Wolfgang Lutz. 2010. "Education or wealth: Which matters more for reducing child mortality in developing countries?” Vienna Yearbook of Population Research 1: 175-199.

Goujon, Anne and Annababette Wils. 1996. “The importance of education in future population: Global trends and case studies on Cape Verde, Sudan, and Tunisia." IIASA Working Paper WP-96-138. Laxenburg, Austria: International Institute for Applied Systems Analysis. <www.iiasa.ac.at/ publication/more_WP-96-138.php>. Accessed 24 October 2012.

Goujon, Anne and Asif M. Wazir. 2011. "Human capital and population development: Pakistan and the cannon and butter dilemma," in Laurel J. Hummel and Richard L. Wolfel (eds.), Understanding Pakistan Through Human and Environmental Systems. West Point, NY: US Army War College Center for Strategic Leadership, pp. 157-182.

Government of Pakistan (GoP). 2012. Pakistan Economic Survey 2011-12. Islamabad: Finance Division, Economic Adviser's Wing.

- 2011a. Pakistan Economic Survey 2010-11. Islamabad: Finance Division, Economic Adviser's Wing.

- 2011b. Pakistan: Framework for Economic Growth. Islamabad: Planning Commission.

- 2009a. Pakistan Economic Survey 2008-09. Islamabad: Finance Division, Economic Adviser's Wing.

. 2009b. "The New Vision for Pakistan: Investing in People-Tenth Five Year Plan (2010-15)." approach paper, Government of Pakistan Planning Commission.

- 2008. "Economic stabilization with a human face: Interim report of the planning commission's panel of economists," Islamabad: Advisory Panel of Economists, Planning Commission.

. 2002. "National policy for the development and empowerment of women," Islamabad: Ministry for Social Welfare and Special Education. <sgdatabase.unwomen.org/uploads/National Policy for Development and Empowerment of Women.pdf $>$.

Headey, Derek D. and Andrew Hodge. 2009. "The effect of population growth on economic growth: A meta-regression analysis of the macroeconomic literature," Population and Development Review 35(2): 221-248. 
Hirashima, S. 2009. "Growth-poverty linkage and income-asset relation in regional disparity: Evidence from Pakistan and India," The Pakistan Development Review 48(4 Part 1): 357-386.

Hobcraft, John. 1993. "Women's education, child welfare and child survival: A review of the evidence," Health Transition Review 3(2): 159-175.

_ 2003. "Towards a conceptual framework on population, reproductive health, gender and poverty reduction, in population and poverty: Achieving equity, equality and sustainability," Population and Development Strategies Number 8. New York: UNFPA.

Hornik, Robert and Emile McAnany. 2001. "Mass media and fertility change," in John Casterline (ed.), Diffusion Processes and Fertility Transition: Selected Perspectives, Washington, DC: National Academy Press.

Hou, Xlaohui. 2010. “Challenges for youth employment: Are they youth-specific?” Pakistan Development Review 49(3): 193-212.

Hussain, Akmal. 1994. Poverty Alleviation in Pakistan. Lahore, Pakistan: Vanguard Books.

1999. "Employment generation, poverty alleviation and growth in Pakistan's rural sector: policies for institutional change," Geneva: ILO/CEPR (mimeo).

_ 2008. "Institutional imperatives of poverty reduction," Research paper series. Lahore, Pakistan: Beaconhouse National University, Institute of Public Policy.

. Forthcoming a. "Institutions, economic growth and participatory development," in S.J. Burki and Rashid Amjad (eds.), Pakistan: Moving the Economy Forward.

- Forthcoming b. "Strengthening democracy through inclusive growth," in Akmal Hussain and Muchkund Dubey (eds.), Democracy, Sustainable Development and Peace: New Perspectives on South Asia, New Delhi: Oxford University Press.

Hussain, Akmal et al. 2003. Pakistan National Human Development Report 2003: Poverty, Growth and Governance. Karachi, Pakistan: United Nations Development Programme and Oxford University Press.

Hussain, Akmal, Khawar Mumtaz, and G.M. Arif. 2010. "Report of the Working Group on Poverty Reduction Strategy and Human Resource Development, Tenth Five Year Plan (2010-15)," Islamabad: Government of Pakistan Planning Commission.

Institute of Public Policy. 2011. "State of the Economy: Devolution in Pakistan." Fourth Annual Report. Lahore, Pakistan: Beaconhouse National University.

International Institute for Population Sciences (IIPS) and Macro International. 2007. India National Family Health Survey (NFHS-3), 2005-06. Mumbai: IIPS.

International Labour Organization (ILO). 2010. Global Employment Trends for Youth. Geneva.

2011. "Economically active population, estimates and projections (6th edition, October 2011)," <http://laborsta.ilo.org/applv8/data/EAPEP/eapep_E.html>. Accessed 20 December 2012.

International Statistical Institute (ISI). 1975. Pakistan World Fertility Survey 1975. Voorburg, Netherlands: ISI and Ministry of Planning and Development (Pakistan), Population Welfare Division.

Islam, Nizamul and Abebe Shimeles. 2007. "Poverty dynamics in Ethiopia: State dependence and transitory shocks," Working Papers in Economics No. 260, Sweden: Goteborg University.

Jafarey, Sadiqua N., Azra Ahsan, et al. 2010. "Deaths of women of reproductive age: In-depth analysis of data from the Pakistan Demographic and Health Survey 2006-07," New York: USAID, JSI Research and Training Institute, Inc., and Population Council. 
James, K.S. 1999. "Fertility decline in Andhra Pradesh: A search for alternatives hypothesis," Economic and Political Weekly of India 34(8): 491-499.

Jayaraman, Anuja and Jill L. Findeis. 2005. "Disaster, population and poverty dynamics among Bangladeshi household," Paper presented at the Annual Meeting of the Population Association of America, Philadelphia, 31 March-2 April.

Jejeebhoy, Shireen. 1995. Women's Education, Autonomy and Reproductive Behaviour. Oxford: Clarendon Press.

Jones, Gavin W. 2009. "Population and poverty: The situation in Asia and Pacific," Asia-Pacific Population Journal 24(1): 65-86.

K.C., Samir, Bilal Barakat, Anne Goujon, Vegard Skirbekk, Warren Sanderson, and Wolfgang Lutz. 2010. "Projection of populations by level of educational attainment, age, and sex for 120 countries for 2005-2050." Demographic Research 22(15): 383-472.

Kakar, Zaheer Khan, Bashir Ahmad Khilji, and Muhammad Jawad Khan. 2011. "Effects of female education on family size in Pakistan: A case study of Quetta City," Journal of International Academic Research 11(2): 37-41.

Karim, Mehtab S. 2011. "Pakistan's demographic scenario, past and present: Population growth and policies, with lessons from Bangladesh and Iran," in Michael Kugelman and Robert Hathaway (eds.), Reaping the Dividend: Overcoming Pakistan's Demographic Challenges. Washington, DC: Woodrow Wilson International Center for Scholars (Asia Program), pp. 121-144.

Khan, Mohsin S. 2011. "Expanding India-Pakistan trade”, Public Lecture No. 11, Annual Conference, South Asia Network of Economic Research Institutes (SANEI), Dhaka, Bangaldesh, 21-22 December (Monograph).

Kugelman, Michael and Robert Hathaway. 2011. Reaping the Dividend: Overcoming Pakistan's Demographic Challenges. Washington, DC: Woodrow Wilson International Center for Scholars (Asia Program).

Kock, Udo and Yan Sun. 2011. "Remittances in Pakistan: Why have they gone up and why are not they coming down?” IMF Working Paper, WP/11/200, Washington, DC: International Monetary Fund.

Kim, Jungho, Henriette Engelhardt, Alexia Prskaweta, and Arnstein Aaassve. 2006. "Does fertility decrease the welfare of households? An analysis of poverty dynamics and fertility in Indonesia." Working Paper 06 / 2005, Vienna Institute of Demography.

Leslie, P.H. 1975. "On the use of matrices in certain population mathematics." Biometrika 33: 183-212.

Lutz, Wolfgang. 2009. "Sola schola et sanitate: Human capital as the root cause and priority for international development." Philosophical Transactions of the Royal Society B: Biological Sciences 364: 3031.

Lutz, Wolfgang, Jesus Crespo Cuaresma, and Mohammad Jalal Abbasi-Shavazi. 2010. "Demography, education, and democracy: Global trends and the case of Iran." Population and Development Review 36(2): 253-281.

Lutz, Wolfgang, Jesus Crespo Cuaresma, and Warren C. Sanderson. 2008. "Economics: The demography of educational attainment and economic growth," Science 319(5866): 1047-1048.

Lutz, Wolfgang and Samir K.C. 2011. "Global human capital: Integrating education and population," Science 333(6042): 587-592.

Martin, Teresa Castro and Fatima Juarez. 1995. "The impact of women's education on fertility in Latin America: Searching for explanations," International Family Planning Perspectives 21(2): 52-57. 
Mason, Andrew. 2001. Population Change and Economic Development in East Asia: Challenges Met, Opportunities Seized. Stanford, CA: Stanford University Press.

Mauldin, W. Parker. 1963. "Population and population policy in Pakistan," Marriage and Family Living 25(1): 62-68.

McAlister, Chryssa and Thomas Baskett. 2006. "Female education and maternal mortality: A worldwide survey," Journal of Obstetrics and Gynaecology Canada 28(11): 983-990.

McCartney, Matthew. 2011. Pakistan: The Political Economy of Growth, Stagnation and State, 19512009. Abingdon, UK: Routledge.

McNicoll, Geoffrey. 1999. Population and Poverty: The Policy Issues, Part 1, Special: Population, Poverty and Environment. Canberra: Australian National University, Research School of Social Sciences.

Mahmood, Arshad. 2012. Birth Spacing and Family Planning Uptake Can Rise Rapidly in Pakistan: Evidence from FALAH. Islamabad: Population Council.

Ministry of Labour and Manpower. 2009. "Labour market situation and school to work transition in Faisalabad," Pakistan Employment Trends Brief, Islamabad: GoP/UNDP/ILO.

National Institute of Population Studies (NIPS) [Pakistan]. 2001. Pakistan Reproductive Health and Family Planning Survey (PRHFPS) 2000-01. Islamabad: NIPS.

_. 2009. "Population projections for the year 2005-2030, Tenth Five Year People's Plan 2010-15, Population Welfare," Unpublished report.

National Institute of Population Studies (NIPS) [Pakistan] and Macro International, Inc. 1992. Pakistan Demographic and Health Survey 1990-91. Islamabad and Calverton, MD: NIPS and Macro International, Inc.

- 2008. Pakistan Demographic and Health Survey 2006-07. Islamabad and Calverton, MD: NIPS and Macro International, Inc.

Nayab, Durr-e-. 2006. "Demographic dividend or demographic threat in Pakistan," PIDE Working Paper 2006: 10, Islamabad: Pakistan Institute of Development Economics.

Oxford Policy Management (OPM). 2009. External Evaluation of a National Programme for Family Planning and Primary Health Care: Lady Health Workers Programme. Oxford: OPM.

Pakistan Institute of Development Economics (PIDE). 2001. Pakistan Rural Household Survey (PRHS) 2001. Islamabad: PIDE.

- 2004. Pakistan Rural Household Survey (PRHS) 2004. Islamabad: PIDE.

Pakistan Medical Research Council. 1998. National Health Survey of Pakistan. Conducted by the Pakistan Medical Research Council in collaboration with the Department of Health and Human Services, Washington, DC and the Federal Bureau of Statistics, Islamabad.

Population Policy of Pakistan. 2002. Ministry of Population Welfare, Government of Pakistan.

Population Council. 2009. Pakistan's Demographic Transition in the Development Context. Islamabad. - 2011. “Population projections of Pakistan 2010-2050," Unpublished report, September.

Qazi, Yasmeen. 2011. "Pakistan on the move: Family planning, reproductive health, and development in Pakistan," in Michael Kugelman and Robert Hathaway (eds.), Reaping the Dividend: Overcoming Pakistan's Demographic Challenges. Washington, DC: Woodrow Wilson International Center for Scholars (Asia Program), pp. 46-55.

Rodriguez, F. and D. Rodrik. 2009. “Trade policy and economic growth: A skeptics guide to the cross-national evidence," Ottawa: WIDER Conference on Trade and Industrialization Reconsidered (mimeo). 
Rogers, Andrei. 1975. Introduction to Multiregional Mathematical Demography. New York: Wiley.

1995. Multiregional Demography: Principles, Methods, and Extensions. New York: Wiley.

Rosen, James E. and Shanti R. Conly. 1996. “Pakistan’s Population Program: The challenge ahead.” Country Study Series No. 3. Washington, DC: Population Action International.

Rukanuddin, Abdul Razzaque and Karen Hardee-Cleveland. 1992. "Can family planning succeed in Pakistan?” International Family Planning Perspectives 18(3): 109-115.

Rutstein, Shea O. 2005. "Effects of preceding birth intervals on neonatal, infant and under-five years mortality and nutritional status in developing countries: Evidence from the demographic and health surveys," International Journal of Gynaecology \& Obstetrics 89(suppl. 1): S7-S24.

Saleem, Shabana and Martin Bobak. 2005. "Women's autonomy, education and contraception use in Pakistan: A national study," Reproductive Health 2(8): 1-8.

Saqib, Najam and Ghulam Mohammad Arif 2012. "Time poverty, work status and gender: The case of Pakistan,” PIDE Working Paper No. 81, Islamabad: Pakistan Institute of Development Economics.

Sathar, Zeba A. 2001. "Fertility in Pakistan: Past, present and future." Paper presented at the workshop on prospects for fertility decline in high fertility countries, Population Division, Department of Economic and Social Affairs, United Nations Secretariat, New York, NY, 9-11 July.

- 2007. "Stagnation in fertility levels in Pakistan," Asia-Pacific Population Journal 22(2): 113.

- 2011. "Demographic doom or demographic dreams: Pakistan at the crossroads," in Michael Kugelman and Robert Hathaway (eds.), Reaping the Dividend: Overcoming Pakistan's Demographic Challenges. Washington, DC: Woodrow Wilson International Center for Scholars (Asia Program).

Sathar, Zeba A. and John B. Casterline. 1998. "The onset of fertility transition in Pakistan," Population and Development Review 24(4): 773-796.

Sathar, Zeba A. and Peter C. Miller. 2012. "The importance of population policy in Pakistan," in Anita M. Weiss and Saba Gul Khattak (eds.), Development Challenges Confronting Pakistan. Sterling, VA: Kumarian Press.

Sathar, Zeba A., Susheela Singh, and Fariyal Fikree. 2007. "Estimating the incidence of abortion in Pakistan," Studies in Family Planning 38(1): 11-22.

Sathar, Zeba A. and Karen Oppenheim Mason. 1993. "How female education affects reproductive behavior in urban Pakistan," Asian Pacific Population Forum 6(4): 93-103.

Sen, Amartya. 1999. Development as Freedom. New York: Knopf.

Simmons, Ruth, Laila Baqee, Michael A. Koenig, and James F. Phillips. 1988. "Beyond supply: The importance of female family planning workers in rural Bangladesh." Studies in Family Planning 19(1): 29-38.

Singh, Susheela, Jacqueline E. Darroch, Lori S. Ashford, and Michael Vlassoff. 2009. Adding It Up: The Costs and Benefits of Investing in Family Planning and Maternal and Newborn Health. New York: UNFPA and Guttmacher Institute.

Social Policy Development Center (SPDC). 2003. "Social development in Pakistan, Annual review 2002-03." Technical report. Karachi: SPDC.

Soomro, Ghulan Yasin and Naushin Mahmood. 2004. "Female education and fertility: Implications for family planning programme," Paper presented at the $20^{\text {th }}$ AGM and Conference of the Pakistan Society of Development Economists. Islamabad: Pakistan Institute of Development Economics.

Sparreboom, Theo and Shahnaz Lubna. 2007. "Assessing labour market vulnerability among young people," The Pakistan Development Review 46(3): 193-213. 
Ssewanyana, Sarah N. 2009. "Chronic poverty and household dynamics in Uganda," Working Paper No. 139, London: Chronic Poverty Research Centre.

Stern, Nicholas. 2001. "Investing for growth and poverty reduction: Institutions and people," Speech delivered in Islamabad.

Syed, Mubashir Ali and Jafar Hussain. 2001. "Fertility transition in Pakistan: Evidence from census," The Pakistan Development Review 40(4): 537-550.

UNESCO. 2011. “The hidden crises: Armed conflict and education.” EFA Global Monitoring report. Paris: UNESCO.

United Nations Educational, Scientific and Cultural Organization (UNESCO). "National adult literacy rates (15+), youth literacy rates (15-24) and elderly literacy rates (65+)," Montreal: UNESCO Institute for Statistics. <http://stats.uis.unesco.org/unesco/TableViewer/tableView.aspx?ReportId=210> Accessed 19 July 2012.

United Nations. 2009. World Population Prospects: The 2008 Revision. New York: United Nations, Department of Social Affairs, Population Division.

- 2011. World Population Prospects: The 2010 Revision. New York: United Nations, Department of Economic and Social Affairs, Population Division.

Wazir, Asif. 2012. "Evolution of population and education in Pakistan: Analysis and projections by provinces," PhD thesis, Department of Statistics and Operations Research, University of Vienna, Austria.

Westoff, Charles F. 1999. "Mass communications and fertility," in Richard Leete (ed.), Dynamics of Values in Fertility Change, Oxford: Oxford University Press, pp. 237-251.

Westoff, Charles F. and Akinrinola Bankole. 1995. Unmet Need: 1990-1994. Demographic and Health Surveys Comparative Studies No. 16. Calverton, MD: Macro International Inc.

1997. “Mass media and reproductive behavior in Africa," DHS Analytical Report No. 2. Calverton, MD: Macro International.

Westoff, Charles F. and German Rodriguez. 1995. "The mass media and family planning in Kenya," International Family Planning Perspectives 21(1): 26-31, 36.

Woolard, Ingrid and Stephan Klasen. 2004. "Determinants of income mobility and household poverty dynamics in South Africa," Discussion Paper No. 1030. Bonn, Germany: Institute for the Study of Labor (IZA).

World Bank. 2007. "Pakistan: Promoting rural growth and poverty reduction," Report No. 39303-PK. South Asia Region, World Bank.

- 2012. South Asia Development Matters - More and Better Jobs in South Asia. Washington, DC: World Bank.

World Economic Forum. 2012. "Seven Billion and Growing: A 21st Century Perspective on Population," World Economic Forum Global Agenda Council (GAC) on Population Growth. <http:// www3.weforum.org/docs/WEF_GAC_SevenBillionGrowing_Report_2012.pdf >. Accessed 4 February 2013.

Zaidi, Batool, Zeba Sathar, Minhaj ul Haque, and Fareeha Zafar. 2012. The Power of Girls' Schooling for Young Women's Empowerment and Reproductive Health. Islamabad: Population Council. 

This book brings together many ideas that have been discussed for some time in Pakistan and around the world. The compelling path forward it lays out, which entails extensive development of education and major efforts in the reproductive health arena, offers an inviting and highly achievable means for shaping and harnessing Pakistan's growing population in a way that promotes inclusive economic development. As such, this book can be considered part of a blueprint for development in Pakistan.

-From the Foreword by David E. Bloom 